
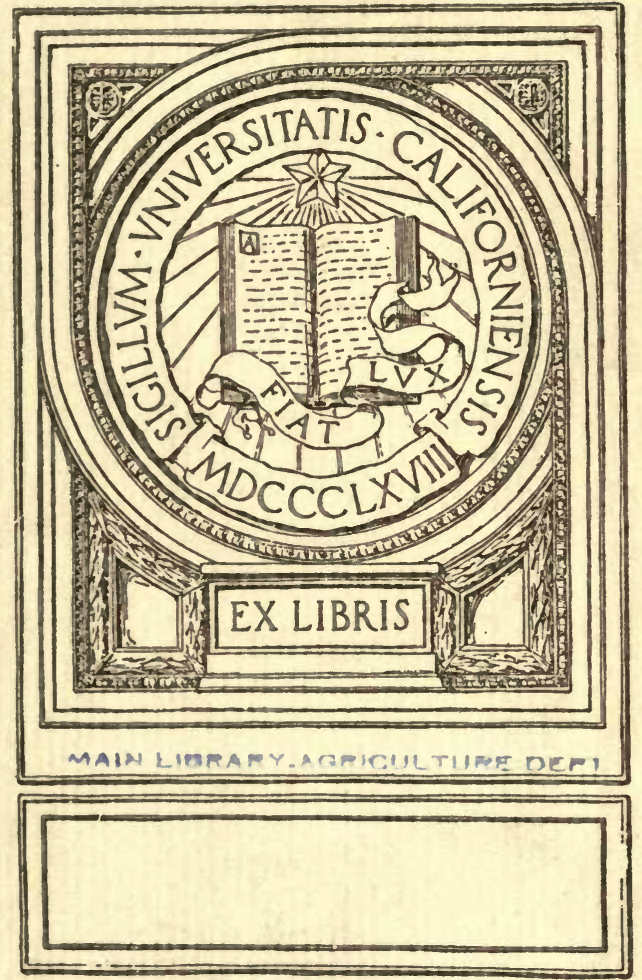

$s$ 
4 


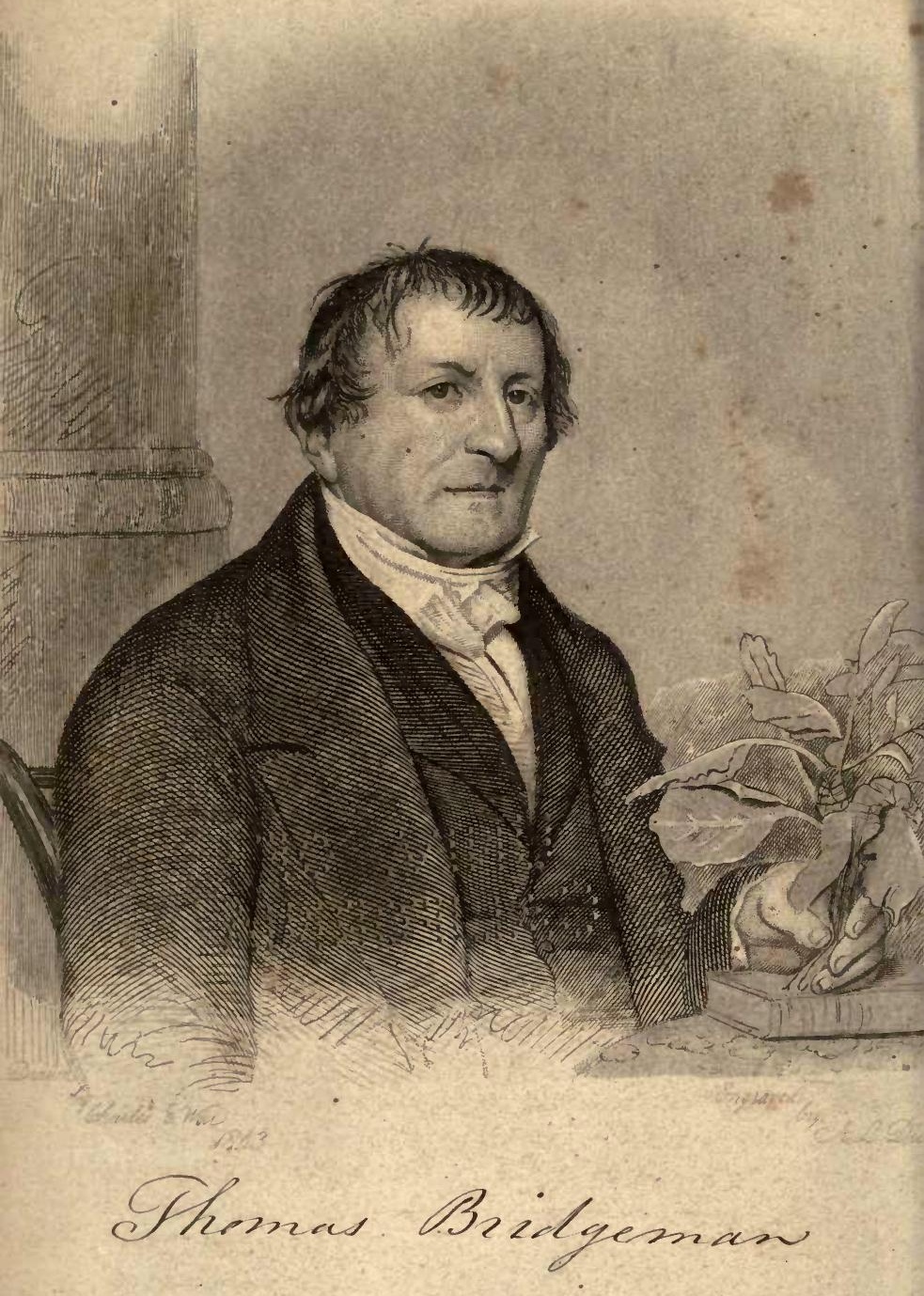




\title{
FRUIT CULTIVATOR'S MANUAL,
}

\author{
$\vdots ;$ \\ CONTAINING AMPLE DPRECTIUNS \\ FOR TIIE
}

\section{CULTIVATION OF THE MOST IMPORTANT FRUITS}

\author{
INCLUDING THE
}

CRANBERRY, THE FIG, AND GRAPE,

WITU DESCRETIV LISTS OF THE MOST ADMURED VARIETUR3.

\section{AND A CALENDAR,}

SHOWING THE WORK NECESSARY TO BE DONE IN THE ORCHARD AND FRUIT GARDEN EVERY MONTH OF THE YEAR.

TEI WHOLI ADAPTED TO THR CLIMATA OF THE UNITED SMATSS.

\section{By THOMAS B̧RIDGEMAN, \\ Gurdener. Seedsman, and Flurist.}

\section{N E W-Y O R K :}

FOR SALE BY THE AUTHOR, BROADWAT, CORNER OF EIGHTEENTH STREET, J. M. Thorhurn \& Co., 15 John-street, Alex. Smith. 388 Brradway, Dunlap \& Thompson, Broadway, N. Y.; Win. Thorburn, Bro'swny. Alling ; C. F. Crowman, Rochester: Ho: vey \& Cu., Joseph Breck \& Co., J. I. I. F. Wirren, Wulker \& Co., Brston; David I, andreth, II. A. Dreer, K hert B ist, Philudplphiy, Gihson \& Ritchie, Newark, N. J.• R. Sinclnir, Jr.. \& Co.. 'Pnltinnore; J. F. Callan, Washingtun City ; Henry Cook, Alex andria, D. C.: Frederink Wittuenn, Chnrlestur, S. C : M ssely \& Co.. Mubile: Wm Dinn, New Öleans; Jas. M. Tinorhirn, St. Lonis; Fly \& Camplell, H. Huxley, Cin cinnati : Charles A.'Praluxiy, Columbis, Gn. ; A. G. Munn, Louisville, Ky.; and other Seedsmen. - Also, by Booksellers in generul. 


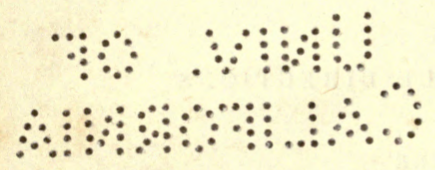

[Entered according to Act of Congress, in the year Eighteen Hundrod and Forty-seven by 'Tномаs Bridgenas, in the Clerk's Office of the District Court of the United States, for the Southern D1strict of New-York.] 
Turs treatise forms the third part of "The Young Gar. dener's Assistant," which, when first issued, in 1829, contained only 96 pages. Since that period, so constant has been the demand for the work, that numerous editions have been published; and being made to embrace the three most important branches of gardening, the entire work has extended to upward of five hundred pages. As each branch forms a distinct subject, the author has been induced to publish the ninth edition in three separate volumes, each of which is complete in itself. The first contains ample directions for the cultivation of culinary vegetables and herbs; the second is designed for the cultivator of flowers; and the present volume is intended to qualify the reader for the superintendence of his own orchard and fruit garden.

Those who wish to obtain a book embracing the three subjects, can be accommodated with the tenth edition of the Young Gardener's Assistant, in octavo form, and which is destined to remain for some time to come, the American standard work on Horticulture in general.

It is presumed that the pomologist will find in this little volume more information on the subject than he could reasonably expect in so small a compass. All the most esteemed species of fruit are treated of under distinct heads, to which is added a descriptive list of the finest varieties under cultivation; and from the several descriptive lists of fruits having been selected from the catalogues of the most eminent nurserymen in our country, it is presumed that they are well calculated to suit the generality of cultivators.

The varieties of the different species of fruit under culti vation are by far too numerous to encourage any attempt to publish a complete description of all. Even to enumerate them would be a difficult task, owing to the gieat uncertainty of their true names, and the multiplicity of names 
under which they are known in different places. Those cultivators who are more anxious to raise large quantities of trees for sale, than to test their characteristics, are often led into error by cherishing the belief that the names of all the varieties they propagate are indisputably correct; and hence it is that so many of our fruits are frequently sold under wrong names. Persons who purchase trees under such circumstances, on discovering a mistake, are apt to compare the fruit with others of a similar character, and very frequently adopt synonymous names, which increases the evil to such an extent, that, unless a nurseryman tests all the various kinds by specimen trees kept for the purpose in his own orcbard, he cannot always be certain what variety he is selling. I do not, however, by these remarks intend to reflect on any of our respectable nurserymen, because tho vast improvement making every year in their catalogues is a convincing proof that they are aiming at perfection in their collections.

In the following pages I have endeavoured to do justice to each article, by embodying all the essential points of cultivation, and as our native vines are destined to become very generally cultivated in the United States, I have occupied over sixteen pages in treating of vine culture, and can truly say that I have thoroughly weighed every point before putting my pen to paper, and have not in any case adopted mere speculative theory, as is too often done by compilers of gardening books.

As I am not disposed to tire the reader with a lengthy preface, I shall conclude by reminding him that the Calen dar and Index is intended as a key to the body of the work; thus, the most important business of each month is briefly shown, with figures of reference to that particular page which treats more fully on the subject. The advantages of this plan must be evident to the most superficial observer.

T. BRIDGEMAN. 


\section{ON TEN TS.}

OBSERVATIONS ON THE ORCHARD AND FRUIT GARDEN.

Page.

Suggestions on the choice of a situation for an orchard, 7

Of the best methods of preparing the various kinds of soil, 8

Directions for transplanting fruit trees, - $\quad$ - $\quad$ - 9

A communication from a friend, showing his plan of

replanting trees, - $\quad-\quad-\quad-\quad-\quad-11$

Hints on the arrangement of trees, with a view to obtain successional crops of fruit.-Different soils described, suited to the various kinds of fruit, - - 12

OBSERVATIONS ON INSECTS AND DISEASES TO WHICH FRUIT TREES ARE LIABLE.

Remedies for the prevention and destruction of insects, 13 The best methods of curing diseases in fruit trees, - 14 Composition to be used as a wash for fruit trees, at the time of pruning, - $\quad$ - $\quad$ - $\quad$ - $\quad 15$

Some of the most annoying insects and reptiles described, 16 An earuest appeal to all agriculturists and horticulturists, showing the importance of encouraging the inhabitants of cities to preserve their ashes and soot in a dry state, for use on the land, - .

OBSERVATIONS ON TRAINING AND PRUNING FRUIT TREES AND VINES.

The primary object of pruning explained, - - - 21

Several methods described of pruning and training the

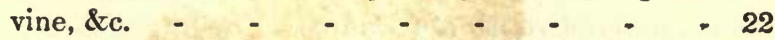

The benefits arising from judicious pruning, - $\quad 23$ Necessary Implements for pruning, \&c. - - - $\quad 24$ 


\section{BUDDING AND GRAFTING FRUIT TREES.}

Information respecting the time and manner of budding fruit trees, - $\quad$ - $\quad$ - $\quad$ - $\quad$ - $\quad$ - $\quad$ - $\quad$ - 25

On the choice of scions, and mode of preparing the stocks, 27 Cleft Grafting, Side Grafting, and Whip Grafting explained, - $\quad$ - $\quad$ - $\quad$ - $\quad$ - $\quad$ - $\quad$ - $\quad$ - 28 Saddle Grafting, Root Grafting, and Grafting by Approach, defined, - $\quad$ - $\quad$ - $\quad$ - $\quad$ - $\quad$ - $\quad$ - 29

Directions for making Forsyth's composition, - $\quad$ - 30 Recipes for preparing liquids for washing the stems and branches of trees,

Instructions for making grafting clay and composition,

ON THE CHOICE OF FRUIT TREES IN THE NURSERY. Rules for judging the qualities of fruit trees,

Directions for the management of Stone Fruits, to pre-

vent their gumming at the ronts, -

A guide to the selection of distinct varieties of fruit, - 35 Apple. Its history, cultivation, propagation, \&c. $\quad-37$ Seventy-six of the choicest varieties of Apples described, Apricot. The best method of training, pruning, \&c. explained, - $\quad$ - $\quad$ - $\quad$ - $\quad$ - $\quad$ - $\quad$ - $\quad$ - 46 Select descriptive list of Apricots, $\quad$ - $\quad$ - $\quad$ - $\quad$ - 49 Armond. Its history, mode of culture, \&c. - $\quad 50$ Cherry. The various kinds enumerated, with directions for their cultivation, - $\quad$ - $\quad$ - $\quad$ - 51

Thirty-one of the most esteemed varieties described, - 53 Chestnut. Its durability and other peculiar characteristics adverted to, - $\quad$ - $\quad$ - $\quad$ - $\quad-56$

Cranberix. Its adaptation for garden culture exemplified,

Currant. The best mode of cultivation shown, Select descriptive list of Currants,

Fra. A fruit well calculated for cultivation in the United States, 
The operation of Girdling or Ringing Trees explained, Gooseberry. Description of fifty-eight of the most celebrated varieties, - - - - - - 66 An improved method of managing the Gooseberry, - 70 Grape. The ficculiar characteristics of the Grape Vine defined, - - - - $\quad$ - $\quad$ - $\quad$ - $\quad$ - 72 The different manures adapted to the vine enumerated, 75 On the various methods of propagating, grafting, \&c. - 76 Select descriptive list of foreign and native grapes, - $\quad 77$ Doctor G. W. Chapman's and Mr. Wm. Wilson's successful experiments on their vines, - - $\quad 79$ Edward H. Bonsall's Vineyard Culture explained, - 80 Doctor R. T. Underhill's account of his vineyard at

Croton Point, - $\quad$ - $\quad$ - $\quad$ - $\quad$ - $\quad$ - $\quad$ - 83

Concluding observations on training, pruning, and cul-

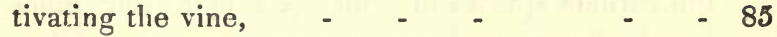

Mulberry. Some of the most useful species described, with directions for their propagation and cultivation,

Nectarine. Important hints, calculated to give this scarce but delicious fruit the best possible chance of success, if strictly attended to, - $\quad$ - $\quad$ - 91 Select descriptive list of Nectarines, - - - - 94 Orange, Lemon, \&c. The several species of this fruit

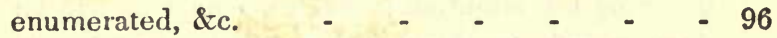

Релсн. An elaborate review of the means best calculated to overcome the difficulties attending the cultivation of this important fruit, - $\quad$ - $\quad-98$ Sixty-one of the best varieties of Peaches described, - 105 PE.AR. A definition of the different qualities of this fruit, with directions for its propagation and cultivation,

Observations on the alleged deterioration of the Pear, and other fruits, -

Eighty-eight of the most esteemed varieties of the Pear described, - 
Prum. The means best adapted for the perfection of

this fruit explained, - - - - - - 124

Fifty-three of the finest varieties of Plums described, - 126

Quince. Its history, its use, and method of culture ex-

plained, - - - - $\quad$ - $\quad$ - $\quad$ - $\quad$ - $\quad 131$

Raspberry. All the most celebrated species and varie-

ties enumerated, - $\quad-\quad-\quad-\quad-\quad-\quad-132$

Select descriptive list of Raspberries, - - $\quad-\quad-135$

Strawbelrry. The valuable properties of the Straw-

berry, with directions for its cultivation, - $\quad$ - 136

A descriptive list of the most esteemed species and

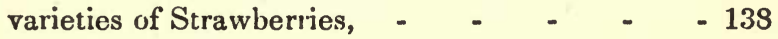

Walnut. Its use both as a fruit and timber tree, $\quad-140$

\section{CALENDAR AND INDEX.}

JanUary.-An essay on the importance of improving the various species of fruit, by propagating none but the finest specimens for seed, and by ameliorating the existing kinds by Cross Fertilization; which process is explained in a clear and comprehensive manner,

Fenruary.-An attempt to prepare the young gardener for the timely performance of his work in the orchard and fruit garden, in a judicious manner, by directing his attention to such business as can be done in unfavourable weather, that he may be enabled to give prompt attention to other important business before the rise of the sap, and thus prevent much anxiety and labour, - - - - $\quad$ - $\quad \mathbf{1 4 7}$

March.-Directions for pruning Grape Vines, and Apple, Cherry, Pear, and Quince Trees; for cultivating Cranberries, Currants, Gooseberries, Raspberries, \&c.; for preparing the ground for the reception of all kinds of fruit trees as soon as the weather becomes favourable ; for supporting newly planted trees by means of stakes, \&c. - . . 149 
Aprir.-Attention is directed to the pruning of fruit trees, including Apricot, Almond, Fig, Mulberry, Nectarine, Peach, Plum, \&c.; also, to the cultivation and propagation of trees, shrubs, and vines, by cuttings, layers, grafting, and other methods,

Max.-The gardener is reminded of the importance of finishing the work that was left undone last month without further delay; and of attending to the dostruction of insects while in a torpid state, and the preservation of the Gooseberry and other fruits from mildew. By cultivating Raspberries and Strawberies as directed in April and June, such fruits may be produced at a late season.

JunE.-The business of this month in the fruit garden consists of summer pruning, clearing the trees and rines of dead leaves and insects, and of protecting and cultivating early fruit to promote its ripening in full perfection,

JuLy.-Remedies for the protection of fruit from birds and ants, and for preserving Grape Vines from mildew. Judicious summer pruning, and attention to Figs, Vines, \&c., recommended,

August--As insects are engendered in rast quantities by the beat of our summers, the attention of gardeners is directed to the use of bitter and acrid substances, which being made into a compost, is calculated to improve the land, as well as to destroy insects,

September.-The sulject treated of under this month relates chiefly to the rejection of various fruits, by many cultivators, and to the propensity of some persons to neglect old inmates of the garden for the sake of trying other varieties, merely because they are new 
Octoвer.-It is suggested that attention be paid to the careful gathering of fiuit, while in a perfect state; also to the preservation of Grapes, \&c. Directions for plauting the pits of Cherry, Peach, Plum, \&c., and the kernels of Apple, Pear, and Quince; also for preparing the ground for the reception of all kinds of hardy fruit trees on the decline of the sap, 16\%

November.-As winter is fast approaching, it is recommended to protect tender vines, trees, shrubs, and plants, including Raspberry, Fig, Strawberry Plants, \&c.; and to plant hardy fruit trees while the land is susceptible of being tilled, - _ $\quad-163$

December. - At all favourable opportunities during this month the gardener is directed to prune hardy fruit trecs, to scrape off all the moss and canker, and to wash the stems and branches with a liquid prepared according to a recipe given,

An Adpress to the People of the United States on the subject of an alleged discovery on TerraCulture, submitted to the attention of the 25th and

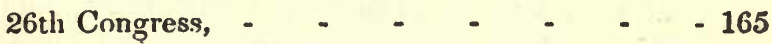

$\Lambda$ summary view of estimates, furnished with a view to aid the Seedsman and Gardener in making out a bill of seed, for the purpose of planting any given quantity of ground, under the regulations suggested in the regetable department of the Young Gardeners Assistant, 


\section{OBSERVATIONS}

\section{ox $\operatorname{xr2} ; 0 ; 0 ; \quad \therefore ;$}

FRUIT GARDEN AND:ORCHART.

Is the preliminary observations on the subjects already treated of, I am aware that it may appear to some that I have not sufficiently urged the importance of a judicious selection of situation, expnsure, aspect, soil, \&c. My object in not insisting on a strict attention to these important points was, because I know that, though gond land is abundant in this extensive country, it is impossible for every one to choose for himself; and rather than any disadvantages in these respects should discourage proprietors of land from attempting to raise garden products, so necessary to the comfort and convenience of every family, I have endeavoured to show them how to use to advantage whatever land may surround their places of abode. As, however, some have a choice, it may be necessary to offer some farther remarks on the subject.

The situation of an Orchard or Fruit Garden should be one that has the advantage of a free circulation of air, and is exposed to the south, with a slight inclination to the east and southwest. When the situation is low and close, the trees are very liable to become mossy, which always injures them, by closing up the pores of the wood ; they are also more liable to be affected by blight. Although having an orchard closely pent up by trees, \&c., is injurious, nevertheless a screen of forest trees, at such a distance from the fruit trees as that the latter will not be shaded by them, is of very groat service in protecting the trees in spring from severe cold winds. 
A good strong loamy soil, not too retentive of moisture, to the depth of thirty inches, or three feet, is most suitable for an orchard. Great attention must be paid to the substratum, as the ground must be well drained; for if the top soil be ever'so good, and the bottom wet, it is very rarely the case that the trees prosper many years; they soon begin to be diserse and "go to decay." As it is so indispensably necessary to the success of fruit trees that the bottom should be dry, if it is not naturally so, it must be made so by judicious draining.

When it is necessary to make the bottom dry by dra.ning, it must be done some time before the trees are planted. In performing this work, the ground must be trenched, and when the trench is open, stone, or brick-bats, \&c., must be laid over the bottom to the thickness of six inches, a little coal ashes, or small gravel, must be sprinkled over the top of the stones, \&c., and then the surface gently rolled. Drains may also be made in different directions, so that any excess of moisture can be taken entirely away from the ground.

It is well known to most cultivators, that exposure of soils to the atmosphere greatly improves them, as is experienced by ridging and trenching. Where the soil is stiff and stubborn, small gravel, sand, coal ashes, lime, light animal and vegetable manure, and other light composts, are very appropriate substances to be applied, and will, if carefully managed and well worked into the ground, soon bring it into a proper condition for most purposes.

Previous to laying out an orchard or fruit garden, the soil should be manured and pulverized to a great depth. It should be made sweet, that the nutriment which the roots receive may be wholesome; free, that they may be at full liberty to range in quest of it; and rich, that there may be no defect in food.

If orchards are made from meadows or pasture lands, the ground should be improved as much as possible by manur. 
ing, trenching, ploughing, \&c. If this is not done to its full extent, it should be done in strips of at least six feet in width along where the fruit trees are to be planted, and at the time of planting let the holes be dug somewhat larger than is sufficient to admit the roots in their natural position, and of sufficient depth to allow of a foot of rich and well-pulverized mould to be thrown in before the trees are planted.

In transplanting trees, they should not be placed more than an inch or two deeper than they were in the nursery bed, and the earth intended for filling in should be enriched and well pulverized by mixing in some good old manure; and if any leaves, decayed brush, rotten wood, potato tops, or other refuse of a farm, are attainable, let such be used around the trees in filling, taking care that the best pulverized mould is admitted among the fine roots. The trees in planting should be kept at ease, and several times shaken, so as to cause an equal distribution of the finer particles of earth to be connected with the small fibres of the roots; and when completely levelied, let the ground be well trodden down and moderately watered, which should be repeated occasionally after spring planting, if the weather should prove dry.

As some difference of opinion exists among practical men as to the best time for planting fruit trees, the following extract from Mr. Prince's Treatise on Horticulture is submitted :

"Seasons for Transplanting. Spring is the season when we find the most pleasure in making our rural improvements, and from this circumstance, probably, it has become the general season for planting trees; but experience has proved autumn planting to be the must successful, especially in those parts of the United States which are subject to droughts, as trees planted in autumn suffer little or none from drought, when those set out in spring often perish in consequence of it. Notwithstanding, with regard to those fruits that have been originally brought from warmer cli- 
mates, such as the Peach, Apricot, Nectarine, and Almond, which are natives of Persia, Armenia, \&c., it is necessary for us to consult the operations of climate also; and, from a consideration of those attendant circumstances, I have come to the following conclusions: In localities south of New-York, autumn planting is preferable only for the Apple, Pear, Plum, Cherry, Quince, and all other trees of northern latitude; whereas, the spring is to be preferred for the Peach, Apricot, Nectarine, and Almond, which, for the reasons before stated, might, during severe winters, suffer flom the intensity of the frosts. Still I do not mean to assert, that trees of those kinds are certain to be injured by the winter, as in very many seasons they are not in the least affected; still they are exposed to vicissitudes which may or may not occur. Many gentlemen, however, of excellent judgment, make their plantations in the autumn, which only serves to prove, that even in the most intelligent minds a diversity of opinion exists.

“Trees, etc., on their Arrival at the Place of DesTination. As soon as the trees arrive at the place where they are to be planted, let a trench be dug in cultivated ground, the bundles unpacked, the roots well wetted, and immediately covered with earth in the trench, observing to make the earth fine that is spread over them, so as not to leave vacancies for the admission of air to dry the roots, it having been found by experience that the thriftiness of trees the first year after transplanting, depends much on the fine fibres of the roots being kept moist, and not suffered to dry from the time they are taken up until they are replanted; their increase, therefore, must depend principally on the subsequent management on their arrival at the place of destination; for if, when the bundles are unpacked, the trees are carelessly exposed to drying winds, the young fibres of the roots must perish, and the trees, if they live at all, cannot thrive the first season, as they can receive little or no nourishment until these fibres are replaced. 
"To cause the Trees to Thrive. The ground where they are planted must be kept cultivated; young trees will not thrive if the grass be permitted to form a sod around them; and if it should be necessary to plant them in grass grounds, care must be taken to keep the earth mellow and free from grass for three or four feet distant around them, and every autumn some well-rotted manure should be dug in around each tree, and every spring the bodies of the Apple, Pear, Plum, and Cherry trees, and others that it is particularly desirable to promote the growth of, should bo brushed over with common soft soap, undiluted with water; this treatment will give a thriftiness to the trees surpassing the expectation of any one who has not witnessed its effect. Should the first season after transplanting prove dry, regular watering will be necessary, as from neglect of proper attention in this respect, many lose a large portion of their trees during a drought"

Such kinds of fruit trees treated on in this work, as may require any other than good ordinary soil, may be supplied,

* The following letter was received by the Author while he was preparing the copy fur the ninth edition of this work :

"In reading your very useful and entertaining work on Gardening, Planting Trees, and otherwise, I need not say, to me, it contained much that was new, original, and very useful; yet, complete as is your admirable work, I found not therein one circumstance connected with replanting trees, of vital importance to be observed, particularly with those trees which have attained several years' growth, say trees from fifteen io twenty feet high, and from three to five inches diameter. Some seven or eight feet above the root, that is to say, at the time of digging up the tree, a mark should be made on the north or south side of the tree; and on replanting the same, it should be set into the ground as nearly as possible in the same position to the gun (north or south) as it occupied before taken up, otherwise the tree will not be so thrifty; if its sides are changed, it not unfrequently appears sickly, and ultimately dies. Over twenty years' experience in replanting some thousands of hard and soft Maple, Elm, and others, enables me to speak positively on this precaution. Whenever the community calls for another edition of your work, in that part relating to Replanting Trees, if you deem the above suitable for insrrtion therein, it might assist many who have not this knowledge, and oblige, "Yours with esteem, JoHN CLOWrs, C. E." 
by judicious management; and if a proper attention be paid to the situation and aspect in arranging a fruit garden, each kind may be so accommodated as to promote its fruits' ripening earlier or later than the ordinary season, by varying the aspect; but Grape Vines, or other tender fruits, should not be planted where the sun's influence does not fully operate.

Where there is a great extent of close fencing or wall, it is advisable to plant trees of the same kind against different aspects. Such as one or two May Duke Cherries against a southern aspect, which will ripen earliest; next, against either an eastern or western; and lastly, against a northern aspect; by observing this method with Dwarf Cherries, Plums, Gooseberries, Currants, \&c., the fruit will ripen in succession, and thus a supply is considerably lengthened. The early blooming fruit trees will sometimes need protection in warm aspects; for which arrangements may be made by keeping awning, matting, netting, \&c., at hand, to shelter them with in threatening weather, or to screen them from the intense heat of the sun after a frosty night; this, with a sprinkling of water, as the air gets warm, will often prevent any serious consequences from slight frost.

Those who have various soils, should suit them to the differcnt kinds of fruit. Apples and Pears require a strong loam, but the Pear rather the lightest. Apricnts, Cherries, Peaches, Plums, and Nectarines, a good deal lighter than the Apple and Pear. Such fruits as may require peat, bog, or any other extraordinary kinds of earth, will be noticed as we proceed. 


\title{
13
}

\section{OBSERVATIONS ON INSECTS,}

\author{
AND \\ DISEASES TO WHICH FRUIT TREES ARE LIABLE.
}

Much may be written relative to the various diseases to which fruit trees are liable, and also to the prevention and destruction of the various kinds of reptiles and insects, which very frequently deprive us of the first fruits of our garden. The preventive operations are those of the best culture. Autumn ploughing, by exposing worms, grubs, the larvæ of bugs, beetles, \&c., to the intense frost of our winters, and the moderate use of salt, lime, ashes, \&c., are beneficial. Insects may be annoyed, and sometimes their complete destruction effected, by the use of soapsuds, lye, tar, turpentine, sulphur, pepper, soot, decoction of elder, walnut leaves, tobacco, and other bitter and acrid substances; but perhaps the most effectual way of keeping some of the most pernicious kinds of insects under, is to gather up such fruit as may fall from the trees, before the insects have an opportunity of escaping into the earth, or to other places of shelter

Where trees are planted in a bad soil, or unfavourable situations, they often become diseased; when this happens, the best remedy is good pruning, and keeping the trees clean by a free use of soap and water. If that will not do, they may be headed down, or removed to a better situation. Barrenness and disease are generally produced by the bad qualities of the earth and air, by a want of water, or by the inroads of insects. These incidents generally show themselves in the early part of the year. Leaves and shoots of any colour but the natural green; curled and ragged leaves; 
branches in a decaying state ; shoots growing from the roots, instead of from the stem or trunk; the stem diseased in its bark, the gum oozing from various parts thereof, are all proofs of the existence of disease. The Peach tree is subject to a disease called the yellows; and the discoloured leaves and feeble branches are often ascribed to the worms which so frequently attack the root; where these are found, they may be removed by a knife or chisel; but if it should appear that the tree is diseased, it should be removed, to prevent other trees from being infected. The Pear, and also the Quince, and sometimes other trees, are subject to the fire blight; this malady may be completely checked on its first appearance, by cutting off and immediately burning the injured branches. Generally speaking, careful pruning, cleaning the bark all over with a brush, applying soap or tobacco water to the leaves, and occasionally putting gord earth and good manure to the roots, will remedy most diseases in fruit trees; removing them from a bad to a better soil will, of course, effect this, where it proceeds from a poorness of land; for the old adage, "Remove the cause, and the effect will cease," will be here exemplified. To cure the oozing of the gum, nothing more is nocessary than to cut away the diseased parts of the bark; and by thus assisting nature in casting out the excrementitious, or noxious juices, a complete cure may be effected.

When a tree is affected by mildew, let it be immediately sprinkled with soapsuds, and then be dusted over with sulphur and tobacco dust, or snuff; at the same time, dig around the tree, and examine the soil and subsoil; if it be wet and cankery, it should be taken away, and replaced with good healthy soil, and the ground drained; if, on the contrary, the ground be dry, give it a plentiful watering; the same remedy may serve as a preventive of the extension of blight, if applied in time. When any canker is ubserved, the part affected must, at the time of pruning, be cut clean out, and the part thus dressed be pared, so that no water 
can lodge in the wound; when this is done, let a quantity of soot be mixed with water, and a little train oil well worked among it, but so that the mixture finally remains stiff; this may be plastered over all the wounds that have been pruned. The application of this mixture keeps out the wet from the wounds, where it would be likely to lodge, and both the soot and oil promote vegetation. When trees are cankery from having a bad subsoil, it is in vain to apply any remedy till the ground is properly drained, some fresh soil mixed with the natural soil, and the tree replanted. When trees are known to be so situated as to be particularly liable to the attacks of insects or disease, they should be attended to at the time of winter or early spring pruning, in order to destroy the insects in their larvæ state.

The following compositions have been known to protect fruit trees from the attacks of numerous insects, by being used as a wash to the trees immediately after pruning. The constitution of some trees will bear a much stronger mixture of ingredients than others; but the proportions, as hereafter described, will not be injurious to any, but will be effectual in the destruction of the larvæ of insects.

For Apricot, Nectarine, and Peach Trees. To eight gallons of water add one pound of soft soap, two pounds of common sulphur, and half an ounce of black pepper.

For Apple, Cherry, Pear, and Plum Trees. To four gallons of water add one pound of soft soap, two pounds of common sulphur, two ounces of tobacco, and one ounce of black pepper.

For Figs and Vines. To four gallons of water add half a pound of soft soap, one pound of sulphur, and a quarter of an ounce of black pepper.

All these ingredients must be boiled together for twenty minutes at least, and when in a lukewarm state, applied to the bark of the trees with a suitable brush.*

* For the destruction of the Aphis which frequently attacks the Apple, as well as other fruit trees, while young, an application of diluted whaleoil soap to the leaves and branches has been found very efficacious. 
The most destructive enemy to our fruit is the Curculio; this insect passes the winter in the earth in a chrysalis state, and if suffered to remain unmolested by the gardener, will be ready to commerce its attacks at about the time the blossoms appear on our fruit trees. The eggs are deposited in the Apple, Pear, and also all stone fruit, at a very early stage of their growth; these eggs soon hatch, and small maggots are produced, which exist in the fruit, causing it to drop off prematurely, with the little enemy within. If this fruit be gathered up, or immediately devoured by hogs, geese, or other animals, a check may be put to their ravages in succeeding years; but if suffered to remain on the ground, they will supply food to myriads of their destructive race, which may not be so easily extirpated.

The canker-worm is another enemy to our fruits, for the destruction of which many experiments have been tried. Some apply bandages round the body of the tree, smeared over with tar or ointment, to annoy or entrap the females in their ascent to the tree; but as these tormentors are frequently on the move from November to the end of June, this must be a very tedious as well as uncertain process. As this insect is supposed to exist within four feet of the trunk of the tree, and not more than three or four inches from the surface of the earth, good culture, and a moderate use of lime, ashes, or any other pernicious ingredient, is the most likely way to destroy them.

The bark-louse is another pernicious insect; they resemble blisters, and are so near the colour of the bark as to be imperceptible; they often prove fatal to the Apple tree, by preventing the circulation of the sap. These insects may be conquered by washing the trees with soapsuds, tobacco water, lime water, or brine, or a wash may be made of soapy water, salt, and lime, thickened to the consistency of cream or paint, with sifted sand or clay, which may be applied with a brush to the trunk and limbs of the trees; this should be done at the latter end of May, or early in June, and the cracks in the bark should be completely covered. 
The Apple-tree borer is said to deposit its eggs beneath the surface of the soil, and the worms are often to be found in the spring of the year, by digging round the tree, and clearing away the earth to the roots, and may be taken out with a knife or gouge, and destroyed. After the worms are removed the wounds should be covered over with grafting clay and wood ashes mixed, and the earth then returned to the roots of the tree. Some use bricklayers' mortar early in the spring, around the base of the tree, so as to cover the part where the deposit is made, and prevent their attacks.

Although our limits will not admit of a farther description of the various sorts of insects which injure our gardens, and frequently destroy the fruit of our labour, I cannot forbear directing the attention of our citizens to the importance of saving all kinds of ashes. If all agriculturists and horticulturists were to offer an inducement to the inhabitants of large cities, to save their ashes in a dry state, they would be supplied not only with a valuable manure, but an antidote for many kinds of insects; and our citizens would be at less risk from fire, by having a brick vault on their premises for safely keeping them. In England, a private dwelling is not considered complete without an ash-vault; and a good farmer would dispense with his barn, rather than be destitute of an ash-house. I have known farmers to supply the cottagers with as much peat as they could burn, on condition of their saving them the ashes; and there are some that will keep men under pay throughout the year, burning peat for the same purpose; and any thing that has passed the fire is so valuable, that a chimney-sweep will frequently clean chimneys for the sake of the soot, which is conveyed miles into the country, and sold at a price sufficient to reward the collectors, besides paying all expenses; even the house-keepers' ashes in cities is a marketable article at all times, bringing from ten to twenty-five cents per bushel, when kept dry and clean, and a guinea a load was formerly the common price in the villages of Berkshire and Hampshire. 
While on this subject, I would urge the importance of a spring dressing of ashes. If cultivators were to prepare turfs from tanners' bark, peat-earth, coal dust mixed with clay, cow dung, \&c., and get them dried in the summer season, these, by being preserved through the winter, may be burned around fruit orchards, while the trees are in blossom, and if the fires are properly managed, a smoke may be kept up by heaping on damp litter every night; this will prove pernicious to such insects as may reside in the trees, and the ashes being spread on the ground, will serve as a means of destruction to others. An orchard thus managed every year, will need no other manure. The smuking should be effected first on one side of the plantation, and afterward on the other, or heaps may be prepared in different parts of the orchard, and fire applied according as the wind may serve to carry the smoke where it is most necessary. I know a gardener in the neighbourhood of New-York, who saved his Plums and Nectarines by burning salt hay, after its having been used as a covering for his Spinach; and I have no hesitation in recommending it as an excellent remedy for securing fruit trees from insects, especially if some coarse tobacco could be procured to add to it. The damper the materials are, in moderation, the more smoke they will create; and if a little tar, pitch, sulphur, or other pernicious combustible be sprinked among them, it will be beneficial. This subject appears to me of the utmost consequence to the farmer, as well as to the community at large; I, therefore, cannot forbear offering some farther observations.

It must be acknowedged that, although this country contains an abundance of wood, coal, and peat, as well as almost every other description of fuel, yet the poor of our large cities, in general, suffer greatly from cold; and if all the tales of wo could be sounded in the ears of a sympathizing community during our severe winters, I am persuaded they would arouse them to the consideration of a remedy. It is an acknowledged fact that the poor of Europe are 
cheaper and better supplied with fuel than those of this country. This arises, in a great measure, from the circumstance of ashes being held in high estimation by agriculturists; they are consequently a saleable article in their large towns and cities, at a price equal, in some instances, to half the cost of a winter's fuel.

Now I would ask, how is it that ashes are not as valuable to the farmers here as they are in Europe? The extreme heat of the summer must certainly engender insects in equal if not greater proportions; and as respects manure, it must be scarcer in some parts of this extensive country than it is in the densely peopled countries of Europe. Perhaps some may answer, that ashes are already used by our cultivators to a considerable extent; but I would remind such, that from the circumstance of their being mixed up with other manures, and exposed to all sorts of weather, (as in our city,) they lose their virtue, so that a load may not be worth more than a bushel would be, if kept dry and clean.

The farmers of Europe consider peat ashes of more value than any others, and I am persuaded that, could they be fairly tested by some of our best cultivators, great good would result to the community. If the farmers in England can afford to keep men under pay, perpetually burning peat for the sake of the ashes, it is natural to suppose that the poor of our community may be placed in easier circumstances as respects the article of fuel. Thousands of acres of land are to be found in the States of New-York and New-Jersey, and within a few miles of this city, which abound with peat earth; and the owners of such have already begun to explore their treasures of this description. Good peat is now to be had in the city at the low price of eight cents per bushel, or three dollars per chaldron. It burns well in all sorts of stoves and grates, whether made for wood or coal, and also on the hearth; and if the ashes are not used to any better purpose than other ashes have hitherto been, it is the cheapest fuel known. I am persuaded that this subject is 
worthy of serious consideration, and if the editors of the different papers would arouse the public attention, so as to direct some of our most active citizens to a consideration of this subject, incalculable good would result to the community at large.

If the public authorities of our cities, and all those who distribute fuel among the poor, gratis, would give them peat instead of wood, it would be much cheaper, and would answer every purpose to the consumers. Twelve bushels might be given in the first winter month to each of the applicants, instead of wood, with a strict injunction to save their ashes in a dry state, in order to their being taken in exchange for a future supply of peat. It could be easily ascertained how much ashes twelve bushels of peat would make; and if a strict attention be paid to the conditions of exchange, it would soon be discovered which of the applicants was the most entitled to the distributor's bounty. The same sheds which it would be necessary to provide for housing the peat, could be used as a deposit for the ashes. If such sheds be conveniently constructed to hold each a moderate quantity, the first which is emptied of peat may be filled with the first ashes that are returned in exchange for a future supply of fuel, and they could all be used for the same purpose as they become empty. These ashes, when fairly tested. may become a merchartable article as in Europe; and it is very probable that farmers may be induced to take them in exchange for future supplies of peat; they could, however, be conveyed into the country at a trifling expense, and would, no doubt, meet with a ready sale. 


\title{
OBSERVATIONS
}

\author{
ON
}

TRAINING AND PRUNING FRUIT TREES AND VINES.

In training and pruning fruit trees and vines, particular attention is required. To supply a tree with a sufficiency of vegetable juices, there must necessarily be living bark and wood in an uninterrupted succession from the root to the extremities of the branches ; pruning, therefore, is useful to remedy any defect, as well as to take off superfluous wood, and prevent unnecessary waste of the sap. Pruning may be performed at different seasons of the year, according to the kinds of fruit, which will be shown under each head, as we proceed.

In the spring or summer pruning, be careful not to destroy the germs of future fruits, but merely remove all unserviceable sprigs. In the winter season, make your selection from the wood shoots of the preceding year; keep those which appear the most healthy, and cut away those which seem redundant. Beginners had better prefer the spring, as the buds will then be a guide for them to go by; but this business must not be delayed too late in the season, as some kinds of trees and vines are apt to bleed from being pruned untimely. When the sap rises in Grape Vines, \&c., before the wound is healed, bleeding ensues, and it is not easily stopped. When this happens, sear the place, and cover it with melted wax, or with warm pitch spread upon a piece of bladder; or peel off the outside bark to some distance from the place, and then press into the pores of the wood, a composition of pounded chalk and tar, mixed to the consistence of putty. Vines will bleed in autumn as well as in 
spring, though not so copiously. The best preventive is timely or early pruning in the spring, and not pruning until the wood is thoroughly ripe in autumn.

With respect to the manner in which vines, and some particular kinds of trees, should be trained, opinions are at variance. Some advise training the shoots in a straight and direct manner, others in a horizontal manner, and others again in a serpentine form, \&c. If vines be trained on low walls or trellises, the horizontal or zigzag manner of training ${ }^{\circ}$ may be adopted. Horizontal training is that in which from a main stem, lateral branches are led out horizontally on each side.

It has been remarked, that in order to be a good trainer of vines, a man must have some forethought, and be capable of making his selection, as the plants shoot. He must predetermine how he shall prune, and where he shall cut at the end of the season; and so, as it were, fashion the plants to his mind. He has this more effectually in his power, with respect to the vine, than any other fruit tree, on account of its rapid growth and docility.

In pruning vines, cut generally two inches above the bud. Some cut nearer, even as near as half an inch, which is apt to weaken the shoot of next season, and sometimes to prevent its vegetating at all, the buds being very susceptible of injury, on account of the soft and spongy nature of the wood. In cutting out old wood, be careful to cut in a sloping direction, and to smooth the edges of the wood, in order to prevent its being injured by moisture. The pruning being finished, let the loose, shreddy, outward rind on the old wood be carefully peeled off, observing not to injure the sound bark, and clear the trellis of branches, leaves, tendrils, \&c. Let the shoots and branches afterward be regularly laid in, at the distance above specified, particularly the young shoots that are expected to bear next season. As to others, it is not so material how near the young shoots be placed to the old, even though they sometimes cross them. Choose 
strands of fresh matting, or pack thread, to tie with; and observe to leave sufficient room for the swelling of the shoots and branches next season.

By attending to the proper training of fruit trees, every advantage is promoted, and by a judicious management in other respects, wood may not only be obtained, but preserved in every part of the tree, so that it will bear down to the very bole, which will evidently be greatly to the credit of the gardener, the benefit of the proprietor, and equally conducive to the beauty and welfare of the tree. While trees are young, it is necessary to lay a good foundation for a supply of bearing wood in future years, for when this is neglected, and they become naked, it is sometime before a supply can be recovered. In shortening a branch, always take care to cut in a direction a little sloping, and the middle of all standard trees should be ker,t as open as possible. It is requisite to have a very sharp knife, that the cut may not be ragged, but clean, and in the operation be careful that the knife does not slip, so that another branch be cut or damaged.

The general pruning of fruit trees is indifferently performed by many persons at any time from autumn to spring, and it may be so done without any great injury to them, provided mild weather be chosen for the purpose, and the wood be well ripened. Although it may be advantageous to prune trees early in the winter, when the wood is well ripened, yet, when the wood is green and the buds have not arrived at a mature state, it is requisite in such cases to defer pruning until spring, taking care, however, that it is performed before the moving of the sap. The necessity of this arises from the circumstance, that as the wood is not ripened in autumn, the sap is then in an active state, and will continue so until the frost, \&c., cause it to become stagnant; and if the shoots were shortened while the sap was in motion, the buds would be considerably injured, and the tree weakened; such unripe shoots are also more liable to suffer by the severity of winter, and when the pruning is deferred 
until spring, all such parts as may have been affected by the weather, can be removed to the extent to which the damage has been sustained. As the pruning of such unripe wood in the autumn would be injurious, so it frequently is when it is done during winter, and the more so according to its severity; because, whenever a cut is made on such green wood, the frost generally affects it, as the sap is not so dense, nor the wood so firm, as to be able to resist its intenseness.

Whatever method is adopted in training trees, care should be taken to keep the two sides as nearly equal as possible; this may easily be done, whether they are trained in the fan or horizontal method. For espalier trees, the horizontal method has many advantages over any other; the small compass within which the trees are obliged to be kept, requires such a direction for the branches, in order to make them fruitful; and were very high trellises formed, so as to admit of the trees being trained in the fan method, such would be very objectionable, by reason of the shade they would cause, and the trees would also be deprived of the benefit of a warmer temperature, which those less elevated receive.

As some young gardeners may not know what is meant by espaliers, it may be necessary to explain, that espaliers aro hedges of fruit trees, which are trained up regularly to a frame or trellis of wood-work ; they produce large fruit plentifully, without taking up much room, and may be planted in the Kitchen Garden without much inconvenience to its other products. For espalier fruit trees in the open ground, a trellis is absolutely necessary, and may either be formed of common stakes or poles, or of regular joinery work, according to taste or fancy.

The implements employed in pruning, and the manner of using them, are matters of moment. If the operation is commenced when the tree is young, and judiciously followed up, a good knife, a small saw, a mallet, and a chisel fixed 
on a six-foot handle, to trim the tops and extremities of the branches, are all the tools that are required. A large saw will be occasionally wanted; but an axe or hatchet should never be employed, as they fracture the wood, bruise and tear the bark, and disfigure the tree.

\section{BUDDING AND GRAFTING FRUIT TREES.}

Budding and Grafting, Lindley observes, are operations that equally depend for their success upon the property that buds possess of shooting roots downward, and stems upward; but in these practices, the roots strike between the bark and wood of the stock, instead of into the earth, and form new layers of wood, instead of subterranean fibres. The success of such practices, however, depends upon other causes than those which influence the growth of cuttings. It is necessary that an adhesion should take place between the scion and the stock, so that when the descending fibres of the buds shall have fixed themselves upon the wood of the stock, they may not be liable to subsequent separation. No one can have studied the economy of the vegetable kingdom, without having remarked that there is a strong tendency to cohesion in bodies or parts that are placed in contact with each other,

\section{BUDDING, OR INOCULATING.}

To bud trees, let the following method be adopted: Procure a knife which has a thin blade, and a sharp ivory handle; the use of the blade is to prepare the buds, and the handle is used to raise the bark of the stocks, so that the buds can be easily inserted. Have some good strong bass in readiness, and then take some good thrifty sprigs from healthy atrees of the sorts you intend to propagate. When 
all is ready, make a cut in the bark of the stock transversely, and from the middle of this cut make another downward, at least two inches in length, so that the two cuts may be in the form of a $\mathrm{T}$; then from one of your sprigs proceed with expedition to take off a bud; this is effected as follows: Insert the knife a little more than half an inch below the bud or eye, force it into the wood, drawing it under the bud, and cut the piece off across the shoot; then immediately let that part of the wood which was cut off with the bud be separated from it, which may be readily done with the knife, by placing the point of it between the bark and wood at one end, and, holding the bark in one hand, pull off the woody part with the other, which will readily come from the bark, if the tree from which it was taken be in a vigorous condition. Examine the bark, so as to be satisfied that the bud remains perfect; if there is no hole in it, let it be immediately inserted into the stock, which is done by raising with the handle of your knife the bark of the stock downward on each side from the cross cut, and thrusting the bud in between the bark and the wood, applying it as close as possi ble. As soon as the bud is put into its place, bind it securely with bass, beginning a little below the cut, and proceeding upward, till you are above the cross cut, taking care to miss the eye of the bud, just so that it may be seen through the bandage of the bass. About a week or ten days after the stocks have been budded, they should be examined, when such as have united will appear fresh and full, and those that have not taken will appear decayed; in the former case the bandage may be left off, and in the latter case, the stock may be budded in another place, provided the first operation was done in the month of July or early in August, as these are the two most preferable months for budding fruit trees in general. Budding is, however, often attended with success, if done early in September.

Scallop Budding is performed by cutting fiom a small stock a thin narrow scallop of wood, about an inch in lengih, 
and taking from a twig a thin scallop of wood of the same length; this is instantly applied, and fitted perfectly at top and bottom, and as nearly as possible on its sides, and firmly bound with wet bass matting. This may be performed in the spring, and if it fails, it may be done again in the month of July. The French practice this mode on Roses.

\section{GRAFTING.}

Grafting is the taking a shoot from one tree and inserting it into another, in such a manner that both may unite closely, and become one tree. These shoots are called scions or grafts, and in the choice of them, and the mode of preparing some descriptions of stocks, the following hints will be useful :

Those scions are best which are taken from the lateral ur horizontal, rather than from the strong perpendicular shoots. The shoots of Apples, \&c., should be taken from healthy trees late in autumn, or before the buds begin to swell in the spring, and buried half of their length in the ground, or in a cool and dry cellar; there to remain until the season of grafting.

For some descriptions of trees, the stocks are headed down near to the ground. In nurseries, Apples intended for standards are generally grafted about nine inches high only, allowing them to grow up standard high, and forming their heads upon the second year's shoots. In cider countries, the stock is generally trained up standard high; and when grown sufficiently large for the purpose, it is grafte. $i$ at the height at which it is intended the head of the tree shall be formed. As respects trees in general, directions will be found under their appropriate heads.

The business of grafting is generally performed in March and April : there are various methods of grafting, but the following are those most generally practised : 
Creft Grafting. This mode of grafting is generally practised on stocks of from one to two inches in diameter, and may be performed in the following manner: Let the head of the stock be carefully sawed off at a part free from knots, and the top pared smooth; then with a thin knife split down the stock through the centre to the depth of about two inches, and insert a veedge to keep it open for the reception of the scion. The scion must be prepared in the form of a wedge, with an eye, if possible, in the upper part, and inserted carefully, so that the inner bark of the scion and of the stock may both exactly meet. Large stocks require two scions, one on each side, and sometimes four are inserted. When done, tie them firmly together with bass, and then cover the grafted part with well-prepared clay, in an oval form, and close it securely.

Side Grafting. This mode is sometimes practised on those parts of a tree where a limb is wanting. There are two ways in which it may be performed. 1st. The scion may be prepared in the same manner as for splice grafting, and the bark and wood on the side of the stock cut sloping; the scion being then adjusted as carefully as possible, it must be bound on and covered with clay. 2d. The scion being cut sloping, a cross-cut is to be made in the side of the tree on the top of a perpendicular slit; the bark of a tree above the cross-cut must be pared down slanting to the wood, and the bark raised as in budding; the scion being then inserted. it must be bound fast, and covered with clay.

Splice, or Whip Grafting. This mode is often practised on small stocks, and it succeeds best when the scion and stock are of an equal size. The scion, which should consist of young wood of the former year's growth, may be cut to the length of about four inches. This and the stock are each to be cut sloping, for an inch or more, and tongued. Tongueing consists in cutting a slit in the middle of the slope of the stock downward, and a corresponding slit in the scion upward ; both are now to be joined, so that one of the sides, 
if not both, shall perfectly coincide, and then securely bound with bass matting, and covered with grafting clay or composition. As soon as the scion and stock are completely united, the bass string may be removed.

Saddle Grafting. The celebrated Mr. Knight practised this mode of grafting on very small stocks. The upper part of the stock is prepared in the form of a wedge, by two sloping cuts, one on each side. The scion is prepared by slitting it upward, and paring out the middle part on each side to a point. When the stock and scion are of equal size, the adjustment may be made perfect; but if unequal, one side must exactly meet. The whole is secured by a string of bass matting, and covered with composition or clay; but the string must be removed as soon as a perfect union has taken place.

Root Grafting. This operation is often performed on Grape vines, just below the level of the surface, by the usual mode of cleft grafting. It is also performed on portions or pieces of root, where suitable stocks are scarce.

Grafting by Approach. The trees, or shrubs, to be grafted in this mode, must be growing very near to those which are to furnish the grafts. The limbs or branches of each tree, which are thus to be united, must be pared with a long sloping cut of several inches, nearly to the centre; and the parts of each tree thus prepared are to be brought together, and finally secured by a bandage of matting, so that the bark shall meet as nearly as possible. The graft may then be covered with clay or composition; and when a complete union has taken place, the trees or shrubs may be separated with a sharp knife, by cutting off below the junction.

It may be here observed that, as young grafted trees ix the nursery progress in growth, the lower side-limbs should be gradually shortened, but not suddenly close-pruned they are essential for a time to strengthen the trunks, anc to the upright and perfect formation of the tree. 


\section{DIRECTIONS FOR MAKING}

\section{COMPOSITION, GRAFTING CLAY, ETC.,}

\section{FOR USE ON FRUIT TREES.}

The British Parliament gave Mr. Forsyth a valuable premium for the following important directions for making a composition for curing diseases, defects, and injuries in all kinds of fruit and forest trees, and the method of preparing the trees, and laying on the composition:

Take one bushel of fresh cow-dung, half a bushel of lime rubbish of old buildings (that from the ceilings of rooms is preferable), half a bushel of wood ashes, and a sixteenth part of a bushel of pit or river sand; the three last articles are to be sifted fine before they are mixed; then work them well together with a spade, and afterward with a wooden beater, until the stuff is very smooth, like fine plaster used for ceilings of rooms.

The composition being thus made, care must be taken to prepare the tree properly for its application, by cutting away all the dead, decayed, and injured part, till you come at the fresh sound wood, leaving the surface of the wood very smooth, and rounding off the edges of the bark with a drawknife, or other instrument, perfectly smooth, which must be particularly attended to; then lay on the plaster about an eighth of an inch thick, all over the part where the wood or bark has been so cut away, finishing off the edges as thin as possible. Then take a quantity of dry powder of wood ashes mixed with a sixth part of the same quantity of the ashes of burnt bones; put it into a tin box with holes in the top, and shake the powder on the surface of the plaster till the whole is covered with it, letting it remain for half an hour to absorb the moisture; then apply more powder, rubbing it on gently with the hand, and repeating the application of the powder till the whole plaster becomes a dry, smooth surface. 
If any of the composition be left for a future occasion, it should be kept in a tub or other vessel, and urine poured on it so as to cover the surface, otherwise the atmosphere will greatly hurt the efficacy of the application.

When lime rubbish of old buildings cannot be easily got, take pounded chalk or common lime, after having been slaked a month at least.

As the growth of the trees will gradually effect the plaster, by raising up its edges next the bark, care should be taken, when that happens, to rub it over with the finger when occasion may require (which is best done when moistened by rain), that the plaster may be kept whole, to prevent the air and wet penetrating into the wound.

As the best way of using the composition is found, by experience, to be in a liquid state, it must, therefore, be reduced to the consistence of a pretty thick paint, by mixing it up with a sufficient quantity of urine and soapsuds, and laid on with a painter's brush. The powder of wood ashes and burned bones is to be applied as before directed, patting it down with the hand.

A Wash for the Stems of Frutt Trees. Take a peck of fresh cow-dung, half a peck of quick lime, half a pound of flour of sulphur, and a quarter of a pound of lampblack. Mix the whole together with as much urine and soapsuds in a boiling state as will form the ingredients into a thick paint.

This composition may be applied to the stems of young standard trees when planted out in the orchard, to prevent their being injured by the depredations of reptiles and insects.

A Wash for the Stems and Branches of Frutt Trees. Take half a peck of quick lime, half a pound of flour of sulphur, and a quarter of a pound of lampblack. Mix the whule together with as much boiling water as will form the ingredients into a thick paint. This composition is recommended to be applied to the stems and limbs of Apple trees which are infested with the White Mealy Insect, having previously removed the moss and loose bark by scraping them 
off with a strong knife, or some other instrument adapted to the purpose.

In using the composition, it will be most efficacious if applied in a warm state, or something more than blool heat.

On young trees, strong vinegar will effectually destroy this insect, and I have for many years, in my own nursery, used it for this purpose; but this would be too expensive to be applied when the trees are large.

A solution of potash to wash the stems of the trees early in the spring, before the buds expand, will effectually destroy them.

To make Grafting Composition. Take equal parts of rosin and beeswax, and a little tallow; melt these together and mix them; then pour the composition into cold water, and as it hardens, take it out and work it up with the hands until it attains a due consistence. It may be spread on brown paper, which being cut into strips of suitable size, is quickly applied, and in cool weather may be warmed by the breath, so as to become adhesive.

Grafting Chay may be made in the following manner: Take equal parts of fresh horse manure, free from litter, cow manure, and good stiff clay; add to this a portion of hair, and work it together in the same manner as masons mix their mortar. It should be well beaten and incorporated several days before it is required to be used.

\section{ON THE CHOICE OF FRUIT TREES IN THE NURSERY.}

In the choice of fruit trees, all possible care and attention are necessary; for, to have trees that do not answer the expectations of the proprietor, is a great disappointment. As the young gardener may need such directions as are calculated to govern him in his choice. I shall endeavour to 
furnish them. Whatever species or varieties of fruit trees are wanted, choose those that are vigorous and straight, and of a healthy appearance. Whether they have been grafted or budded, be careful to select such as have been worked on young stocks. Grafts and buds inserted into old, crooked, stunted stocks, seldom succeed well. Trees that are healthy, have always a smooth, clean, shining bark; such as are mossy, or have a rough, wrinkled bark, or are the least affected by canker, should be rejected. Canker is discoverable in the young wond, and generally two or three inches above the graft or bud. If the tree be an Apricot, Nectarine, Peach, or Plum, and any gum appears on the lower part of it, do not fix upon that. Let the tree you select (if a dwarf) be worked about six inches from the ground, and only one graft or bud should be upon each stock, for when there are more, the tree cannot be brought to so handsome a form.

In some of the following articles, it will be seen that several descriptions of trees may be transplanted with safety, even when far advanced in growth. When trees of four or five years' growth, after having been headed down, that are healthy, and well furnished with fruit-bearing wood close up to the centre of the tree, can be obtained, they will do very well; but great care is requisite in taking up, removing, and planting such. Let the tree be taken up with as great a portion of the roots as possible, taking care not to bruise, split, or damage them ; for want of attention to these points, trees often become diseased. Whenever (notwithstanding all due caution) any roots have been accidentally broken, split, or otherwise damaged in taking up the tree, let them be cut off; or if they cannot be well spared, let the damaged or bruised part be pared clean with a sharp knife, and a portion of the following composition be spread over the wound, in order to keep the wet from it, which would otherwise injure the tree: To equal parts of soft soap and tar, add a little beeswax; let them be boiled together, and when cold 
they may be used. The necessity of pruning-in and dressing mangled roots is more particularly required in trees of the stone fruit, such as Apricots, Nectarines, Peaches, Plums, \&c.; for without the application of some remedy, they gum at the roots, which defect, if not counteracted, very materially injures the upper part of the trees, which may become so affected as never to recover afterward; therefore, great care should be taken not to occasion such injury; and when accidents happen, all due caution and application are necessary to promote a healthy and vigorous growth.

A young tree, likely to do well, should have roots nearly corresponding to the branches; at least, it should have one strong root in a similar proportion to the bole of the tree, with a proper distribution of branching fibres. Healthy roots are always smooth and clear; their colour varies a hittle according to the kind of tree, but the older the roots are, the darker the colour is.

After the tree is taken up, be careful, in conveying it to the place where it is to be planted, that the roots are not chafed or rubbed. If trees are to be conveyed to a considerable distance, they should be well guarded by straw, or otherwise, in order to prevent injury. All damaged or bruised roots should be pruned as soon as the tree is taken up, but if it be necessary to prune away any sound, good roots, such pruning should be delayed until the time of planting. In pruning away roots, always let them be finished by a clear cut, and in a sloping direction; the slope should be toward the under stratum, so that the wet may not be allowed to lodge upon the part so cut. When trees are planted at an advanced season in the spring of the year, it will be necessary to prune the tops; and if trees are removed that have been trained three or four years, and are not properly supplied with young wood, they must be cut down either wholly or partially, in order to obtain a sufficiency. In practising this upon Apricot and Nectarine trees, \&c., always prune so as to have a leading shoot close below the cut, as it is 
very rare they will push a shoot below, unless there be a lead. This attention is not so particularly required in the Pear, \&c., as such will generally push forth shoots, although no leading ones are left; but in all kinds, the younger the wood is, the more certain are shoots to be produced. If a tree that has been under training for one or two years, should only have one good strong leading shoot, and two or three weaker ones which do not proceed from it, let the weak shoots be pruned clean away, and shorten the strong one, from which a handsome head may afterward be formed. For farther directious as respects pruring or planting fruit trees, \&c., the reader is referred to the preceding articles on these subjects; and as respects any species of fruit in particular, directions will be found under its distinct head.

In order to assist the reader in making a judicious selection of fruit trees, I have furnished a short description of such species and varieties as are in great repute for every good quality. Previous to making this selection, I carefully perused 'Prince's Pomulngical Manual,' 'Kenrick's Ámerican Orchardist,' 'Lindley's Guide to the Orchard and Fruit Garden,' and 'Manning's Descriptive Catalogue of Fruits;' beside these important guides, I had the select catalogues of different nurserymen before me, and have chosen such only as have been most. generally recommended. In doing this, I have had difficulties to contend with, of the nature of which, none but those who have duly considered the subject can form any idea. The facility with which seedling plants are raised, and the paternal fondness with which people are apt to regard their own seedlings, have occasioned hundreds of names to appear in the various catalogues, which tend not a little to swell the large and increasing list of fruits.

In many instances, the English, French, Spanish, and other names, provisional, local, and barbarous, are given to the same variety; consequently, some fruits appear in the different catalogues under all the varied names; and the patience and labour necessarily requisite for ascertaining 
which are really distinct varieties, and which are most worthy of cultivation, are correspondingly great.

To exemplify: Suppose from a catalogue of Pears the following names should be selected by a person wishing to plant as many varieties in his orchard, namely, Brown BEURRE, Beurre Gris, Beurre Rouge, Buerre Dore, Buerre d' Anjou, Buerre d' Or, Buerre d' Amblense, Buerie d' Amboise, Poire d'Amboise, Isambert, Red Beurre, Golden Beurre, Beurre du Roi. White Doyenne, Doyenne Blanc, Doyenne, Beurre Blanc, Bonne-ante, Saint Michael, Carlisle, Citron de Septembre, Kaiserbirne, Poire a court quene, Poire de Linon, Valencia, Poire de Neige, Poire de Seigneur, Poire Monsieur, White Beurre. Here is a list of twenty-nine kinds, as the purchaser supposes, but when the trees produce their fruit, he finds, to his great disappointment and mortification, that he has only two varieties, namely, the Brown Beurre and the White Doyenne.

In making out the descriptive lists, I have generally adopted the names given in the catalogues of the most celebrated nurserymen, as a heading; and have caused the synonymes, or names by which the same variety is known, or has been called, to be printed in italics; thus, my lists of about four hundred varieties of the various species of fruit, will embrace what has been deemed by some as different varieties, perhaps to the number of nearly two thousand.

In preparing the following articles, the object has been to furnish information which would entertain, as well as instruct the reader. Besides the authorities quoted, I have gleaned from those inexhaustible treasures to horticulturists, Loudon's Encyclopædia of Plants, and that of Gardening; but on account of the brevity necessarily observed throughout this work, it has been found impracticable to give many entire extracts; suffice it to say, that the historical facts aro generally collected from these sources. 


\section{APPLE}

\section{Pommier. Pyrus malus.}

Tre Apple being so closely connected with our wants and enjoyments, is entitled to the first notice in the catalogue of our fruits. The Apple Orchard is, in truth, the vineyard of our country ; and the delicious beverage that can be obtained from some of the varieties of this excellent fruit being calculated to cheer the invalid, as well as to strengthen the healthy, entitles it to high consideration. It is one of our oldest and best fruits, and has become completely naturalized to our soil; none can be brought to so high a degree of perfection with so little trouble; and of no other are there so many excellent varieties in general cultivation, calculated for almost every soil, situation, and climate, which our country affords.

The Apple tree is supposed by some to attain a great age: Haller mentions some trees in Herefordshire, England, that were a thousand years old, and were still highly prolific; but Knight considers two hundred years as the ordinary duration of a healthy tree, grafted on a crab stock, and planted in a strong, tenacious soil. Speechly mentions a tree in an or: chard at Burtonjoice, near Nottingham, about sixty years old, with branches extending from seven to nine yards round the bole, which in some seasons produced upward of a hundred bushels of apples.

The Romans had only twenty-two varieties in Pliny's time. There are upward of fifteen hundred now cultivated in the garden of the Horticultural Society of London, under name; the catalogue of the Linnæan Botanic Garden at Flushing contains about four hundred; and one of our enterprising horticulturists, Mr. William Coxe, of Burlington, New Jersey, enumerated one hundred and thirty-three kinds . cultivated in the United States, some years ago. They are usually divided into dessert, baking, and cider fruits: the 
first, highly flavoured; the second, such as fall, or becomo mellow in baking or boiling; and the third, austere, and generally fruit of small size. Besides this division, Apples are classed as pippins or seedlings, pearmains or somewhat pear-shaped fruits, rennets or queen-specked fruits, calviles or white-skinned fruits, russets or brown fruits, and some are denominated burknots.

The Apple may be propagated by layers, and many sorts by cuttings and budding, but the usual mode is by grafting on seedling stocks of two or three years growth, and for dwarfing, on stocks of the Quince or Paradise Apple. All the principal varieties are cultivated as standards in the orchard, and should be planted from thirty to forty feet from each other, or from any other spreading trees, in order that the sun and air may have their due influence in maturing the fruit.

Many of the dwarf kinds may be introduced.into the Kitchen Garden, and trained as espaliers, or dwarf standards. An Apple Orchard may be planted at any time after the trees are two years old from the graft; and as trees from young stocks will not come into full bearing until ten or twelve years old, they will bear removing with care at any time within that period.

Old Apple trees may be grafted with superior varieties by being headed down to standard height: most commonly, in very old subjects, the branches only are cut within a foot or two of the trunk, and then grafted in the crown or cleft manner. In all the varieties of the common Apple, the mode of bearing is upon small terminal and lateral spurs, or short robust shoots, from half an inch to two inches long, which spring from the younger branches of two or more years' growth, appearing at first at the extremity, and extending gradually to the side: the same bearing branches and fruit spurs continue many years fruitful.

Pruning.-As, from the mode of bearing, Apple trees do not admit of shortening the general bearers, it should only 
be practised in extraordinary cases. If trees have not the most desirable form when three or four years old, they should be judiciously pruned to promote regular spreading branches. In annual pruning, the main branches should not be cut, unless in cases of decay; but all superfluous cross branches and dead wood should be taken out, and the suckers eradicated. Espaliers require a summer and winter pruning.

\section{SELECT DESCRIPTIVE LIST OF APPLES.}

\section{SUMMER FRUIT.}

American Summer Pearmain, Early Summer Pearmain. This apple is of medium size and oblong form; its colour bright red on the sunny side, and on the opposite side yellow, streaked or blotched with red; the flesh is very juicy, tender, fine flavoured, and excellent. It ripens early in August, and is good either for the dessert or for cooking. Tree a good bearer.

BENoni. Fruit of medium size, form round and regular; the flesh yellow, high flavoured, and excellent; it ripens in July and August. "The tree bears well," says Mr. Manning, "and should be found in every good collection."

EARLX Bovgr, Sweet Bough. The size of this fruit varies from medium to large; its colour pale yellow; its form oblong; its skin smooth; flesh tender, juicy, sweet, and excellent. Ripens early in August.

Early Crofton, or Irish Peach Apple. An Irish apple, of the middle size and flattish shape; of an olive green colour, much variegated with red; has a rich saccharine flavour ; is much esteemed for the dessert, and is excellent also as a sauce apple. Ripens in August. The tree grows well, and is not apt to canker.

Early Harvest, Prince's Yellow Harvest, Pomme d'ete, July Pippin. A very early apple, of medium size; bright straw colour; flesh white and tender; juice rich, lively, and very fine. The tree bears young, and makes a fine garden espalier; ripening its fruit in July and August.

Early Red Juneating, Red Margaret, Early Striped Juneating, Strawberry, Eve Apple of the Irish. Fruit below the middle size; skin greenish yellow, richly and closely streaked with deep red; flesh white, juicy, breaking, sub-acid, very rich and agreeable. Ripens early in August.

Porter. This variety, says Mr. Manning, originated on the farm of the Rev. Samuel Porter, of Sherburne, Massachusetts. The fruit is large, of oblong shape; the skin a bright yellow, with a red blush; the flesh fine, sprightly, and agreeable. Ripens in September and October.

RED Astracar. This beautiful apple is of medium size, and roundish; the skin is dark red, covered with thick bloom like a plum; the flesh is white, tender, and somewhat acid. At perfection early in August. 
Rad Quarendon, Devonshire Quarenden. Sack Apple. A much egteemed Devonshire apple; of medium size; skin of a uniform deep rich crimson. with numerous green dots intermixed; flesh of a brisk, pleasant, and peculiar flavour. A very desirable dessert apple: from August to October; tree very productive.

Summer Pippin, Pie Apple. This fruit, in size and shape, resembles the Fall Pippin; it differs in having a little more red on the sunny side, and in arriving at maturity about a fortnight earlier. It is a very popular apple in New Jersey.

SUMMER QUEEN. A large oblong apple, striped with red on a yellow ground; the flesh is yellow, very high flavoured, and excellent. The tree is of vigorous growth, says Mr. Manning, a great bearer, and ripens its fruit in August.

Summer Rose, Harvest Apple. A very beautiful and excellent fruit, of moderate size and roundish form; the skin is yellow, striped and mottled with red; the flesh is sweet, juicy, and fine: in July and August; tree a great bearer.

Wrlliams's Farly, Williams's Favourite Red. This apple originated in Roxbury, Mass. ; it is of medium size ; oblong form ; the skin a bright and deep red; the flavour pleasant and agreeable. The tree is a great bearer, and its fruit commands a good price in the Boston markets: in $\mathbf{A u}$ : gust and September.

\section{AUTUMN FRUIT.}

ArbXander, Emperor Alexander, Aporta. Fruit very large, somewhat cordate, smallest at the crown; of a greenish yellow colour, striped or marbled with red; pulp tender, sweet, rich, and aromatic: ripens in October, and lasts till Christmas.

American Nonpareic, Doctor Apple. A beautiful apple of medium size and roundish form; its colour yellow, streaked and stained with red on the sunny side; flesh firm, juicy, and agreeable. A very fine market apple in October and November. Tree a great bearer.

Boxford. A very superior variety, says Mr. Manning; which was first cultivated at Boxford, Massachusetts. Fruit roundish, of medium size; skin striped with red and yellow; the flesh, yellow, rich, and good. The tree is a great bearer, and ripens its fruit in October.

Cumberland Spice. A fine dessert fruit. large, rather oblong; of a pale yellow colour, clouded near the base; the flesh white, tender, and of fine flavour. It ripens in autumn, and will keep till February.

Downton Pippin, Elton Golden Pippin, Knight's Golden Pippin. The Downton Golden Pippin is a most abundant bearer, and the fruit extremely well adapted for market; it is rather larger than the common Golden Pippin; skin nearly smooth; yellow, sprinkled with numerous specks; flesh yellowish, crisp, with a brisk, rich, sub-acid juice; specific gravity 10.79. Ripe in October and November, and will keep good till Christmas.

DRAP D'Or of France, Cloth of Gold. This apple is very large and handsome; its form globular; its colour a fine yellow, with dark specks; its flesh white, firm, and rich flavoured. The tree bears well, and should be fonnd in every good collection. Fruit in perfection from September to November. 
Fale Harvey. This is a large and handsome fruit, the shape flat, the skin light yellow, with a bright red cheek; flesh yellow. firm, rich, and high flavoured. Mr. Manning considered it "the finest Fall and karly Winter variety; a gnod bearer, and deserving extensive cultivation."

Fale Pippin, Cobbell's Fall Pippin, Reinnete Blanche D'Espagne, D'Expagne, De Rateau, Concombre Ancien. While Spanish Reinette, Camuesar. This extremely valuable variety stands in the first class of autumn fruits, and is very large ; its form is roundish oblong; skin smooth, yellowish green. tinged with orange; flesh yellowish, crisp, and tender, with a very ricl, sugary juice. It ripens in October, and kceps well as a fall apple.

Fameuse, Pomme de Neige. A Canadian apple of great beauty ; in size medium; skin light green. stained with bright red; flesh white, very tender; juice saccharine, with a musky perfume: ripe in October, and will keep good till Christmas. Tree hardy and productive.

Gozdren Russer, Aromatic Russet. A dessert apple. of medium size, and of a pale copper-coloured russet ; in great repute for its rich saccharine, aromatic, and slightly musky flavour. The tree is hardy and very productive : in October and November.

Gravenstern. Fruit rather large and compressed; of a yellowish green colour, striped with red; flesh crisp, and high flavoured : ripens in October, and lasts till A pril. This variety originated in Germany, and is considered the best dessert apple in that country.

KENRICk's RED AUtumn. A native apple of largish dimensions, raised by John Kenrick, Esq., of Newton, Massachusetts; colour pale green in the shade. but bright red next the sun, and streaked with deeper red; the flesh white, stained more or less with red; tender, juicy, and rich, with an agreeable sub-acid flavour: ripe in October.

Кгнам Hric. This apple, one of the most saleable varieties in Salem markets, originated on the farm of Dr. Kilham. in Wenham, Essex county. Massachusetts; the size is above medium; form a little oblong; the skin yellow, striped with red; the flesh is ycllow and high flavoured: from September to November.

Mon mouth PIPPIN. This variety originated in Monmouth county, New Jersey. It is above medium size, of greenish colour, striped with red; flesh frm, and of plcasant flavour. It is considered one of the most saleable and productive varieties of the season; and will keep good till after Christmas.

Orange Sweetriva, Yellow Sweeting, Golden Sweeting. This variety is much cultivated near Hartford, Connecticut, for the Boston. Providence, and Philadelphia markets; the fruit is rather large, flattened at its base and summit; the colour yellow, or orange; flesh very sweet and excellent : from September to December.

RED Ingestrie. A first-rate dessert apple, of medium size, and bright yellow colour, deeply tinged with red; raised by Mr. Knight, President of the London Horticultural Socicty. The tree bears well in America, and ripens its fruit in October. which is very rich, juicy, high flavoured, and grateful to the palate.

Red and Green Swertivo. Prince's Large Red and Green Sweeting. The fruit is of oblong shape; colour green, striped with red; the pulp is very sweet, tender, and of delicious flavour: from September to November 
SKEK No FARTHER, Rambo, or Romanite. This apple is much cultivated in Pennsylvania and New Jersey. Its form is flat, resembling the Vandervere in appearance. but is a more juicy fruit; the skin pale yellow, streaked with red; flesh tender and sprightly during the autumn months.

Stroat, Straat. A fine autumn apple, introduced by the late Jesse Buel, Esq., of Albany; in size medium; form rather oblong; skin yellowish green; flesh yellow and tender; juice rich and lively : in use from September to December.

Yellow Ingestrie. A beautiful apple, raised by Mr. Knight. President of the London Horticultural Society. The size is small, form round and regular; the colour of the skin golden yellow, with some black spots; the flesh yellow, firm, and delicate. The tree is an abundant bearer, and ripens its fruit in October. The late Judge Buel considered this variety as likely to rival the Lady apple as a fashionable fruit.

YoRK Russeting. ^ very large russety apple, well known about Boston. Its form is rather oblong; its flesh pleasant and agreeably acid; an excellent apple : from October to December.

\section{WINTER FRUIT.}

Esopus SPItzenburg. A beautiful apple; large and oval; of red coour, covered with numerous white specks; the flesh is yellowish; slightly acid, and of the finest flavour : ripens in October, and continues good till February.

BAI.DWIN. No apple in the Boston markets is more popular than this; it is rather above medium size; its form round; its colour bright red, strcaked with yellow ; its flesh is juicy, rich, saccharine, with a most agreeable acid flavour. The tree bears fruit abundantly, which ripens in Novem ber, and keeps till February or March.

Barceiona PEarmain, Speckled Golden Reinctte, Reinette Rouge Reinctte Rousse, Reinette des Carmes, Glace Rnuge, Kleiner Casseler Ro inette. This variety is said to be a very produrtive and excellent dessen apple; fruit of medium size; oval, not angular; colour brownish yellow in the shade, deep red next the sun; flesh firm, yellowish, with a rich aro. matic agreeable acid: from November till February.

BeAuty or the West. A large, oblate, beautiful fruit, of yellow and red colour; its flesh juicy, rich, saccharine, and firm. A good marketable apple from November until March.

BELI. Flower. A very large and beautiful apple; its colour bright yellow, with an occasional blush on the sunny side; its form oblong; the flesh tender. juicy, rich, and finely flavoured, and is alike excellent for the dessert and for cooking. It ripens early in November, and will keep all the winter. It is a valuable market fruit.

Blfnherm Pippin, Woodstock Pippin, Blenheim Orange. Fruit large, roundish, of a yellowish colour, tinged with red next the sun; pulp sweet and high flavoured : ripe in November, and keeps till March: a very superior dessert apple.

Bi.ue Pearmain This variety is well known about Boston as a large apple, of red colour, covered with a dense blue bloom, and of a delicious flavour; good as a dessert or for cooking: from October to January Tho tree grows strong, and is very productive. 
Court Pendu, Capendu, Court Pendu Plat, Garnm's Apple An estimable dessert apple, of medium size; in shape round, depressed; the colour yellow, a good deal covered with full red; it is of a high saccharine flavour and of close consistence; the fruit keeps till February or March. The tree grows upright, and bears well.

Danvers Winter Sweet, Epses Sweet, Danvers Sweeting. This varicty originated at Danvers, near Salem, Massachusetts; fruit of medium size; a little oblong; skin yellow, slightly tinged with red; its flesh sweet and excellent cooked, or as a dessert : from November to A pril. The tree is a great bearer, and of rapid growth.

Domins, Dumini. A first rate winter apple, of medium size and greenish yellow colour, clouded with brown blotches; the flesh is juicy, tender, and excellent. Tree a great bearer.

Goldren Bald, Golden Apple. A beautiful and superior fruit from the State of Maine; of large size and golden yellow colour; flesh firm; juice very rich, sweet, aromatic, with a good proportion of acid. It will keep good from November to A pril.

Golden Harvey, Brandy Apple. A dessert apple, not larger than the Golden Pippin; colour light yellow, with a flush of red, and embroidered with a roughish russet. It is called Brandy Apple from the superior specifis strength of its juice, being 10.85 ; it is of remarkably close texture, very rich in flavour, and will keep till A pril or May.

GREEN SwEET, Green Sweeting, Green Winter Sweet. This apple is much cultivated in Massachusetts. It is of medium size; the skin dull green, approaching to yellow; the flesh very sweet and delicious. It possesses the valuable property of retaining its soundness till May or June.

HubBakdston Nonesuch. A large apple of globular form; red and yellow colour, streaked and blotched; the flesh is juicy and of excellent flavour : from December to March. The tree is of vigorous growth, a great bearer, and worthy of extensive cultivation.

Jonathas, King Philip, New Spitzenburgh, Philip Rick. A winter fruit very generally admired in the State of New York. It is of medium size; the skin of pa'e yellow and bright red colour, occasionally tinged with purple; flesh tender, juice abundant, and highly flavoured. This fruit will keep till May.

LAdy Aprte, Pomme d'Api. Fruit small, flat; of pale yellow colour, tinged with a deep red on the side; flesh crisp, sprightly, and pleasant: ripens in November, and continues till April. It is a very saleable fruit on account of its great beauty.

LADIEs' SWEeting, Winter sweeting. This apple is above medium size; conical; skin yellow, streaked, and mottled with red; flesh juicy, sweet, and high flavoured : from November to May.

LFmon Pippin. An old and much esteemed dessert apple; of medium size and oval shape, much like a lemon both in form and colour, having a firm texture, brisk flavour, and plenty of acid: from October to March. Tree handsome, and a great bearer.

Maiden's Btush, Hawthornden. Fruit large, roundish; skin, pale greenish yellow, tinged with blush; the pulp is white, tender, juicy, and acid; and the fruit is good for the table as well as for all kitchen purposes: in September and October. The tree is hardy and prolific.

Malcarle, Charles Apple, Mela Carla. Poinme Finale. A far-fanned 
fruit. In the climate of Italy, this is supposed to be the best apple in the world. It is cultivated extensively in the territories of Genoa, as an article of export and commerce to Nice, Barcelona, Cadiz, and Marseilles The fruit is rather large, its form inclining to globular. Its beautiful waxen skin is a little marbled with a very faint green near the eye; its colour in the shade is a pale yellow, tinged with flaming crimson next the sun; the flesh is white, tender, delicate, sweet, with the fragrant perfume of roses. It ripens in September, and will keep till spring.

MENAGerf. Mr. Manning pronounced this to be the largest apple he had seen; the form is flat like a large English turnip; the skin of a light yellow; the flesh pleasant. but more adapted to the kitchen than the dessert : from October to February. It bears well trained as a dwarf.

Minister. A native apple of large size, and oblong sliape; the skin a light greenish yellow, striped with bright red; flesh yellow, light, high flavoured. and excellent. Mr. Manning considered this as one of the finest fruits that New England ever produced. It ripens in November, and will keep till after Christmas.

Monstrous Pippin, Baltimore, Gloria Mundi, Ox Apple. Fruit of enormous size, often weighing twenty-five ounces or more; of a pale yellowish green and blush colour, with white spots; and of a sprightly flavour; ex cellent for cooking : ripens in October, and continues fit for use till January

MURPHY. This apple in appearance resembles the Blue Pearmain; the shape is more oblong, the size not so large; the skin pale red, streaked or blotched with darker red, and covered with blue bloom; flesh white, tender, and good. Raised from seed by Mr. Murphy, and introduced to notice by Mr. Manning.

Newtown Pippin, American Newtoun Pippin, Yellone Newtoun Pippin. This variety, when perfectly matured, is considered by some the finest apple in our country; its skin is green, changing to an olive yellow at maturity, having a thin russet covering the greatest part of the base ; flesh pale yellow and firm; juice saccharine, and possessing a rich and highly aromatic flavour: from December to A pril.

Newtown Spitzenburg, Matchless. A beautiful apple of medium size; skin streaked, and tinged with red and yellow; flesh yellow, rich, and highly flavoured: from October till February.

Norfolx Beaufin. Fruit middling size, flattish, of a deep red and pale green colour; the flesh is firm and savoury; the tree hardy, upright, and a good bearer; fruit excellent for use in the kitchen, and highly esteemed for the dessert. It ripens in November, and is frequently to be obtained in England in July following.

Ortrey Pippin, Orlley Aipple, Vandyne, Woolman's Long of Prince. A fruit very much resembling the Yellow Newtown Pippin, but a little more oval; skin olive yellow at maturity, partially covered with pink and russet; flesh yellow. crisp, and breaking: very juicy, with the same pine-apple flavour which distinguishes the Newtown Pippin : good from November to A pril.

Pennock's Red Winter, Felican. Fruit very large and compressed; of deep red colour, streaked with yellow ; flesh tender. juicy, and of a sweet and pleasant flavour : ripens in November, and will keep good till March. It is a evry popular apple in the Philadelphia markets

Puntexin Swet, Ramsdel's Red Pumpkin Sweet. A beautiful frait, 
over medium size, round, inclined to oblong; of a dark red colour, covered with dense blue bloom ; flesh tender, rich, and sweet. It ripens in Novembcr, and ketps till January. The trees bear prodigious crops.

Rirode island Griening. Fruit large and depressed; skin at maturity greenish yellow; flesh slightly acid, and of the finest flavour : ripens in November, and continues till A pril. A most estimable apple for cooking as well as for the dessert.

Rrastone Prppin, Formosa Pippin, Traver's Apple, Glory of York. Fruit of medium size, roundish, and partially depressed; of a pale yellow colour, tinged with red; pulp slightly acid, and of fine flavour: ripens in November, and continues till April. It is one of the most popular dessert apples in England.

Roxbury Russet, Boston Russet, Pineapple Russet. This variety is cultivated extensively in Massachusetts for the Boston markcts, and for exportation. 'The fruit is of medium size; of a fine yellow russet colour, mixed with dull red; flesh white, juicy, rich, sub-acid, and excellent; for use in winter, and will keep till June.

Sw A AR APPLE. A much celebrated winter table fruit in some parts of New York and New Jersey; it is a large apple of uncommon flavour and richness: skin of a greenish yellow. tinged with blush. The tree is very productive, and highly deserving cultivation in every collection of fine fruit. Good till March.

VANDevere. An apple of medium size, the form flat; skin pale red, with rough yellowish blotches; flesh yellow and tender; juice plentiful, rich, and sprightly: from October till January.

Western Russet, Putnam's Russet. This variety is exfensively cultivated in Muskingum county, Ohio, where it is esteemed above all others of their fine winter varieties. It is above the middle size, of a greenish yellow colour, covered with russety blotches, and will keep all the winter.

White Winter Calville, Calville Blanche d'Hiver, Bonnet Carre. This fruit is large; its colour at maturity bright yellow, tinged with red; its form rather flat; flesh white, tender, and pleasant: from November to March. Tree an abundant bearer.

Wine A prev, Hay's Winter, Large Winter Red. Fine Winter. A variety highly esteemed in the Philadelphia markets; the fruit is large; of bright red colour. striped with yellow, the stalk end russety; its flesh is rich, aromatic, and pleasant: from October to February. The tree bear young and abundantly.

\section{CIDER FRUIT.}

CAMprizid. or NXWARK Swertro. This apple is next in reputation, as a cider fruit, to the Harrison, and is often mixed with that apple in equ.l proportions when ground; it is of the middle size, skin smooth, of red and yellow colour; the flesh is white, firm, stveet, and rich.

GranNIWIN KI.E. Fruit of moderate size, rather oblong; the skin a dark red, somewhat rough; flesh yellow, sweet, and rich. It is commonly mixed with the Harrison for making cider of a superior quality : ripe in November.

Hewe's VIrgrni Crab. From this fruit is obtained the celebrated Crab Cider, it is of small size, nearly round; skin of a dull red, strcakef 
with greenish yellow; the flesh is fibrous and astringent; juice acid and austere.

HARRISON, Harrison's Newark. This fruit is much celebrated in New Jersey as a cider apple; it is somewhat ovate, below the middle size; the skin is yellow, with black spots; flesh yellow, firm, rich, and sprightly. Ten bushels will make a barrel of exquisite cider, from which may be taken fourteen quarts of distilled spirits.

\section{APRICOT.}

\section{Abricotier. Prumus Armeniaca.}

The fruit of the Apricot is next in esteem to the Peach, and as it ripens three or four weeks earlier, should be more generally cultivated. The flowers appear in April, on the shoots of the preceding year, and on spurs of two or more years' growth, and the fruit ripens in July and August. The London Horticultural Society's catalogue describes fifty-four sorts, and Messrs. Prince have eighteen in their catalogue; besides these, is the Peach Apricot, a large fruit, supposed to be a hybrid between a Peach and an Apricot.

Our enterprising fellow citizen, Mr. William Shaw, has succeeded for many years in maturing large quantities of this excellent fruit on standards ; but they ripen best when trained against close fences. In England some of the varieties are cultivated as standards and espaliers; but they seldom bear much fruit under ten or twelve years, and then the fruit is abundant and of the finest flavour. They are commonly cultivated as wall trees, in an east or west aspect; for if they are planted to face the south, the great heat causes them to be mealy before they are eatable. New varieties are procured from seed, as in the Peach, and approved sorts are perpetuated by budding on plum stocks, \&c.

The varieties of the $\Lambda$ pricot, in general, bear chiefly upon the young shoots of last year, and casually upon small spurs rising on the two or three years' old fruit branches. The Moor Park bears chiefly on the last year's shoots, and on 
close spurs formed on the two year old wood. The bearing shoots emit the blossom buds immediately from the eyes along the sides, and the bud3 have a round and swelling appearance.

Apricot trees may be planted at any time after the head is formed: some head them down in the nursery bed, and remove them to their destined places when five or six years old.

Standards will require only occasional pruning, to regulate such branches as may be too numerous, too extended, or cross formed, and to remove any casually unfruitful parts and dead wood; but the regular branches, forming the head of the tree, should not be shortened unless necessary.

The general culture of the wall Apricots comprehends a summer and winter course of regulation, by pruning and training. The fan method is generally adopted, but some prefer training horizontally. With young trees some contrive to fill the wall by heading down twice a year.

The winter, or early spring management, comprehends a general regulation both of the last year's shonts and the older branches. A general supply of the most regularly situated young shoots must be every where retained, for successional bearers the ensuing year. Cut out such branches. as are not furnished with competent supplies of young wood, or with fruit spurs, to make room for training the most promising branches retained. Generally, observe in this pruning. to retain one leading shoot at the end of each branch; either a naturally placed terminal, or one formed by cutting (where a vacancy is to be furnished) into a proper leader. Let the shoots retained for bearers be moderately shortened; reduce strong shoots in the least proportion-cutting off one fourth or less of their length; from weak shoots take away a third, and sometimes a half. This shortening will conduce to tho production of a good supply of lateral shoots the ensuing summer, from the lower and middle placed eyes; whereas without it, the new shoots would proceed mustly from the 
top, and leave the under part of the principal branches naked, and the lower and middle parts of the tree unfurnished with proper supplies of bearing wood. Never prune below all the blossom buds, except to provide wond, in which case cut nearer to the origin of the branch. As, in these trees, small fruit spurs, an inch or two long, often appear on some of. the two or three years' branches furnished with blossom buds, these spurs should generally be retained for bearing. As each tree is pruned, lay in the branches and shoots from three to six inches distance, and nail them straight or close to the fence or wall.

The summer pruning is principally to regulate the young shoots of the same year. In the first place, take off close all the irregular foremost shoots, taking care to retain a competent supply of close side shoots, with a good leader to each parent branch. Continue these mostly at full length all the summer, regularly trained in, to procure a sufficiency to choose from in the general winter pruning, for new bearers the next year.

If the summer regulation commences early, while the shoots are quite young, and, as it were, herbaceous, those improper to retain may be detached with the finger and thumb; but when of firmer growth, they must be remored with the knife. If any very strong shoots rise in any part where the wood is deficient, they may be topped in June, which will cause them to produce several laterals the same year, eligible for training in, to supply the vacancy.

Sometimes the fruit is much too numerous, if not destroyed by insects, often growing in clusters; in which case thin them while in a young, green state, leaving the most prominent fruit singly, at three or four inches distance, or from about two to six on the respective shonts, according to their strength. The Apricots so thinned off, and the first prines pal green fruit, are very fine for tarts. 


\section{SELECT DESCRIPTIVE LIST OF APRICOTS.}

Breda, Abricot de Hollande, Amande Aveline, Royal Persian. Fruit medium size, of a round form, and deep yellow colour; the pulp is soft and juicy; the tree is a great bearer, and the fruit, which ripens early in August, is in great esteem.

Brussels. Highly esteemed for its productiveness; fruit medium size, inclining to an oval form; of a yellow colour, and next the sun covered with numerous dark spots; the flesh is of a greenish yellow colour, of a brisk flavour, and not liable to become mealy : ripens in August.

Blotched Leaved Roman, Blotch Leaved Turkey, Variegated Turkey, Abricot Macule of the French. Fruit middle size, in form slightly compressed, inclining to oval ; skın dull straw colour, with orange or red spots ; flesh pale straw colour, soft, dry, rather mealy ; kernel rather bitter. A very hardy and productive variety; ripe towards the end of July.

Early Orange, Royal George, Royal Orange. The fruit of a medium size; of a deep yellow colour, spotted with red or dark purple next the sun; flesh deep orange, succulent, and well flavoured; not perfectly a free stone : ripens early in A ugust.

HEMSKIRKE. Fruit middle sized, roundish, slightly compressed; of a bright yellow colour; flesh tender, juicy, with a particularly rich, delicate flavour, resembling that of the Green Gage Plum : ripe in July

LARge EARLY Apricot, Abricot Gros Precoce, Abricot de St. Jean, Abricot de St. Jean rouge, Abricot gros d'Alexandrie. Fruit somewhat oblong; skin downy, orange, spotted with red; flesh orange, juicy, and rich, parting from the stone. This is the earliest of all apricots; in France it has ripened by midsummer day, whence its name of $A$. de St. Jean.

Moorpark, Anson's, Temple's, Dunmore's Breda. The tree is of vigorous growth, and extraordinarily productive; the fruit is very large; of a bright gold colour, or orange, with dark spots next the sun; flesh orange colour, melting, and excellent : ripens in August.

Muscr, Musch. A fine new variety from Persia; in shape round; of a deep yellow colour, and remarkable for the transparency of its pulp, through which the stone is visible; the flesh is very fine and agreeable: ripens in July.

Pench Apricot, Abricot Peche, Abricot de Nancy, Imperial Ansons. This is a first-rate fruit; form variable, generally flattened; skin slightly downy; fawn colour next the sun, tinged with reddish spots or points; pulp yellow, melting, juice abundant, high flavoured, and excellent : ripens early in August.

Purple, Alexandrian Abricot, Abricnt Angoumois, Abricot Violet, Black Apricot. A small, globular, downy fruit, a little oblong; of a pale red colour, becoming deep red or purple next the sun ; flesh pale red, but orange next the stone; a little acid, but good : ripens in August.

RED Masculixe, Abricot Precoce, Abricot Hatif Musque, Easly Masculine. This is an old and very early variety; the fruit of which is small, of a roundish form, and greenish red colour; the pulp is tender; the tree a good bearer, and the fruit esteemed for its earliness and tart taste; ripens in July. 
Roraz. Abricot Royale. This fruit is next in size to the Moorpark ; rather oval, compressed; of dull yellow colour, slightly red; flesh pale orange, firm, juicy, sweet, and high flavoured, with a slight acid : ripens early in August.

Turkey, Large Turkey. A superior apricot; fruit of a medium size: deep yellow colour, with red blotches next the sun; form globular; flesh firm, juicy, rich, and excellent: ripe in July and A ugust.

White Apricot, White Masculine, Abricot Blanc. Fruit, in size and Ggure, similar to the Red Masculine. Skin nearly white; flesh white, very delicate; juice sweet, with an agreeable peach-like flavour. Ripe in July.

\section{ALMOND.}

\section{Amandier. Amygdalus.}

Although Almonds are not much cultivated in this part of our country, they are entitled to notice. The species are fruit trees, or ornamental trees and shrubs, both much esteemed for the gay colour and early appearance of their flowers; these vary in their colour from the fine blush of the apple blossom to a snowy whiteness. The chief obvious distinction is in the fruit, which is flatter, with a coriaceous covering, instead of the rich pulp of the Peach and Nectarine, opening spontaneuusly when the kernel is ripe. It is a native of Barbary, China, and most eastern countries. There are twelve sorts described in the catalugue of the Linnæan Botanic Garden at Flushing; some of which are represented as new varieties from France and Italy, where they are cultivated extensively for their fruit.

In France, they have above a dozen species or varieties, besides a hybrid, called the Almond Peach. The common and bitter Almond are only to be distinguished by the taste of the kernels of their fruit, which is the only part used. The tender-shelled is in the greatest esteem, and next, the Sweet, and Jordan. The bitter cuticle or skin of Almonds is taken off by immersion in boiling water.

The sweet Almond and other varieties are used as a dessert in a green or imperfectly ripe, and also in a ripe or 
dried state. They are much used in cookery, confectionary, perfumery, and medicine.

The Almond is propagated by seed for varieties, or for stocks; and by budding on its own, or on Plum stocks, for continuing varieties. The Almond tree bears chiefly on the young wood of the previous year, and in part upon small spurs or minor branches; it is therefore pruned like the Apricot and Peach, and its culture in other respects is the same.

\section{CHERRY.}

\section{Cerisier. Prunus cerasus.}

The Cherry, of the cultivated varieties, is said to have been first introduced into Italy in the year 73 , from a town in Pontus, in Asia, called Cerasus, whence its specific name; and it was introduced into Britain one hundred and twenty years afterward.

The Romans had eight species in Pliny's time, red, black, tender-fleshed, hard-fleshed, small bitter-flavoured, and heartshaped. There are now upward of two hundred in cultivation. The French divide their Cherries into griottes, or tender-fleshed; bigarreau, or heart-shaped; and guignes, or small fruit. The fruit of many varieties is somewhat heartshaped, whence they are called ox-heart, white-heart, blackheart, \&c.; why some sorts are called dukes, is not so obvious. The morello cherry is very different from the other varieties, bearing almost exclusively from the preceding year's wond, and the pulp of the fruit having the consistence and flavour of the fungi called morel, whence the name. The Chinese Cherry is valuable on account of its bearing an excellent fruit, and ripening it in forcing-houses.

Cherries are grafted or budded on seedlings from Cherry stones, and from seedlings of the red and black mazzard. For dwarfing they are worked on the morello, or perfumed 
Cherry; the latter is preferred in Holland. In this country, the budding system is more frequently practised on the various species of stone fruit than grafting.

Cherry trees, in general, produce the fruit upon small spurs or studs, from half an inch to two inches in length, which proceed from the sides and ends of the two year, three year, and older branches; and as new spurs continue shooting from the extreme parts, il is a maxim in pruning both standards and espaliers, not to shorten the bearing branches when there is room for their regular extension.

The Morello is in some degree an exception, as it bears principally on the shoots of the preceding year, the fruit proceeding immediately from the eyes of shoots; and bears but casually, and in a small degree, on close spurs formed on the two-year-old wood, and scarcely ever on wood of the third year; therefore, in pruning, leave a supply of young shoots on all the branches from the origin to the extremity of the tree, for next year's bearers.

All kinds of Cherry trees, except the Morello, are apt to grow very tall; to remedy this, and to enable them to form handsome heads, the leading shoot should be cut off when of about three years' growth from the bud; after which give only occasional pruning, to reform or remove any casual irregularity from cross-placed or very crowded branches, and take away all cankery and decayed wood.

Dwarf Cherry trees may be introduced into the Kitchen Garden, and trained as espaliers, \&c. When Morellos are planted in an orchard, they may be placed from fifteen to twenty feet apart; trees of the duke kind may be planted from twenty-five to thirty feet apart; and the heart-shaped, in general, will require to be from thirty to forty feet from each other, or from any spreading trees.

Cherry trees may be removed the first year after the bud is established; but they will bear removal at any time before they come into bearing, which is about the fifth year.

The gum which exudes from Cherry trees is equal to 
Gum Arabic; and Hasselquist relates, " that more than one hundred men, during a siege, were kept alive for nearly two months, without any other sustenance than a little of this gum taken sometimes into the mouth, and suffered gradually to dissolve." The wood is hard and tough, and used by the turner and cabinet maker.

\section{SELECT DESCRIPTIVE LIST OF CHERRIES.}

\section{DUKE AND ROUND FRUIT.}

Ambres de Chorst. Belle de Choisy of Downing. Cerise Doucette, Cerise de la Palembre of the French gardens. A middle size roundish fruit, highly deserving of cultivation. Skin transparent, red, mottled with amber; flesh amber coloured, tender, and swcet. It bears well as a standard, and ripens its fruit in June.

A Rchdure, Rıyal Duke, Grio'te de Portugal, Portugal Duke. A large globular-formed red cherry; like the May Duke, it grows in clusters, but the tree grows more vigorously than that variety; and yields an abundance of fruit, which hangs a long time on the tree improving in flavour. in July.

Ber.j. Ex MAcNifique. A fine round cherry, much esteemed in Massachusetts. The tree is vigorous and productive; the fruit truly magnifcent ; its colour red, mottled with white spots, and abounding in acid; valu. able from its late maturity, in July.

Carnation, Cerise Nouvelle d'Angleterre, and Cerise de Portugal, of Downing. Late Spanish, Griotte d'Espagne, and Griotte de Villenes, of Prince. Fruit round, of a pale red colour; flesh firm, vith a very good flavoured juice; makes excellent preserves, and is gooa for the table in July.

DowxER's LATE RED, Downer's Favourite. A large round cherry, deserving a place in every garden, raised by S. Downer, Esq., of Dorchester, Massachusetts; colour light red; flesh firm and of a fine sprightly flavour ; ripening after most other superior varieties are gone, on which account this variety is bighly prized in the markets.

Kexтish, Early Kentish, Early Richmond, Virginian May, Long Stem Montmorency. Montmorency a longue queue. Mr. Prince says that other varieties are sold erroneously under the above names. The fruit of this variety is round; skin red; flesh sprightly acid; juice abundant; excellent for the table and kitchen. It will bang long on the tree, in favourable weather, in June and July.

Late Duks. Cerise Anglaise tardive, Unique nouvelle. Fruit large, above the aize of a May Duke; obtuse heart shaped, rather flat; skin a shining dark red: flesh amber coloured, tender, juicy, and bigh flavoured. Tree a great bearer, and ripens its fruit in July.

May Duxz, Early Duke, and Cerise Guigne of Downing. Hol- 
man's Duke. June Duke, Griotte de Portugal, and Royulc hative, of Prince. Fruit of medium size, roundish, growing in clusters; the skin, when fully ripe, very dark red; the flesh is solt and juicy, with a very pleasant acid This excellent variety ripens about the middle of June.

Morello, English Mirello, Milan, Cerise du nord, Griotte du nord Fruit of medium size, round; of a dark red colour, nearly black at matu rity ; flesh deep red. tender, juicy, and blended with an agreeable acid; ripe in July, and hangs some time on the tree. This variety is excellent for preserves, and for Brandy.

Plumstone Morelco. A tree of moderate size, of the Duke or Kentwh species; a very large, dark, round cherry, nearly black; of a rich acid Aavour. The stone is very large, and resembles that of a plum; a native of Virginia, introduced by William Prince, of the Linnæn Botanic Garden, Flushing.

WAtrkzDo. A large, roundish, dark cherry, inclining to black at maturity ; the flesh is firm and of an excellent flavour; raised by a daughter of Mr. Knight, and so named from perfecting its fruit soon after the battle of Waterloo. The tree is of strong but irregular growth, and ripens its fruit in July.

\section{HEART-SHAPED AND BIGARREAUS.}

American Ambrr. Early Amber New Honey. A beautiful heart-shaped cherry, of medium size, and dark pink or amber colour; flesh, rich, sweet, and excellent. It ripens early in June.

American Hzart, Arden's White Heart. A medium sized cherry, of pale yellowish colour; obtuse heart shaped; flesh tender and palatable, but not high flavoured. The tree, which ripens its fruit in June, is very productive.

Bri.e de Rocmont, Bigarreau de Rocmont, Cour de pigeon, Flesh Col. Bigarreau. A beautiful heart shaped fruit, of pale yellowish and red colour, marbled and glossy; flesh firm, white; juice sprightly and of an agreeable flavour : in June and July.

BrGARREAU, Black. Manning's Black Bigarreau. This varicty is considered highly deserving a place in every good collection; it originated in Mr. Manning's nursery at Salem; the fruit is large, colour black; flesh weet and of peculiar rich flavour. The tree grows handsome, is very productive, and ripens its fruit in July.

Bigarreau, Grafion, Turkey Bigarreau, Yellow Spanish, White Bigarreau, Imperial, Guigne Ambree, White Orleans. Very large, obtuse, heart-shaped; yellowish amber colour, but fine red next the sun; flesh firm, white, sweet, and well flavoured; a beautiful and excellent fruit : ripo in June and July. This variety commands the highest price in market.

BigarReAu Whrte, White Ox Heart, and Harrison's Heart, of Downing. White Bigarreau Tradescrnt, and Bigarreau blanc le gros. of Prince. Fruit large; obtuse heart shaped; of pale yellow and white colour, mottled with red; flesh white, firm, and well flavoured : ripe in June and July.

BLAck EAGLe. A beautiful variety, raised by Miss Knight. of Downton Costle, 1506: fruit of globular form, and middle size; skin dark purple, or ncarly black; flesh very tender, rich, and of excellent flavour. The tree grows strong, very upright, and ripeus its fruit early. 
Bracx HzARт, Guignier a Fruit noir. Fruit rather large, heart-shaped; dark purple, approaching to black at maturity; flesh dark red, tender, of excellent flavour : ripe early in July. Tree a good bearer.

Black TARTarian, Black Circassian, Fraser's Black Tartarian, Black Russiun, Ronult's Large Black Heart, Fraser's Black Heurt. A very large heart-shaped fruit, of a most superior quality; colour dark shining purple, or black ; flesh firm, dark red or purple ; sweet, and of most excellent flavour : in June and July. The tree grows rapid, and is very productive.

Davenport's Early Black, New May Duke. This variety is considered as one of the finest and most productive of early cherries known. The fruit is of medium size, heart-shaped, of a dark glossy black colour; flesh firm, and of a pleasant sub-acid flavour. It ripens a week or ten days earlier than the May Duke.

Elkhorn, Black Oxheart, Tradescant's Black, Bigarreau gros noir, Large Black Bigurreau. A large, black, heart-shaped cherry, well suited to bear carriage to inarket from the firmness of its flesh. This varicty ripens the second and third week in July, when other kinds are scarce.(Prince.)

Elton. This excellent variety was raised by Mr. Knight in 1806 ; the tree is very vigorous and productive; the fruit is pretty large, heart-shaped; pale glossy yellow in the shade, but marbled with bright red next the sun; flesh firm, sweet, and rich : ripens soon after the May Duke.

FLORENCE. A very tine heart-shaped cherry; of a yellow amber colour, marbled with bright red in the shade, bright red next the sun; flesh tolerably firm. juicy, rich, and sweet: ripe end of June and in July.

GrinLEY, Apple Cherry. A native fruit of medium size, which originated on the farin of Mr. Gridley, of Roxbury, near Boston; the colour is black, the flesh $\mathrm{frm}$, and of a fine flavour: in July. The tree grows vigorous, and is very productive.

KNIGHT'S EARLY BLACK. The blossoms of this variety appear very early; its fruit resembles the Waterloo; of a rich dark hue; its flesh is firn. juicy, and abundantly sweet : by the middle of June.

MAzzARD, BLACK. This cherry grows wild, and is cultivated also in abundance in various parts of England. It is the principal fruit employed for the making of Cherry Brandy, and the stocks of the species are best adapted for nursery men to bud and graft the better kinds on.

Napoleon Bigarreau, Bigarreail Napoleon, Lauermann, Gros Bigarreau de Lauermann. The tree of this variety is remarkable for the vigour and beauty of its growth; it produces a fine large white fruit with red spots; the flesh is remarkably white, solid, and of a sweet, agreeable flavour: early in July.

WiIte Bigarreau. Mr. Manning represents this as one of the largest and finest cherries known. The form is obtusc, heart-shaped; skin pale yellow, with a bright red cheek; flesh very firm, juicy, sweet, and fine flavoured: ripe in July. Mr. Manning observes. that this variety has the reputation of being a shy bearer, but that in his orchard it yields an abundance of fruit; and, that owing to the harduess of its flesh, is not liable to injury from birds; on this account, he says, it is highly deserving of cultivation.

Wuite HeArt, Remington White Heart, Late White Heart. A mode sate sized cherry, of pleasant flavour; chiely valuable for its very late ma- 
turity, being towards the end of August. It is said to have originated in Rhode Island.

White TARtarian, White Transparent Crimea, Fraser's White, Guigne de Russie blanc. A beautiful cherry, pale yellow, approaching to amber next the sun; a much admired fruit, of excellent flavour: a good bearer, ripening early in July.

\section{CHESTNUT.}

\section{Chataigner. Castanea.}

The Chestnut is well known as a large tree, spreading its branches finely where it has room, but planted closely, will shoot up straight to a great height. It is supposed to have been originally from Sardis. It is so common as to be considered a native of France and ltaly, and some consider it as naturalized in England; it is also indigenous in America. The London catalogues contain the names of thirty-two sorts under cultivation. The Chestnut is, like the Walnut, both a timber and fruit tree; some of the oldest trees in the world are of this species.* The American Chestrut differs so little from the European, that no specific distiuction can be drawn. It is one of the largest trees of the forest, the wood being extremely durable, and in high esteem for posts and rails to construct fences; and the nuts are very delicious. The Castanea pumila, or Chinquapin nut, is a small tree, or rather shrub, growing to the height of thirty feet in the Southern States, but seldom exceeding ten in cold latitudes; the fruit is very sweet and agreeable to eat.

There is a variety with striped leaves, which is very ornamental. The most esteemed of the French kinds are called Marron. Some excellent fruit-bearing varieties are culti-

* At Fortworth, in Gloucestershire, England, is a large tree, fifty-two feet round, which in 1150 was called the "Great Chestnut of Fortworih." Marsham states that this tree is 1100 years old, and that the timber is almost incorruptible, and more durable than oak. Its durability is commensurate with the long life of the tree. 
vated in England, France, Italy, and Spain, as also in other parts of Europe ; these are increased by giafting or budding in the usual methods, but the plants for coppice wood, or timber, are best raised from nuts. Some varieties ripen their fruit a few days earlier than others, but none of these have been fixed on, or perpetuated by nurserymen, so as to render them available to purchasers. The fruit is a desirable nut for autumn or winter, and is eaten roasted, with salt, and sometimes raw; and in some countries it is not only boiled and roasted, but ground into meal, and puddings, cakes, and bread are made from it.

\section{CRANBERRY.}

\section{Canneberge. Oxycoccus.}

Thrs genus of plants is well distinguished from the Vaccinium, or Whortleberry, by the narrow revolute segments of corolla; and are pretty little trailing evergreen plants, to which a peat soil, and rather moist situations, are absolutely necessary. They are very little changed by culture.

The Oxycoccus macrocarpus is a red acid fruit, highly valned as a sweetmeat, or for tarts. It is well known that this excellent fruit grows in many parts of our country spontaneously; and that the mere gathering of it, is all that bountiful nature requires at our hands ; but it is well worth cultivating where there are none. This fruit will keep a whole year, if properly preserved in close covered stone jars, and is considered by many as superior to the best currant jelly, and may be kept for many months in a raw state without injury.

The Oxycoccus palustris bears edible berries, which are gathered wild both in England and Scotland, and made into tarts. Lightfoot says, that twenty or thirty pounds' worth are sold each market day, for five or six weeks together, in the town of Langtown, on the borders of Cumberland. 
Nicol says, the American species is more easily culti vated than the English, but is inferior to it in flavour. There is reason to believe that the quality of fruit of each of these species is subject to variations, which have not yet been practically distinguished. Their cultivation is now so well understood, that both may be considered with propriety as inmates of the fruit garden. Some raise them from seed sown early in the spring; but it is best to set out plants, and lay the runners as they progress in growth.

It is customary in England to prepare beds on the edges of ponds, which are banked up so as to admit of the wet getting underneath them; bog or peat earth is considered essential for the roots to run in, but it has been discovered that they can be cultivated in damp situations in a garden, with a top dressing of peat or bog earth, and if they are once suited as to the soil, the plants will multiply so as to cover the bed in the course of a year or two, by means of their long runners, which take root at different points. From a very small space a very large quantity of Cranberries may be gathered; and they prove a remarkably regular crop, scarcely affected by the state of the weather, and not subject to the attacks of insects. Sir Joseph Banks gives an account (in Hort. Trans., 1. 71) of his success in cultivating this fruit. "In one year, viz., 1813, from 326 square feet, or a bed about eighteen feet square, three and a half Winchester bushels of berries were produced, which, at five bottles to the gallon, gives one hundred and forty bottles, each sufficient for ond C'ranberry pie, from two and a half square feet."

\section{CURRANT.}

Groseiller a grappes. Ribes.

Thrs is a genus of well-known shrubs, much cultivated for their fruit. It is a native of the Northern parts of 
Europe, and found in hedges and wonds in England; and there are some species indigenous in America. The fruit, being of an agreeable sub-acid taste, is generally relished both as a dessert and in pies and tarts; it is also much used in making wine, and is grown to a considerable extent for that purpose in Essex, Kent, and about Pershore, in Worcestershire, England. There are ten species cultivated in the garden of the Horticultural Society of London, comprising twelve varieties of red, ten of white, five kinds of black, together with a champagne, mountain, rock, upright, Pennsylvanian, \&c. Any number of varieties of the red and white may be procured from sowing the seed, but they are generally propagated by cuttings of the last year's wood, which should be of sufficient length to form handsome plants, with a clear stem ten inches high; these may be planted immediately upon losing their leaves in autumn, or very early the ensuing spring.

The Currant will grow in almost every soil, but prospers best in one loamy and rich. The best flavoured fruit is produced from plants in an open situation, but they will grow under the shades of walls or trees, and either as low bushes, or trained as espaliers. They bear chiefly on spurs, and on young wood of from one to three years' growth, and, therefore, in pruning, most of the young wood should be cut to within two or three buds of that where it originated. After the plants are furnished with full heads. they produce many superfluous and irregular shoots every summer, crowding the general bearers, so as to require regulating and curtailing, both in the young growth of the year, and in older wood.

The principal part of the work may be done in winter, or early in spring; but a preparatory part should be performed in summer, to eradicate suckers, and thin the superfluous shoots of the year, where they are so crowded as to exclude the sun and air from the fruit. In training espaliers and for standards, two branches are laid in a horizontal direction 
along the bottom of the trellis, perhaps half a foot from the surface of the earth, and the growth from these, or of all upright shoots, which will admit of being arranged at the distance of five or six inches from each other, is encouraged. Fan standards are sometimes trained with the branches radiating from the crown of the stem.

The black Currant, or Ribes nigrum, is common in moist woods in Russia and Siberia; its culture is similar to that of the red, but as it is less apt to bear in spurs than on young wood, the shoots should not be so much shortened in this as in the other.

Currant bushes will require to be planted at different distances, according to the situation and mode of training, \&c. When planted in beds, borders, or squares, they should be six feet apart, but if trained as espaliers, they will require to be eight feet apart.

Many people dislike the flavour of black Currants; they are, therefore, not much used in the kitchen or dessert, and seldom in wine making. They make a jelley or jam, in estimation as a gargle for inflammatory sore throats. "In Russia and Siberia, wine is made of the berries alone, or fermented with honey, and with or or without spirits. In Siberia they make a drink of the leaves; these tincture common spirits so as to resemble brandy, and a few of them dried and mixed with black tea, answer all the purposes of the green material."-(Loudon.)

All kinds of Currants may be forced by placing them in any forcing department in January or February; they will produce ripe fruit in April and May.

\section{SELECT DESCRIPTIVE LIST OF CURRANTS.}

Brack Exglish, Common Black. This species is most generally cultivated in private gardens for medicinal purposes; the berries are plentiful, of large size, and frequently hang on the bush two months, improving in fixvour. 
Bracr NApLEs. In this variety the fruit is larger, the clusters more numerous, and each cluster produces more berries than the ordinary kinds, on which account it is highly esteemed.

Champagns. The berries of this varipty are of a pale red colour, which being transparent, causes it to be generally estimated as a dessert fruit. It is a prolific bedrer.

LARGE RED, Red Dutch. This is the most desirable kind of the red fruited currant celtivated; the bush, when properly trained and pruned, grows strong and upright, and produces an abundance of fine large berries.

White Crystal, White Grape. An excellent variety, the berries of which are large, and of a beautiful clear transparent brilliancy; hence its name.

White Detch. This variety is held in great esteem for different purposes; the clusters and berries are large, of a yellowish white colour, and delicious flavour. The bushes are often so productive that the branches of the bearing wood trail beneath the weight of the fruit.

Missouri Currant. This species is quite distinct from the ordinary kinds ; its berries are purple, and although of rather agreeable flavour, they are not to be compared with those under general cultivation.

To these may be added Knight's Sweet Red, Wilmot's Large Red, Wentworth Red, Victoria, and Green Fruited, lately introduced.

The above are the most celebrated species of Currants. Some nurserymen's catalogues contain many other names, a great proportion of which are, probably, a repetition of the same fruit. Where the Currant is cultivated for the purpose of making wine, the White and Red Dutch are to be preferred to all others. For the dessert, the White Crystal and Champagne are great favourites, on account of their transparent clearness.

\section{FIG.}

Frguier. Ficus carica.

Thene are many species of the Fig, which are all natives of warm climates. In some parts of Asia, and in the South of Europe, they are always grown as standards; and the fruit, green and dried, forms an important part of the food of the inhabitants. The London Horticultural catalogue contains the names of seventy-five sorts; and Messrs. Prince, of Flushing, have about forty names in their catalogue. It 
is cultivated in England as a fruit tree, and, in warm situations, will ripen its fruit in the open air. In Sussex, on the sea-coast, it ripens its fruit on standards. Some of the best in England are at Arundel Castle; and there is a Fig orchard of one hundred trees at Tarring, near Worthing. Those at Arundel are planted six or eight feet apart, and from a single stem allowed to continue branching conical heads, pruning chiefly irregular and redundant growths, and cutting out decayed or injured wood.

The Fig tree may be propagated from seed, cuttings, layers, suckers, roots, and by grafting; the most generally approved method is by layers or cuttings, which come into bearing the second, and sometimes the first year. No tree is more robust or more prolific ; even plants in pots or tubs kept in a temperature adapted for the Orange tree, will fruit freely, and ripen two crops a year, and by being taken care of through the winter, will go on growing and ripening fruit without intermission. Mr. Knight has obtained from his hot-house in England, eight successive crops in a year, by bending the limbs in a position below the horizontal. The trees will produce tolerable crops in the second year if rung or decorticated; and by this process maturity of the fruit is accelerated, and its size increased.* Its maturity is also hastened by pricking the fruit with a straw or quill dipped in olive oil, or even by slightly touching the fruit with oil, at the finger's end. In Fig countries the fruit is preserved by dipping it in scalding lye, made of the ashes of the Fig tree, and then dried in the sun.

* Girdling, decortication, ringing, or circumcision, as it is sometimes va. riously called, consists in making two circular incisions quite round the limb, through the bark, at the distance of about a quarter of an inch asun. der, more or less, according to the size and thickness of the tree; then by making a perpendicular slit, the ring of the bark is wholly removed to the wood. Ringing or decortication is applicable to every kind of fruit tree, and to the vine. Its operation is twofold. First, in the early production and abundance of blossom buds which it induces: and second, in increasing the size of the fruit and hastening its maturity, according to the season in whinh the operation is performed. 
When Figs are cultivated in a garden, a good loamy soil should be provided; and they may be trained to close fences, or trellises, in sheltered situations. At the approach of winter they must be protected; those trained to close fences may be secured through the winter by a covering of matting; and such as may be in open situations should be liberated from the treilis, and laid down close to the ground, and covered three or four inches with earth; or trenches may be formed of that depth, sufficient to contain the branches, which should be fastened down with hooked pegs, without cramping them : such of the strong central branches as will not bend may be enveloped in litter. They should be pruned before they are laid down in November, and on being raised again in April, they may be trained as before. Figs may be cultivated in private gardens as easily as the vine.

\section{SELECT DESCRIPTIVE LIST OF FIGS.}

Angerique, Coucourelle Blanche, Melitte. Fruit rather small, somewhat pyramidal; skin yellow, mottled with white; pulp white; seed tinged with red. In the neighbourhood of Paris this variety produces two crops annually; the first is usually thin, but the second very abundant and excellent.

Black Italian. Fruit small and round; pulp very delicious. Mr. Fursyth used to cultivate this kind in pots, and it is recorded that he has gathered from one plant two dozen figs in a day.

Blue or Purple, Large Blue, Great Blue, Large Purple Fruit large, oblong; skin purple, covered with thick blue bloom; pulp deep red, and of a rich flavour: ripe in August. The tree is hardy and prolific.

Bourdenux, Figue Poire, Violette de Bourdeaux. Fruit of a pyramidal figure; skin brownish red, slightly mottled; pulp red, succulent, and sweet. This is cultivated throughout France, and produces two crops annually.

Brown TURKer. Fruit small and round; pulp very delicious. This and the Rlack Italian are mentioned by Mr. Forsyth as being cultivated by him in pots, and each possessing equal merit.

BRUnswick, Madonna, Hanover. Fruit very large, obovate; skin pale green, tinged with yellow; flesh pinkish, extremely rich, and high flavoured. This is one of the largest and best hardy figs for garden culture, and it will ripen in the neighbourhood of London by the middle of A ugust.

Chestnut, Chestnut-colnured Ishia, Broun Ischin. Fruit globular. of large size; skin of a brown chestnut colour; pulp purple. sweet, and hick 
flavoured This kind will often yield two crops in England, the first fruit of which ripens in August.

EARLY W hITE, Small Early White. Fruit somewhat round; skin thin; when fully ripe of a pale yellow colour; pulp white, sweet, and of pleasant flavour. This generally ripens two crops in one season.

GreEN Ischia. Fruit oblong; skin green, very thin; pulp purple, which, when fully ripe, stains the skin to a brownish cast. This is a very high flavoured fig, especially in warm countries : ripe in August.

Large White Genoa. Fruit large, globular; skin thin, white, turning to yellow when fully ripe; pulp red, and of good flavour, This in England bears two crops, annually.

Ma ı.TA, Small Brown, of some gardens. Fruit small ; skin pale brown; pulp very sweet and well flavoured: ripe in August, and if left hanging on the tree until shrivelled, it becomes a fine sweetmeat.

Nerir. The Nerii fig is highly esteemed in England. Fruit oblong, of medium size; skin pale greenish yellow; the flesh is very rich, and the juice possesses a delicate acidity, which renders it peculiarly palatable: ripe in A ugust.

Pregussata. Fruit large, oblate; skin dark brown; pulp deep red; remarkably sweet and rich : ripe in August.

PURpl.e Gtanos. Fruit large, long; skin dark purple; pulp extremely sweet and luscious: ripe in August.

Violette, Figue Violette. The Violet Fig, like the Angelique, is much cultivated in the neighbourhood of Paris, and produces two crops annually. Fruit small ; skin deep violet; pulp, near the skin, white; the interior red, and of excellent flavour.

White Marseilles, Pocock, Figue Blanche. Fruit medium size, somowhat turbinate; skin pale green, becoming yellowish when fully ripe : flesh white, dry, sweet, and rich : ripe in August.

Yelnow Ischra, Cyprus. Fruit large, of a pyramidal form, skin yellow, when fully ripe; pulp purple and high flavoured: in August and September.

\section{FILBERT AND HAZLENUT.}

\section{Noisetier Avelinier. Corylus.}

ThE Fillert, in many varieties, and also the common $\mathrm{Ha}$ zlenut, grow spontaneously in the woods of Britain, and some few varieties are indigenous in this country. The kinds of Filberts generally cultivated are the white, red, cob, clustered, and frizzled; of each of which there are many varieties. As this shrub is so easily cultivated, it is a matter of astonishment that the nuts from this genus of plonts are so scarce in our markets. In different parts of England 
there are Filbert orchards. In the Filbert grounds about Maidstone, in Kent, it is a prevailing practice to cultivate Hops, standard Apples, and Cherries, among the Filberts; when these come into a bearing state, the Hops are taken up and transplanted elsewhere, and the fiuit trees only suffered to remain. The spare ground is then planted with Gooseberies, Currants, \&c. The Red Filbert is allowed to have a finer flavour than the White. The Cob-nut is large, with a thick shell, but the kernel is sweet and of considerable size. The Barcelona is a good large nut, with a thin shell. The Cosford is very sweet, kernels well, and the trce is a great bearer. The Bond Nut, and the Lambert Nit are of large size, roundish shape, and very prolific bearers. The Frizzied Filbert is highly esteemed. It is beautiful when in the husk, and its flavour is very similar to that of the White Filbert; the shell of which is also thin, and its kernel sweet and fine.

All the different kinds may be grown as dwarf standards; or they will bear very well if planted in clumps: but as they produce an abundance of suckers, these should be parted off frequently, and planted in a nursery bed for stocks; as the bearing plants will cease to produce fruit in any quantity, if the suckers are allowed to form a thick bush. They may be propagated by seed, by suckers, by layers, or by grafting in the spring upon seedling or sucker stocks.

The Filbert bears principally upon the sides of the upper young branches, and upon small shoots which proceed from the bases of side branches cut off the preceding year. The leading shoot is every year to be shortened, and every shoot that is left to produce fruit should be clipped; which prevents the tree from being exhausted in making wond at the end of the branch. Such branches as may have borne fruit, must be cut out every year, in order to promote the growth of a supply of young fruit-bearing branches. 


\section{GOOSEBERRY.}

\section{Groseiller. Ribes grossularia, uva, crispa, etc.}

THE Gonseberry is a native of several parts of Europe, and is indigenous in America, as far north as $68^{\circ}$. It is cultivated to greater perfection in England than in any other part of the world. In Spain and Italy, this fruit is scarcely known. In France, it is neglected. In Lancashire, England, and some parts of the adjoining counties, almost every cottager cultivates the Gooseberry, with a view to prizes given at what are called Crooseberry Prize Meetings; of these, there is annually published an account, with the names and weights of the successful sorts, in what is called the Manchester Gooseberry Book. The prizes vary from ten shillings to five and ten pounds sterling. There are meetings held in the spring to "make up," as the term is, the persons, and the conditions of exhibition; and in August, to weigh and test the fruit, and determine the prizes.

In Lindley's Guide to the Orchard and Fruit Garden, seven hundred and twenty-two varieties are described; fiom which the following are selected, as in most repute for size, flavour, and other good qualities:

RED.

Britrsh Crown, Boardman's. This variety is noted as being a fine flavoured fruit, esjecially for tarts. Thirty-three prizes had been awarded for it in 1829; the largest berry weighing 18 pennyweights and 10 grains.

Champagne. The fruit of this variety is held in great esteem for its delicious flavour; the berry is of medium size. somewhat oblong and hairy.

CAPPER'S TOP SAwrFr. This is a late fruit, of oblong shape, and hairy near the base. One hundred and seventy-one prizes were obtained for this in 1838 and 9 ; the he iviest berry weighing 22 dwts. 17 grains.

Crown Bов. Melling's. This variety won eighty-five prizes in two seasons; tha largest berry weighing $21 \mathrm{dwts.}$ and 12 grains. It is a late fruit, of oblong shape, bright red colour, and hairy.

EARI.Y RED, Wilmot's. This variety is considered by Mr. Wrilmot as first rate of its colour. It has a thin skin; is of large size, very early, of excellent flavour, and incredibly productive.

Huntsman. This variety, which originated with Mr. Bratherton, took 
two hundred and sixteen prizes in 1828 and 9 ; the heaviest berry weighed $24 \mathrm{dwts.}$

LANcashire LAd, Hartshorn's. One hundred and fifty-six prizes were awarded for this variety in two years; the heaviest berry wcighing 22 dwts. 11 grains.

MARQuis of StAFFORD, Knight's. This much esteemed late variety is hairy, of medium size, bright red colour, and delicious flivour.

OLD Rough RED. This is a favourite fruit for family use ; the berrie. are of medium size, of dark red colour; excellent for preserving as goose. berry jam, and for bottling in an unripe state.

OVER-ALl, Brathertim's. This variety took seventy-four prizes in two seasons, the average weight of the berries being $20 \mathrm{dwts}$. It is a highly esteemed fruit.

Provgнвог. This is a medium sized early fruit, in great repute for its delicious flavour and productiveness.

Prince REgent, Buardmau's. This variety won one hundred and forty-one prizes in two seasons; the heaviest berry weighing $22 \mathrm{dwts} .11$ grains.

RoARING LION, Farmer's. In 1828 three hundred and forty-nine prizes were awarded for this variety ; and in 18:29 it won four luundred and fiftythree prizes, the largest berry weighing 29 dwts.; since which time, berries have been known to weigh over an ounce and a half.

Shakspeare. Sixty prizes were awarded for this variety in two seasons; the average weight of the berries were about $20 \mathrm{dwts}$. It is a great bearer.

SIR John Cotgrave, Bratherton's. This variety took three hundred and forty-three prizes in two seasons; the heaviest berry weighing $25 \mathrm{dwts}$. 2 grains.

TriUmphant, Denny's. This is a medium sized early berry, weighing about $16 \mathrm{dwts}$. It is considered equal in quality to any gooseberry of its colour.

WARRINGTON. This is a favourite fruit for private gardens; the berries are of medium sizc, very rich flavoured, and ripen gradually without deteriorating.

\section{YELLOW.}

Bunker's Hrlc, Capper's. Two hundred and ten prizes were awarded for this variety in two years; the heaviest berry weighing $20 \mathrm{dwts}: 2$ grains.

BRITANNA. This variety is noted for its earliness and delicious flavour. The fruit is of medium size, weighing about $18 \mathrm{dwts}$.

Cotragr. Girl, Heaps's. This rariety won one hundred and thirty-three prizes in two seasons: the largest berry weighing $19 \mathrm{dwts} 14$ grains.

Golden Gourd. Hill's. A fine early fruit of medium size; shape oblong; skin thin, slightly hairy, of rich flavour, and not apt to mildew.

Goldex Yellow, Dixon's This is a favourite, medium sized, early fruit for private gardens; the skin is smooth. thin, and transparent, and the berries will hang some time without becoming flat and insipid.

GuNNER. Hirlcastle's. One hundred and ninety-two prizes were given for this variety in 1828; and in 1829 one hundred and eighty-one prizes were awarded; the heaviest berry weighing 24 divts. 5 grairs ; fruit rathe: late. 
INv1ncrвLL, Haywood's. This celebrated fruit is of medium size, weighing about $18 \mathrm{dwts}$; skin thin, transparent; pulp saccharine and delicious.

Krlton Hero, Hamlet's Kilton. One of the best early yellow fruited gooseberries; fruit oblong, slightly hairy, excellent for cooking while immature, and delicious eating when fully ripe.

Regulator, Prophet's. A very fine fruit, of medium size and rich acid flavour; good for bottling, being firm, and not liable to crack.

Rockwood, Prophet's. 'The fruit of this variety is very early; it is of a roundish, oblong shape, and slightly hairy. It won three hundred and three prizes in two years; the largest berry weighing $21 \mathrm{dwts.} 3$ grains.

Soveneign, Bratherton's. Two hundred and two prizes were obtained for this variety in two seasons; the heaviest berry weighing $22 \mathrm{dwts} .17$ grains.

VIPER, Gordon's. This is an early smooth fruit, and won eighty-seven prizes in two years; the largest berry weighing $18 \mathrm{dwts.} 5$ grains.

\section{GREEN.}

Angler, Collier's. Three hundred and sixty-five prizes were awarded for this variety in two seasons; the heaviest berry weighing $20 \mathrm{dwts} .1$ grain.

Earty Green, Harry. This variety is described in the Pomological Magazine as a very early fruit; it is round, hairy, of a deep green colour and excellent flavour, but not large.

FAvourite, Bates's. 'Two hundred and thirty-five prizes were given for this varicty in two years; the heaviest berry weighing $18 \mathrm{dw}$ ts. 20 grains.

Greenwood, Berry's. This variety obtained two hundred and four prizes in two seasons; the largest berry weighing $17 \mathrm{dwts.} 4$ grairs. It is a deliciously flavoured fruit.

Green GAGE. Fitmaston's. A beautiful berry of medium size; skin pale green, smooth and transparent; will hang long on the bush, and retain its rich acid flavour when fully ripe.

Green Myrtie. Nixon's. A fine late gooseberry of large size. oblong shape; skin smooth, of pale green colour; pulp saccharine, jucy, and of peculiar rich flavour.

Heart of OAK, Massey's. Fruit of medium size, early; skin smooth, green. with pale yellow veins; pulp rich, and high flavoured even when fully ripe.

InDEPENDENT, Bigg's. One hundred and twenty-one prizes were given for this variety in two years; the largest berry weighing $16 \mathrm{dwts} .4$ gruins. It is an early rich fruit.

Jolly TAR, Edwards's. Fruit early, of medium size; skin smonth, green, with yellow veins; average weight about $15 \mathrm{dwts;}$ good to preserve while immature, and of delicious flavour when fully ripe.

Laurkl, Parkinson's. Fruit of medium s:ze; skin pale green, very downy ; an exrellent dessert fruit, in great repute.

LORn CREWE, Clutton's. This celebrated variety obtainet ninety-six prizes in two seasons; the heaviest berry weighing about $23 \mathrm{dwts.}$ It is a prolific bearer, and worthy of general cultivation.

Ocxan, Wainman's. This variety won two hundred and seventy-eight 
prizes in two seasons; the heaviest berry weighing $18 \mathrm{dwts.} 8$ grains. The fruit is oblong and smooth.

TROUBLER, Moore's. One hundred and sixty prizes were taken for this variety in two years; the largest berry weighing $17 \mathrm{dwts} .13$ grains.

Wistaston Hero, Bratherton's. Fruit of medim size, pale green colour; of rich pungent lavour; excellent for preserves, and when fully ripe it is a delicious dessert fruit.

\section{WHITE.}

Bonny LAss, Capper's. This variety won one hundred and sixty-seven prizes in two seasons; the heaviest berry weighing $21 \mathrm{dwts} 10$ grains.

Cheshire Lass. Saunders's. This is one of the earliest varieties, and makes excellent tarts. The fruit is large, oblong, downy, and fine flavoured.

Governess, Bratherton's. One hundred and twenty-four prizes wero awarded for this variety in two years; the largest berry wcighing 24 dwts.

LADY Detamere, Wylds's. This variety took two hundred and fiftythree prizes in two seasons; the heaviest berry weighing $22 \mathrm{dwts} .6$ grains.

LADY OF THE MANOR. This variety won ninety-eight prizes in two seasons, the heaviest berry weighing 20 dwts. 9 grains. It is held in great esteem for its productiveness.

LIONEss. Fruit of medium size, oblong shape; skin thin, transparent ; pulp and juice saccharine and delicious.

NAIL.E, Blomiley's. One hundred and thirty-four prizes were given for this variety in two seasons; the largest berry weighing $18 \mathrm{dwts} .12$ grains.

QUEen CAROLINE. This variety won one hundred and forty-two prizes in two years; the heaviest berry weighing $18 \mathrm{dwts.} 1$ grain. It is a richly flavoured fruit.

SHEBA QUEEN, Crompton's. This is a favourite variety for private gardens; the fruit is early, of medium size; shape oblong; skin rather downy; pulp pungent and rich.

Smiling GrRL. This is a smallish early fruit, with thin transparent skin, and of peculiarly rich flavour even when fully ripe.

WELLINGTON's GLORY. One hundred and seventy-three prizes were obtained in two seasons for this variety; the largest berry weighing $20 \mathrm{dwts}$. 4 grains.

White Bear, Mnore's. A fine early dessert fruit; of medium size and oblong shape; skin hairy and somewhat bristly; a prolific bearer.

White EAGCF. This variety gained four hundred and seventy-six prizes in two seasons; the heaviest berry weighing $23 \mathrm{dwts} .12$ grains.

White Lron, Cheluorth's. One hundred and two prizes were given for this variety in two years; the largest berry weighing 18 dwts. 22 grains. The fruit is late, slightly hairy, and excellent for tarts.

Whiтesmiti, Woodward's. 'This is a small early berry, weighing about $14 \mathrm{dwts}$. The skin is downy, and the fruit is fully equal to any gooseberry of its colour.

The Gooseberry may be propagated by all the modes applicable to trees or shrubs, but that by cuttings is usually adopted for continuing varieties, and that by seed for pro- 
curing them. The cuttings should be taken from promising shonts just before the leaves begin to fall in the autumn; the greatest part of the buds should be taken off, leaving only two or three buds on the top. Cut them at such a length as the strength and ripeness of the wood will bear; and plant them in good pulverized soil. On the approach of winter, lay some moss or litter around them; and, by being well cultivated, they will be fit to transplant when they are a year old.

When bushes are procured from the public nurseries, let the general supply be in such kinds as will ripen in succession. They may be planted in the kitchen garden, in eingle rows, along the side of the walks or paths, or in compartments by themselves, in rows from six to eight feet apart from row to row, and five or six feet apart in the rows; or in small gardens, they may be trained to a single tall stem, and tied to a stake; this, though six or eight feet high, occasions scarcely any shade, and it does not occupy much room, nor exclude air, while, at the same time, the stem becomes closely hung with berries, and makes a pleasant appearance in that state. Persons of taste may train them on arched trellises, and if they are judiciously managed, the ground around them may be more easily cultivated; the fruit may be kept from being splashed with rain, and may be easily gathered when wanted, or preserved by shading with mats, \&c. Those who may have a choice of soil and site, should fix on a good, rich, loamy earth, and plant some of the choice kinds in a northern and eastern aspect, near the fence, to come late in succession.

The Gooseberry produces its fruit not only on the shoots of the preceding year, and on shoots two or three years old, but also on spurs or snags arising from the older branches along the sides; but the former afford the largest fruit. The shoots retained for bearers should therefore be left at full length, or nearly so; the first pruning should be done before tho buds swell, so as not to endanger their being rubbed off 
in the operation. Cut out all the superfluous cross shoots, and prune long ramblers and low stragglers to some well placed lateral or eye : retain a sufficiency of the young well situated laterals and terminals to form successional bearers. In cutting out superfluous and decayed wood, be careful to retain a leading shoot at the end of a principal branch. The superfluous young laterals on the good main branches, instead of being taken off clean, may be cut into little stubs of one or two eyes, which will send out fruit buds and spurs.

Some persons not pruning the Gooseberry bush on right principles, cause it to shoot crowdedly full of young wood in summer, the fruit from which is always small, and does not ripen freely with full flavour; on which account it is an important point in pruning, to keep the middle of the head open and clear, and to let the occasional shortening of the shoots be sparing and moderate. Between the bearing branches keep a regulated distance of at least six inches at the extremities, which will render them fertile bearers of good fruit.

The prize cultivators of this fruit in Lancashire are particular in preparing a very rich soil, and they water occasionally with the liquor which drains from dunghills; and there are sume who, not content with watering at the ront and over the top, place a small saucer of water under each Gooseberry, only six or eight of which are left on a bush; this is technically called suckling. There are others who ring some of the branches; this is done by cutting out small circles of bark round them; and by pinching off a great part of the young wood, the strength is thrown to the fruit.

Unripe Gooseberries may be preserved in bottles against winter: some, after filling the bottles in a dry state, stand them in a slow oven, or in hot water, so as to heat them gradually through without cracking them; they will keep a whole year if closely corked and sealed as soon as cold.

The Gooseberry may be forced in pots or boxes, placed in pits, or in the peach house or vinery. "Hay plants in 
pots in November, removes to the peach house in January, and has ripe fruit in the end of April, which lie sends to table growing on the plants."-Hort. Truns. iv. 415.

\section{GRAPE.}

Vigne. Vitis, vinifera, vulpina.

The Grape Vine is described by Loudon as a trailing deciduous hardy shrub, with a twisted, irregular stem, and long, flexible branches, decumbent, like those of the bramble, or supporting themselves, when near other trees, by means of tendrils, like the pea. The leaves are large, lobed, entire, or serrated and downy, or smooth, green in summer, but when mature, those of varieties in which the predominating colour is red, constantly change to, or are tinged with some shade of that colour; and those of white, green, or yellow Grapes, as constantly change to yellow, and are never in the least tinged either with purple, red, or scarlet. The breadth of the leaves varies from five to seven or ten inches, and the length of the foot stalks from four to eight inches. The flowers are produced on the shoots of the same year, which shoots generally proceed from those of the year preceding: they are in the form of a raceme, of a greenish white colour, and fragrant odour, appearing in the open air in June; and the fruit, which is of the berry kind, attains such maturity as the season and situation admit, by the middle or end of September. The berry, or Grape, is generally globular, but often ovate, oval, oblong, or fingershaped; the colour green, red, yellow, amber, and black, or a variegation of two or more of these colours. The skin is smooth, the pulp and juice of a dulcet, poignant, elevated, generous flavour. Every berry ought to enclose five small heart or pear shaped stones; though, as some generally fail, they have seldom more than three, and some varieties, 
when they attain a certain age, as the Ascalon, or Sultana raisin, none. The weight of a berry depends not ouly on ats size, but on the thickness of its skin and texture of the flesh, the lightest being the thin-skinned and juicy sorts, as the Sweet Water or Muscadine; and what are considered as large berried of these varieties, will weigh from five to seven pennyweights, and measure from one to two-thirds of an inch in girth. A good-sized bunch of the same sorts may weigh from two to six pounds; but bunches have been grown of the Syrian Grape, in Syria, weighing forty pounds, and in England weighing from ten to nineteen pounds. A single vine, in a large pot, or grown as a dwarf standard, in the manner practised in the vineyards in the North of France, ordinarily produces from three to nine bunches; but by superior management in gardens in England, the number of bunches is prodigiously increased, and one plant, that of the red Hamburgh sort, in the vinery of the royal gardens at Hampton Court, has produced two thousand two hundred bunches, averaging one pound each, or in all nearly a ton. That at Valentine, in Essex, has produced two thousand bunches of nearly the same average weight.

The age to which the vine will attain in warm climates is so great as not to be known. It is supposed to pe equal or even to surpass that of the oak. Pliny speaks of a vino which had existed six hundred years; and Bose says, there are vines in Burgundy upward of four hundred years of age

In Italy there are vineyards which have been in a flour ishing state for upward of three centuries, and Miller tells us that a vineyard a hundred years old is reckoned young. The extent of the branches of the vine, in certain situations and circumstances, is commensurate with its produce and soil. In the hedges of Italy, and woods of America, they are found overtopping the highest elm and poplar trees; and in England, one plant, (lately dead,) trained against a row of houses in Northallerton, covered a space, in 1585, of one hundred and thr:-y-se ren square yards; it was then above 
one hundred years old. That at Hampton Court, nearly of the sams age, occupies above one hundred and sixty square yards; and that at Valentine, in Essex, above one hundred and forty-seven square yards. The size to which the trunk, or stem, sometimes attains in warm climates, is so great as to have afforded planks fifteen inches broad, furniture, and statues; and the Northallerton vine, above mentioned, in 1785 measured four feet in circumference near the ground, and one branch of the Hampton Court vine measures one hundred and fourteen feet in length. Vine timber is of great durability.

The varieties of the Grape in countries where it is grown for the wine press, are as numerous as the vineyards; for as these for the most part differ in soil, aspect, elevation, or otherwise, and as the vine is greatly the child of local circumstances, its habits soon become adapted to those in which it is placed. When it is considered that a vineyard once planted will last two or three centuries, it will readily be conceived that the nature of a variety may be totally changed during only a part of that time. The varieties mostly in esteem for wine making are small berries, and bunches with an austere taste. The Burgundy, as modified by different soils and situations, may be considered the most general vineyard Grape of France, from Champagne or Marne, to Marseilles or Bordeaux.

The best wine in Italy and Spain is also made from Grapes of this description ; but in both countries many of the largerberried sorts are grown on account of their producing more liquor. The sweet wines, as the Malmsey, Madeira, Constantia, Tokay, \&c., are made from sweet-berried Grapes, allowed to remain on the plants till over-ripe. That wine is the strongest, and has most flavour, in which both the skins and stones are bruised and fermented. The same thing is the case in making cider; but in both processes bruising the stones or kernels is neglected. The vine was formerly extensively cultivated in Britain for the wine press, 
but its culture is now confined to the garden as a dessert fruit; and they have in that country not only the best varieties, but they grow the fruit to a larger size, and of a higher flavour, than is done any where else in the world; this is owing to the perfection of their artificial climates, and the great attention paid to soil and subsoil, and other points of culture. The fruit is produced in some vineries during every month in the year; and in the London markets (generally) it is to be had in the highest degree of perfection from March to January.

The vine will thrive in any soil that has a dry bottom; and in such as are rich and deep it will grow luxuriantly, and produce abundance of large fruit; in shallow, dry, chalky, or gravelly soils, it will produce less fruit, but of better flavour. Speechly recommends dung reduced to a black mould, the dust and dirt of roads, the offal of animals, or butchers' manure, horn shavings, old rags, shavings of leather, bone dust, dung of deer and sheep, human excrement when duly meliorated by time, a winter's frost, and repeatedly turning over. Abercrombie says that dung out of a cow-house, perfectly rotted, is a fine manure for the vine; he recommends drainings from dunghills to be used over the ground once in ten or fourteen days from the time the buds rise, till the fruit is set, and that fresh horse dung be spread over the ground in autumn as a manure, and also to protect the roots from the inclemency of the weather; some, however, disapprove of manuring high, as being calculated to produce wood rather than fruit.*

The general mode of propagating the vine is by cuttings, either a foot or more long, with a portion of two year old

* It has been proved by repeated experiments that the best manure for vines, is the branches pruned from the vines themselves, cut into small pieces and mixed with the soil by means of a garden hoe. Dr. Liebig, in his 'Organic Chemistry,' mentions several instances of vines being kept in a thriving condition for from ten to thirty years by the trimmings of vines alone. The discovery was made by poor peasants, who could not afford to buy the ordinary kinds of manure. 
wood, or short, with only one bud, or one bud and a half joint, \&c. Vines are to be had at the nurseries, propagated either from layers, cuttings, or eyes ; but plants raised from cuttings are generally preferred; many are of opinion that it is a matter of indifference from which class the choice is made, provided the plants are well rooted, and in good health, and the wood ripe. A mode of very general utility is to select the plants in the nursery a year before wanted, and to order them to be potted in very large pots. Varieties without end are raised from seed, and it is thought that by propagating from the seed of successive generations, some sorts may ultimately be procured, better adapted for ripening their fruit in the open air than now known. A seedling vine, carefully treated, will show blossoms in its fourth or fifth year; say that it produces a fair specimen of its fruit in the sixth year, then a new generation may be obtained so often; but seed ought never to be sown, except for experiment.

The following method of grafting the vine is recommended by Mr. Loudon: Select a scion with one good eye; pare it beneath the eye and on the opposite side, in the form of a wedge. Select from the stock to be grafted on, a branch of the preceding year; cut this off a little above the second eye from its base; then with a sharp knife split it down the centre nearly to the old wood. Out of each half of the stock, but chiefly out of that half which is opposite the bud, pare off as much as is necessary to make it fit the scion, which must be inserted with its eye opposite to the eye which is left on the top of the stock, and bandaged together carefully with bass matting. Some use grafting clay, others composition; in either case, a small hole for the eye of the graft, and another hole for the eye left on the stock, must be left open. Tie over a little moss, to be occasionally sprinkled with water. It is very essential that the young shoot on the top of the stock should be allowed to grow for ten or fifteen days; then cut it off, leaving only one eye and one 
leaf to draw the sap and keep alive the circulation, till both scion and stock are perfectly united.

William Robert Prince, in his Treatise on the Vine, published in 1830, enumerated about five hundred and fify varieties under cultivation, in the vineyard attached to the Linnæan Botanic Garden at Flushing, including about ninety American native Grapes; but no sufficient evidence has as yet been exhibited of the foreign varieties flourishing in vineyards here, equal to what they do in Europe. Mr. Loubat once attempted to establish a vineyard on Long Island, which he abandoned after six years' arduous exertion. The following have been found to succeed best in private sheltered gardens in the vicinity of New-York: the Sweetwater, the Chasselas, the Muscadine, the White Tokay, the Black Hamburgh, the Blue Cortiga, the Miller Burgundy, the Austrian Muscadel, the Messlier, the Morilon, the Black Prince, Blanc, and some excellent seedling sorts from the imported Lisbon Grapes. To plant a vinery for a full crop of gnod Grapes of variuus flavours, take a white and red Muscat, a white and red, or black Muscadel, a white Raisin Grape, a white and red Hamburgh, a Stilwell's, and red Sweetwater, a white and red Nice, a black Damascus, a red Syracuse, and a black Constantia. The above list contains some of the most esteemed table Grapes of all colours and flavours, which will ripen in succession.

\section{SELECT DESCRIPTIVE LIST OF NATIVE GRAPES.}

Alexander, Constantia of Vevay, Madeira of York, Pa., Winne, Schuylkill Muscadel. A good wine fruit, of large size, blackish colour, and oblong form; very juicy and pungent; a great and sure bearer.

Bland, Bland's Madeira, Bland's Virginia, Mazzci, Po:rel. A pale red grape, of large size and round shape, rather musky, but the juice is sweet and lively.

Carolina Perfumed. A medium sized fruit, of purple colour and rather an unpleasant odour; it is, however, considered as well adapted for wine, being rather pungent, very juicy, and pulpless. 
Catawba, Red Muncy, To Kalon. A fine variety, above medium size, of dark red colour, in firm round, in flavour delicious for the dessert, and highly productive; it ripens soon after the Isabella.

Cunningham. A native of Prince Edward's county, Virginia; the berries are round, black, of medium size, and not liable to rot; they are said to resemble, in taste, the Nigrillo of Madeira, and are considered good for wine as well as for the table.

Elsinburg. Fruit small. round, of purple colour, and delicate musky flavour, without pulp; good for wine, and as a dessert fruit; the vine is very hardy and productive.

Hide's Eliza. Berries large, oval, of violet colour, and excellent fla. vour; alike suited, for the dessert and for wine.

IsABELLA. A well known and highly estimated variety. Fruit large, oval, of rich purple colour, covered with bloom ; skin, under good cultivation, thin; flesh juicy, rich, and vinous; an excellent dessert fruit.

LUFBorovgr. A sweet fox grape of large size and round shape; skin, dark purple; pulp dissolving in a saccharine musky juice; good for wine

MADDox. A good wine grape, not liable to rot; it is of medium size; roundish; of a brownish red colour, and a brisk vinous flavour.

Norton's Virginia SeEdiring, Longworth's Ohio. An early fruit of medium size and dark purple colour; it ripens in September; makes excellent wine; it is also generally approved as a dessert fruit.

Pond's SEnding. A large purple grape of roundish form, thin skin, and of rich pungent flavour; adapted for wine, as well as for the table.

SCUPPERNONG. This species is very prolific; the berries are large, roundish, and of a colour varying from brick red to black; makes peculiar Muscat wine, and is highly esteemed as a dessert fruit.

WARREN, Madeira. A round fruit of medium size and dark purple co lour; it is considered by some as the most luscious of all native grapes; it makes excellent wine.

Woodson. A small round black Virginian variety, from Prince Edward's county; it is celebrated as a very proper fruit for the manufacture of sparkling wine; it ripens later than most other varieties, but yields abuudantly.

The above list comprises the most esteemed species of Native Grapes under cultivation: the greater part of which, with the best of the foreign varieties, may be purchased at the Commercial Garden and Nursery of Messrs. Parsons \& Co., Flushing, Long Island, near New-York.

Previous to planting vines, care should be taken that the ground be well pulverized and prepared for some distance around for the roots to spread. The soil should be deep and dry, and some rich compost, or vegetable mould, should be used around the roots in filling in; a handful or two of wet 
ashes to each plant is recommended by Mr. Loubat, as beneficial; and he recommends the planting to be done in the month of March, or early in April.

There are various methods adopted in training and pruning the vine; and it appears impossible to lay down rules to suit every cultivator. The vine having, like other trees, a tendency to produce its most vigorous shoots at the extremities of the branches, and particularly so at those which are situated highest, it generally happens, when it is trained high, that the greater portion of the fruit is borne near the top; and it has been observed, that the fruit produced on the vigorous shorsts, which naturally grow at the extremities of the long branches, is generally more abundant, and of finer quality than that produced on the short lateral ones, from which circumstance, high training seems to be the best calculated for private gardens.

In some parts of Italy, vines are cultivated together with Mulberry trees, and are allowed to mingle and hang in festoons; thus silk and wine are produced on the same spot; and it is considered that when vines are allowed to grow over trees, on the side of a house, or on bowers, or extended on tall poles, without much trimming, they will produce more fruit, and are not so liable to mildew.

Dr. G. W. Chapman, of New-York, having paid some attention to the cultivation of native Grapes, observes, that the vine, in its natural state, seldom or never throws out bearing shoots until it reaches the top of the tree on which it ascends, when the branches take a horizontal or descending position. From this fact he considers horizontal training preferable to that in the fan shape. From the experiments he has made, he has found that the shoots coming from those parts of the branches bent downward, are more productive than from those ascending; he considers deep digging around the vine, even to the destruction of some of the extending roots, as calculated to promote the growth of more fruit and less wood, than if allowed to spread near the sur- 
face; and he disapproves stopping the shoots before the fruit until early in July.

Mr. William Wilson, of Clermont, leares his foreign vines their whole length at the time of trimming in October. In November, they are laid on the ground at full leugth, fastened down with pins, and covered lightly with earth; in this state they lie all the winter. In April, as soon as the weather will permit, they are uncovered, and left lying on the ground ten or twelve days : by the first of May, the vines are trained to stakes or poles of the length of ten feet and upward; and by the middle of June the stakes are entirely covered by new shoots of the vine, and with plenty of fruit, which ripens in September. Mr. W. says, that until he pursued his present course, his fruit was frequently blasted and mildewed, but that he has now vines twenty or thirty feet long, which run up the fruit trees adjoining; others, being carried up eight or ten feet, are stretched horizontally. It is seldom he gathers fruit within three or four feet of the ground, and he has never any blasted or infected with mildew; he keeps the ground cultivated by frequent hoeing; but he says he has used no manure for ten years or more.

Edward H. Bonsall has a vineyard of American Grapes at Germantown, $\mathrm{Pa}$., in a high state of cultivation. In page 331 of Prince's Treatise on the Vine, is a letter to the author, containing some valuable information, from which the following is extracted as appropriate to our subject.

Mr. Bonsall's vineyard is situated between the Schuylkill and Delaware Rivers, four miles from the former, and eight from the latter, at an elevation of three hundred feet above their level; has an aspect facing S.S. E., with a substratum of light isinglass soil, and seems well suited to the purpose. He says, "from my experience, both on my premises and at other places, it is my opinion that we should reject almost all the foreign varieties, especially where our object in cultivating them is to make wine." He has upward of thirty varieties of American vines under cultivation; he recom- 
mends preparing the ground by ploughing with two ploughs with strong teams, one immediately behind the other, in the same furrow, each of them set deep; and after the ploughing is completed, to be harrowed thoroughly. Then in the direction the rows are intended to be planted, parallel furrows are run across the field, at the distance of eight feet from each other; these are afterward crossed at right an gles, five feet asunder. In the opening, at the intersection of these furrows, cuttings from nine to twelve inclies long are planted, and arranged with a view to the vines being, when grown, at distances of four by seven feet from each other; to this end, he frequently plants two cuttings in a place, some of which are used to fill up with, in case of failures. He says, that in 1829 he planted in nursery beds from two to three thousand cuttings as late as the middle of April to the middle of May, with better success than at any previous time. "In this case the slips should be kept in a crol, damp place, where vegetation may be held in check. To insure their freshness, sprinkle them occasionally with water. Previous to planting cut them a proper length, and place them with their lower ends three or four inches in water, in a tub above ground, where they may soak three or four days. At this season the temperature will be likely to be such as to spur vegetation at once into healthy and vigorous action. The autumn, or early in the spring, is preferable for rooted plants. In the autumn of the first year, after the frost has killed the unripe part of the young shoots, they should be pruned down to the mature, firm wood, and then with a hoe hilled over with the surrounding soil, which will completely protect them through the winter. If left without protection the first winter, many of them will perish."

Mr. Bonsall says, his mode of training, as far as he is aware of it, is entirely peculiar to himself, which he describes as follows: "I take chestnut posts, the thickness of large fence rails, seven feet in length; these I plant along the 
rows, at distances of ten feet from each other, and at such a depth as to leave five feet above the surface of the earth; then taking three nails to each post, and driving them to within half an inch of their heads, the first two and a half feet from the ground, a second midway between that and the top, and the third near the top, I attach No. 11 iron wire (one degree soft is best) firmly to one of the nails in the end post, pass on to the next, and stretching it straight and tight, give it one turn round a nail in the same line as the one to which it was first attached. Having in this manner extended it along the three courses, the whole length of the row, my trellis is formed. I have had a portion of my vineyard fitted up in this way for three years, and experience has confirmed the superior fitness of the plan. It is not its least recommendation, that it possesses in a degree the character of labour-saving machinery. A very important and extensive labour-making portion of the operations in the vineyard during the summer, is the attention required by the growing shoots to keep them properly trained up. They grow and extend themselves so rapidly, that where the strips of the trellis are lath, or where poles are used to support vines, unless very closely watched, they fall down in every direction, in a very unsightly and injurious manner. Here the wire being small, the tendrils or claspers eagerly and firmly attach themselves to it, and thus work for themselves in probably twi-thirds of the instances where the attention of the vigneron would otherwise be required. There is a free access afforded to the sun and air, and no hold for the wind to strain the frame," \&c. Mr. Bonsall says farther, "I shall not enter into a minute description of my manner of pruning, but may just say, that after the vines have attained a full capacity for production, (say five years from the cutting,) my view is to prepare them for bearing an average of fifty clusters to each, leaving several shoots of from three to five joints on a vine for this purpose. When fresh pruned, they will not be more than four feet high, at their greatest age." 
Dr. R. T. Underhill, of New-York, has a vineyard at Croton Point, near Sing Sing, where, after having sunk thousands of dollars in attempting to raise the most celebrated foreign varieties, he abandoned the project as visionary, and commenced planting the Isabella Grape in 1832, and the Catawba in 1835. Mr. Underhill has now upward of twenty acres of these grapes, chiefly of the former, under the most successful cultivation. He says that the Isabella Grape ripens two or three weeks earlier than the Catawba, and that these two varieties are, in his estimation, the best adapted for general purposes; the former yielding with him a more valuable crop than any other with which he is acquainted. He says that the quality of this fruit has improved very much within a few years, the clusters and berries being much larger and sweeter; and that they are capable of still greater improvement by high cultivation.

The following extracts are from Dr. Underhill's communication to the editor of the 'Cultivator,' published January 28th, 1843 :

"In this latitude, (south of the highlands of the Hudson,) I find that the Isabella Grape ripens quite as well when planted in a level field, protected from the north and west winds by woods or hedges, as on declivities. Several of $\mathrm{my}$ vineyards are thus located, and, as far as I can perceive, the fruit ripens at about the same time, and is of the same quality as those planted on steep side-hills. I think, however, that worth of the highlands, side-hills would be preferable. To prepare the ground for a vineyard, the best way is to turn over the whole of the surface soil from fifteen to eighteen inches in depth, early in the spring, by ploughing twice in the same furrow. This will place the richest part of the soil in a position where it will give the greatest supply of nourishment to the vines. Few vineyards in this countiy have been prepared in this way; but the cost is so small and the advantages so great, that it should be done wherever there are no racks or large stones to prevent it." 
The following observations on the destruction of the Rosebug, were also published in the 'Cultivator,' Sept. 13 1842:

"I observed that when the rose-bugs first appeared on the vines, they were so feeble as to be unable to fly even for a few yards. Having surmounted all other difficulties, I was determined not to be defeated in the vineyard cultivation of the Grape by this insect, and consequently resorted to the following means for its destruction. I directed my men to take each a cup, with a little water in it, and go through the vineyards every morning, removing every bug from the vines; and this was done quite rapidly by passing the cup under the leaf and merely touching it, when the bugs instantly dropped, and were received in the cup containing the water. When the cup was full, they were soon destroyed by pressing the foot upon them on a hard surface. This plan was persevered in every morning as long as a bug could be found, and was attended with such success, that they have given me very little trouble since. I also tried ploughing my vineyards just before winter set in, so as to expose to the weather the insect in the larvæ state, which will certainly destroy the young tribe that have not descended below the reach of the plough. For two years past the number has been so small that I bave omitted this process for their destruction.-R. T. Underhill."

Although the man of taste and capacity for improving on the improvements of others, may have gleaned ideas from the above extracts, sufficient to enable him to cultivate the vine in his own garden, it may be necessary to direct the reader's attention to the different methods of cultivating this excellent fruit in varied situations.

A vine may be trained horizontally under the coping of a close fence or wall, to a great distance, and the borders in an east, southeast, and southern aspect of large gardens, may be furnished with a variety of sorts, which will ripen in great perfection, without encumbering the borders; or the plants may be trained low, like currant bushes; in 
which case, three or more shoots, eighteen inches or two feet in length, may diverge from the stem near the ground, to supply young wood annually for bearing. The summer pruning consists in removing shoots which have no fruit, or are not required for the succeeding season; and in topping fruit-bearing shoots, and also those for succeeding years, when inconveniently long and straggling. For as, by this mode, the shoots destined to bear are all cut into three or four eyes at the winter pruning, no inconvenience arises from their throwing out laterals near the extremities, which topping will geuerally cause them to do.

In training vines as standards, the single stem at the bottom is not allowed to exceed six or eight inches in height, and from this two or three shoots are trained, or tied to a single stake of three or four feet in length. These shoots bear each two or three bunches, within a foot or eighteen inches of the ground, and they are annually succeeded by others which spring from their base, that is, from the crown or top of the dwarf main stem. This is the mode practised in the North of France and in Germany; in the South of France and Italy, the base or main stem is often higher, and furnished with side shoots, in order to afford a great supply of bearing wood, which is tied to one or more peles of greater height. The summer pruning, in this case, is nearly the same as in the last. In the winter pruning, the wood that has borne is cut out, and the new wood shortened, in cold situations, to three or four eyes, and in warmer places, to six or eight eyes.

Nicol observes, that "Mrst of the summer pruning of vines may be performed with the fingers, without a knife, the shoots to be displaced being easily rubbed off, and those to be shortened, being little, are readily pinched asunder." After selecting the shoots to be trained for the production of a crop next season, and others necessary for filling the trellis from the bottom, which shoots should generally be laid in at the distance of a foot or fifteen inches from each-other, 
rub off all the others tnat have no clusters, and shorten those that have, at one joint above the uppermost cluster. For this purpose, ga over the plants every three or four days till all the shoots in fiuit have shown their clusters, at the same time rubbing off any water shouts that may rise from the wood.

Train in the shoots to be retained, as they advance. If there be an under trellis, on which to train the summer shoots, they may, when six or eight feet in length, or when the Grapes are swelling, be let down to it, that the fruit may enjoy the full air and light as it advances toward maturity. Such of these shoots as issue from the bottom, and are to be shortened in the winter pruning to a few eyes, merely for the production of wood to fill the trellis, may be stopped when they have grown to the length of four or five feet. Others that are intended to be cut down to about two yards, and which issue at. different heights, may be stopped when they have run three yards, or ten feet, less or more, according to their strength. And those intended to be cut at or near the top of the trellis, should be trained a yard or two down the back, or a trellis may be placed so as to form an arbour; or they may be placed to run right or left a few feet on the uppermost wire.

The stubs or shoots on which the clusters are placed will probably push again after being stopped, if the plants be vigorous. If so, stop them again and again; but after the fruit are half grown, they will seldom spring. Observe to divest the shoots, in training, of all laterals as they appear, except the uppermost on each, in order to provide against accidents, as hinted before, in training the newly-planted vines. When these shoots are stopperl, as directed above, they will push again. Allow the lateral that pushes, to run a few joints, and then shorten it back to one, and so on as it pushes, until it stops entirely. When the proper shoots get ripened nearly to the top, the whole may be cut back to the originally shortened part, or to one joint above it, if there 
be reason to fear that the uppermost bud of the proper shoot will start.

Divest the plants of all damped and decayed leaves as they appear, as such will sometimes occur in continued hazy weather, and be particularly cautious not to injure the leaf that accompanies the bunch, for if that is lost, the fruit will be of little value.

"Every one of penetration and discernment," Nicol observes, "will admit the utility of thinning the berries on bunches of Grapes, in order that they may have room to swell fully; and, farther, that of supporting the shoulders of such clusters of the large growing kinds as hang loosely, and require to be suspended to the trellis or branches, in order to prevent the bad effects of damp or mouldiness in very moist seasons. Of these, the Hamburgh, Lombardy, Royal Muscadine, Raisin, St. Peter's, Syrian, Tokay, and others, should have their shoulders suspended to the trellis, or to the branches, by strands of fresh matting, when the berries are about the size of garden peas. At the same time, the clusters should be regularly thinned out with narrow pointed scissors, to the extent of from a fourth to a third part of the berries. The other close-growing kinds, as the Frontignacs, Muscats, \&c., should likewise be moderately thinned, observing to thin out the small seedless berries only of the Muscadine, Sweet Water, and flame-coloured Tokay. In this manner, handsome bunches and full-swelled berries may be obtained; but more so, if the clusters or over-burdened plants be also moderately thinned away. Indeed, cutting off the clusters, to a certain extent, of plants overloaded, and pushing weak wood, are the only means by which to cause them to produce shoots fit to bear fruit next year; and this should be duly attended to, so long as the future welfare of the plants is a matler of importance."

The preceding observations may be considered as falling short of what may be expected on the cultivation of so important a fruit as the Grape; but it is introduced into this 
book only as a dessert fruit. The modes of training in vineyards and vineries are alike suited to the garden. Low training may be practised in borders or hedge rows, in large gardens; and high training in sheltered situations, on high trellises or arbours. By proper management, the vine may ine elevated to the middle story of a house by a single stem, and afterwards trained to a great height according to the taste of the proprietor. As the vine is often trained near buildings, an awning may be conveniently formed over the tops so as to admit of fumigating the vine with smoke from tobacco, \&c., as may be necessary in the summer season; or a sort of movable tent may be made of light boards, and cheap glazed linen, or an old sail, \&c., capable of covering the vine while a smoke is created underneath; this will effectually destroy such insects as may annoy the vine, and may prevent mildew and other diseases.

\section{MULBERRY.}

\section{Murier. Morus.}

There are several species of the Morus or Mulberry. The white kind is commonly cultivated for its leaves to feed silkworms, though in some parts of Spain, and in Persia, they are said to prefer the Black Mulberry. In China, it appears that both sorts are grown for this purpose. The most esteemed variety of the white is grown in Italy, and especially in Lombardy, with vigorous shoots, and much larger leaves than the other. The Morus multicurlis is cultivated in many parts of France, and is by some preferred to all other varieties. It is said that a less quantity of foliage from this variety will satisfy the silkworms. The late Andrew Parmentier, Esq., was the means of introducing several choice varieties from that country; and our nurserymen in general, have of late vears, turned their attention to the 
cultivation of such as are best adapted to silkworms, which are sold at moderate prices.

In France, the white Mulberry is grown as pollard Elms are in England. In Lombardy, it is grown in low, marshy ground. In China, it is also grown in moist, loamy soil, and both there and in the East Indies, as low bushes, and the plantations rooted up and renewed every three or four years. In many parts, when the leaves are wanted for the worms, they are stripped off the young shoots, which are left naked on the tree; in other places, the shoots are cut off, which is not so injurious to the tree, while the points of the shoots, as well as the leaves, are eaten by the worms.

The plarits are sometimes raised from seed, and one ounce of seed will produce five thousand trees, if sown in rich loamy soil in the latter end of April, or early in May; but the young plants will require protection the first winter; they are more commonly propagated by layers and cuttings, put down in the spring. The Italian variety is frequently grafted on seedling stocks of the common sort, in order to preserve it from degenerating. In the East Indies, the plants are raised from cuttings, three or four of which are placed together where they are finally to remain.

But Mulberry trees are valuable for their fruit; and in England the black and red kinds are in great esteem, and much cultivated. The fruit of the white Mulberry is white, and less acid than that of the black species. The black is naturally a stronger tree than the other; the fruit is of a dark, blackish red, and of an agreeable aromatic and acid flavour. The red Mulberry has black shoots, rougher leaves than the black Mulberry, and a dark, reddish fruit, longer than the common sort, and of a very pleasant taste. The fruit of the yellow Mulberry is very sweet and wholesome, but not much eaten, excepting by birds; the timber, however, is valuable, from its abounding in a slightly glutinous milk of a sulphurnus colour, and is known in Europe under the name of fustic wood, for dying a yellow colour. 
In Russia, the fruit of the Morvis tajtarica is eaten fresh, conserved, or dried; a wine and a spirit are also made from them, but the berries are said to be of an insipid taste.

All the species of the Morus are remarkable for putting out their leaves late, so that when they appear, gardeners may safely set out their green-house plants, taking it for granted that all danger from firost is over; from this circumstance, plantations of Mulberry trees may be made in this country in the spring of the year with greater safety.

The Mulberry produces its fruit chiefly on little shoots of the same year, which arise on last year's wood and on spurs from the two-year-old wood; in both stages, mostly at the ends of the shonts and the branches. In pruning, thin out irregular crossing branches, but never shorten the young wood, on which fruit is produced. If any of the dwarfish kinds are cultivated as espaliers for their fruits, cut so as to bring in a partial succession of new wond every year, and a complete succession once in two years, taking the old barren wood out, as may be necessary. As the blossom buds cannot be readily distinguished from others in the winter, the best period for pruning is when the blossoms first become visible in the spring.

There is another genus of plants, known as the Paper Mulberry, which is very ornamental, called Broussonetia papyrifera; though a low tree, it has vigorous shoots, furnished with two large leaves; the fruit, which is small, is surrounded with long purple hairs, changing to a black purple colour when ripe, and full of juice. "In China and Japan, it is cultivated for the sake of the young shoots, from the bark of which the inhabitants of the Eastern countries make paper. The bark being separated from the wood, is steeped in water, the former making the whitest and best paper. The bark is next slowly boiled, then washed, and afterward put upon a wooden table, and beat into a pulp. This pulp being put in water, separates like grains of meal. An infusion of rice, and the root of manhiot, are nixt added 
to it. From the liquor so prepared, the sheets of paper are poured out one by one, and when pressed the operation is finished."

"The juice of this tree is sufficiently tenacious to be used in China as a glue, in gilding either leather or paper. The finest and whitest cloth worn by the principal perole at Otaheite, and in the Sandwich Islands, is made of the bark of this tree. The cloth of the Bread Fruit tree is inferior in whiteness and softness, and worn chiefly by the common people."

\section{NECTARINE.}

Pechera Fruit lisse, ou Brognons. Amygdalus nectarina.

THE varieties of this fruit resemble the Peach in every respect, except that the skin is perfectly smooth, of a waxen appearance, and the flesh generally more firm; although of the same genus as the Peach, which is so plentiful in this country, the fruit of the Nectarine is quite a rarity, and seldom appears in our markets. There are seventy-two varieties cultivated in the Horticultural Garden of London under name.

It is generally allowed that their failure here is occasioned by the attacks of insects. The most efficacious method that I have heard of for securing any thing like a crop of Nectarines, is to fumigate the trees in the evening, when the air is calm and serene, at the season when the fruit is ready to set. Tobacco is the most effectual antidote for these insects ; but a friend of mine collected a quantity of salt hay that had been used for his Spinach the preceding winter; with this he created a smoke, first on one side of his plantation, and afterward on the other, by which means he obtained a good supply of fruit. Our enterprising horticulturist, $\mathrm{Mr}$. W. Shaw, has succeeded in gathering fine fruit, by pursuing the English plan, namely, in training his trees against a close 
fence; and it has been discovered by others, that the Nectarine, like the Grape vine will yield best in sheltered situations. That eminent horticulturist, Mr. David Thomas, observes, that "A vast quantity of fruit is annually destroyed by the Curculio, which causes the Plum, Apricot, and Nectarine prematurely to drop from the tree. To prevent this loss, let the tree, after the blossoms fall, be frequently shaken by a cord connected with a swinging door, or with a working pump-handle, \&c.; or let the bugs be jarred from the tree and killed. Or keep geese enough in the fruit garden to devour all the damaged fruit as it falls. We know that this last method is infallible."

As some may object to shaking or jarring fruit trees, for fear of disturbing the fruit, such are here reminded, that if the blossoms set more fruit than can be supported, it will not come to full perfection, and the trees may be injured in their future bearing; for these reasons, when fruit sets too thick, it should be thinned in an early stage of its growth.

The Nectarine, as also the Peach tree, is subject to injury by an insect different from the Curculio species, which feeds on the sap beneath the bark, principally near the surface of the earth; but if not checked, will commit ravages on the trunk and root, so as eventually to destroy the tree. The egg is supposed to be first deposited in the upper part of the tree; and in the months of June and July, it becomes a very small maggot, which drops to the ground, and approaches the tree near the surface. If the ground be kept clear around the roots, as it ought always to be, the worm can readily be detected by a small speck of gum, which appears on the tree after it has made its entrance, which gumminess will increase in quantity as it progresses; but if the trees are thoroughly examined about once a week or ten days, and the gum, wherever found, removed by means of a small knife or pointed wire, the worm may be at once defeated from making any havoc on the trees. An orchard of several acres may be kept free from worms by going over it a few times. 
After a shower of rais is a good time, as the gum can then be more easily discovered; and when it is removed, the wound will soon heal up, and the danger is over, provided the ground be kept cultivated around the trees, and the collar, or that liart from which emanate the main roots, be near the surface.

This is an important precaution, and should be attended to at the time of transplanting all descriptions of trees and smaller plants; because deep planting prevents the essential circulation of the juices of plants in their regular and natural courses, and, consequently, causes disease and premature death; and it must be admitted, that from the circumstance of this fruit being generally raised on standard trees, and in a light soil, our cultivators are apt to plant too deep; and thus act contrary to sound judgment and philosophy, with a view to save the trouble and expense of staking or otherwise supporting their newly-planted trees, which precaution is absolutely necessary to their preservation, even in less tempestuous climates, and in stiff as well as in light soil.

Saltpetre dissolved in the proportion of one pound to five gallons of water, and applied round the stems and roots of trees, as recommended for plants in general, is, in my opininn, one of the best remedies for the destruction of various kiuds of insects; it is, moreover, allowed by modern and learned physiologists to contain the most essential nutriment tn all descriptions of trees or smaller plants, when judiciously used. Other remedies are recommended to be applied for the destruction of these insects around fruit trees, besides those previously mentioned; as, dissolved potash, coal tar, sul phur and lime-mortar mixed, vinegar, soapsuds, \&c. Culture, upon correct principles, will, however, in general operate not only as a radical cure, but as a preventive to all defects in trees and plants; which, to be healthy and productive, should be so managed that the sap and nutrimental juices can circulate through every pore which nature has designed for their perpetuity. (Sce article on the choice of Fruit Trees in the Nursery; also, article Peach.) 
The Nectarine is generally budded on stocks of the same species, or on the Peach or Plum, two or three years old. Knight recommends growing Almond stocks for the finer kinds of Nectarines and Apricots, as likely to prevent the mildew, and as being allied to the Peach. Dubreuil recommends a Plum stock for clayey soils, and the Almond for such as are light, chalky, or sandy. The same opinion is held by the Montreal gardeners. The Flemish nurserymen graft both the Peach and Nectarine on the Myrabella Plum, a very small cherry-shaped fruit.

The budding may be performed in July or August, in the side of the stock, which will, if properly managed, shoot the following spring, and attain the length of three or four feet the first year. After the budded trees have ripened their first year's shoots, they may either be planted where they are to remain, or retained in the nursery for two, three, or four years, till in a bearing state. Whether the plants be removed into the orchard at a year old, or remain in the nursery, the first shoots from the bud must be headed down in a judicious manner, in order to promote the most desirable form. In annual pruning, thin out superfluous branches and dry wood, and shorten the bearing shoots.

Nectarines may be trained to a close fence, or wall, in private gardens; in which case, such plants should be chosen as are budded low. (See article Apricot.)

\section{SELECT DESCRIPTIVE LIST OF NECTARINES}

\section{FREESTONE NECTARINES.}

Aromatrc. A middle sized, rather globular fruit, skin pale straw colour with deep red or brown next the sun; flesh pale straw, but red at the stone ; juice of a rich vinous flavour; ripe early in A ugust.

Boston, Lewis's Seedling. A fine native variety, raised by Mr. Lewis, of Boston; fruit of medium size; heart-shaped; colour bright yellow, mottled with red; flesh yellow, firm, pleasant and peculiar in flavour; ripo in Septemuber. 
Elruge, Claremont, Tenıple's, Vermash of some collections. One of the rery best and most high flavoured Nectarines; fruit inedium size, of a green or pale yellow colour, with violet cheek; pulp whitish, melting, very $\mathrm{J}$ sicy, rich and high tlavoured; ripens early in August.

Fairchil.d's Eari.y. Fruit very early, but small; of globular shape, yellow in the shade, deep scarlet next the sun; flesh yellow, not juicy, but well flavoured; ripe in July and August.

Perkins's Sredi.rig. A very large beautiful Nectarine, raised by S. G. Perkins, from the Boston, Lewis's Seedling; the form is globular; colour bright yellow, with dark crimson on one side; flesh tender, juicy and high flavoured; ripe in September.

Pitmaston's Orange. A good sized globular, almost heart-shaped fruit, of a rich yellow colour, but dark crimson or purple next the sun; flesh golden yellow, but red next the stone, from which it separates; it is melting. juicy, saccharine and high flavoured; ripe in August.

Sc^rцet. A middle sized fruit, somewhat ovate, of a beautiful scarlet colour next the sun, and pale red on the shader side; the flesh separates from the stone, and is at maturity in August.

Vermash, True Vermash. This fruit is rather of small size, and roundish form, tapering towards the eye; the shin is of a very deep red colour next the sun; and of a greenish hue on the other side; flesh white, rich melting and juicy; at maturity in August.

Violex, Violette Hative, Petile Violette Hative, Lord Selsey's Elruge, Large Scarlet. Fruit variable in size, generally medium; pale jellowish green, but darkish purple and red next the sun; thesh melting, juicy, rich and excellent; ripe in July and $\mathrm{A}$ ugust.

Wuite, or Flanders Nictarine, New White, Emerbon's New White, Neale's White. A middle sized, roundish, very pale fruit, slightly tinged with red next the sun; flesh tender and juicy, with a fine vinuus flavour: ripe in $\Lambda$ ugust.

\section{Clingstones, or pavies.}

Brugnon Viotet Musque, Brugnon Musque. Fruit large, of a deep red and yellow colour; skin very smooth; flesh yellow, but red at the stone; saccharine, vinous, musky ; at maturity in August and September.

Early Newington, Large Black Newington, Lucombe's Stedling. Fruit below the middle size, ovate; skin pale green, and on the sunny side of a deep red colour; pulp super-excellent ; considered by some as the best of all Nectarines; ripe in August and September.

Gor.DEN. Fruit mediun size, of the finest orange colour, delicately and beautifully mottled with rel next the sun, which gives to it a clear waxen appearance; flesh firm, yellow, pale red at the stone, and has a poignant, rich flavour; ripens in August and September.

RED Roman, Roman Red. A very excellent Nectarine, of large size; the skin dark red next the sun, and of a yellowish hue on the other side; flesh yellowish, but red next the stone; it abounds with rich juice when fully ripe, in August and september.

Scarlet Newington, Late Neuing'on, Sion Hill. This variety is much esteemed, the fruit is large, of a beautiful red colour next the sun, and 
of a fine yellow or amber un the other side; its quality is excellent heing rich and juicy; early in September.

rawny Newington. Fruit large, somewhat ovate; tawny-coloured, marbled with dull red or orange next the sun; flesh pale yellow, but red at the stone; very juicy, sugary, and of the most delicious flavour; ripens in A ugust and Septemter. This, in kngland, is considered one of the best of clingstone Nectarines.

ORANGE, LEMON, \&c.

Oranger, Citronier, etc. Cilrus.

Notwrthstanding this fruit, and also the Lemon, Lime, \&c., are attainable at all seasons of the year, by supplies from our Southern States, the West Indies, and the South of Europe, yet the plants are entitled to our notice on account of their being so easily cultivated, and from their affording an ornament by exhibiting their fruit the whole of the year.

The Orange, as well as others of the same genus, are generally cultivated as green-house plants, but may be kept in a light room throughout our severe winters, provided the temperature is not suffered to be below the freezing point, 32 degrees. Its recommendations are, handsome evergreen, shining, tree-like form; most odoriferous flowers, and bri!liant, fragrant, and delicious fruits, which succeed each other perpetually, and are not unfrequently seen on the tree at the same time, in two or three stages of growth. A work has recently been published at Paris, edited by Messrs. Risso and Poiteau, which contains engravings and descriptions of one hundred and sixty-nine varieties. They are arranged as sweet Oranges, of which they describe 42 sorts; bitter and sour Oranges, 32 sorts; Bergamots, 6 sorts; Limes, 8 sorts; Shaddocks, 6 sorts; Lumes, 12 sorts; Lemons, 46 sorts; Citrons, 17 sorts.

All the species of Citrus endure the open air at Nice, Genoa, and Naples; but at Florence and Milan, and often 
at Rome, they require protection iluring the winter, and are generally planted in conservatories and sheds. In England, these trees have been cultivated since 1620 ; they are generally planted in conservatories. Loudon says that in the south of Devonshire, and particularly at Saltcombe, may be seen, in a few yardens, Orange trees that have withstood the winter in the open air upward of a hundred years. The fruit is as large and fine as any from Portugal. Trees raised from seed, and inoculated on the spot, are found to bear the cold better than trees imported.

At Nuneham, near Oxford, are some fine old trees, planted under a movable case, sheltered by a north wall. In summer, the case is removed, and the ground turfed over, so that the whole resembles a native Orange grove. The author of this work, being a native of Abingdon, which is within three miles of the Earl of Harcourt's estate, has had frequent opportunities of tasting the fruit, which he believes to be equal to that of warmer climates. At Woodhall, near Hamilton, trees of all the species of Citrus are trained against the back walls of forcing-houses, and produce large crops of fruit.

Any of the varieties of the Orange, Lemon, Lime, Shaddock, Citron, \&c., may be grafted or budded on stocks of the cummon Orange or Lemon; but the seed of Shaddocks and Citrons produce the strongest stocks; and on these may be grafted such kinds as may be needed for a conservatory. The most suitable time for budding is July and August; but this operation may be performed at any time when the sap is in motion. The directions for the management of green. house plants, apply also to this family of plants, to which I refer my readers. A friend of mine, who is a native of Rouen, in Normandy, informs me, that a Mr. Valee, of that city, succeeds in clearing about twelve thousand francs per annum from the flowers of Orange trees, which are distilled for essences, \&c. 


\section{PEACH.}

\section{Prcher. Amygdalus Persica.}

IT is generally considered that the Peach is of Persian origin. In Media, it is deemed unwholesome; but when planted in Egypt, becomes pulpy, delicious, and salubrious. It has been cultivated, time immemorial, in most parts of Asia; when it was introduced into Greece, is uncertain. The best Peaches in Europe are supposed to be grown in Italy, on standards.

The list of Peaches in the London Catalogue, contains about two hundred and fifty-names, fifty of which are denominated American Peaches. Several attempts have been made to class the varieties of Peaches and Nectarines by the leaf and flower, as well as the fruit. Mr. Robertson, a nurseryman at Kilkeuny, has founded his arrangement on the glands of the leaves; and Mr. George Lindley, of London, has, in a peculiarly distinct manner, arranged no fewer than one hundred and fifty-five sorts of Peaches and Nectarines in well-defined divisions and sections. There are various instances on record, (Hort. Trans. vol. i. p. 103,) of both fruits growing on the same tree, even on the same branch; and one case has occurred of a single fruit partaking of the nature of both. The French consider them as one fruit, arranging them in four divisions; the Peches, or freestone Peaches; the Peches lisses, or freestone Nectarines, or freestone Peaches; the Pavies, or clingstone Peaches; and the Brognons, or Nectarines, or clingstone smonth Peaches.

Although this fruit will thrive in any sweet, pulverized soil that is properly prepared, a rich sandy loam is the most suitable. Next to the selection and preparation of a suitable soil, a choice of good healthy trees is of the utmost import ance. The seed for stocks should be selected from the vigorous growing young, or middle-aged healthy trees; and the buds should be taken from some of the choicest fruit- 
bearing trees that can be found. Let the stocks be fairly tested before they are budded, and if any infection exist in the stocks, or in the vicinity of where the choice of buds may fall, reject them if you wish to rear a healthy progeny; as more depends upon these particular points than many are aware of.

In this country, the Peach is generally budded on stocks of its own kind; but in England it is often budded on damask Plum stocks, and some of the more delicate sorts on Apricot stocks, or old Apricot trees cut down; or on seedling Peaches, Almonds, or Nectarines. (See article Nectarine.) Cobbett says, "There are thousands of Peach trees in England and France that are fifty years old, and that are still in vigorous fruitfulness." $\mathrm{He}$ attributes the swift decay of the Peach tree here to their being grafted on stocks of their kind.

Mr. Michael Floy, of the Harlæm Nursery, in a note, page 364 of the American edition of Lindley's Guide to the Orchard and Fruit Garden, edited by him, makes the following observations on this subject, which he says are the resuit of thirty years' experience as a nurseryman in the vicinity of New-York:

“In this country Peaches are generally budded on Peach stocks. Their growth is very rapid, and they will form a tree large enough to transplant from the nursery, the first and second year after budding; but notwithstanding the rapid growth of our Peaches, and their coming to maturity so early, with but little care and trouble, it must at the same time be admitted that they too often come to decay with almost the same celerity. A question here will naturally arise on this subject, what can be done to remedy this ? I answer, first, I think the Peach stock is defective; it is not sufficiently strong and lasting to make a permanent tree; the roots are soft and delicate, very liable to rot in cold heavy ground, particularly if suffered to stand in a sod, or where the ground is not kept clean, dry, and manured every 
season. Secondly. Supposing that the trees are planted in a warm free soil, (which is the proper soil for the Peach,) they are liable to the attacks of the worm, which eats into their roots, and barks the trees all round, until they completely destroy them. No better method of destroying these worms has been discovered, than simply digging round the trees, and examining the infested plants, and where gum is seen onzing out, there the worm may be generally found and destroyed.

"I think an effectual remedy against this intruder may be found, by budding Peaches and Nectarines on the common bitter Almond Stock. The worm does not like this stock. Peaches will take on it, and grow nearly as free as on the common Peach stock. Thirdly. The Peach stock causes the Peaches and Nectarines to grow too rapidly, making very strong shoots, these producing secondary or lateral shoots; and the fruit of the following summer is produced on the top of these lateral shoots, instead of being produced on the principal or first shoots; this causes naked wood at the bottom, and a straggling, unsightly tree, whose branches being heavy at the top with the fiuit, are broken down by high winds. Fourthly. In addition to all this, the trees are of late years subject to what has been deemed a disease called the yellows, from the circumstance of the trees having a yellow and sickly appearance. Much curious philosophy has been spent on this subject without arriving at any satis. factory conclusion."

Mr. Floy, after discovering that the Almond stock is susceptible of injury from our Northern winters in extreme cold weather, farther recommends the Plum stock in cold latitudes, and the Almond for our Southern States. Hear him :

"The Plum stock is undoubtedly the best for Peaches and Nectarines in the Northern and Eastern States, but especially for open dwarfs or espaliers, for which I give the following reasons: First. The Plum stock prevents tho 
too rapid growth of the shoots, and causes the principals to bear the fruit the following season, instead of producing lateral shoots the same season, and causing the tree to be more dwarf; the branches strong and fruitful to the bottom of the shoot, thereby having more fruit in a smaller compass. Secondly. It makes harder and less pithy wood, and enables it the better to withstand the cold; and this may be easily proved by cutting the branches of each : the shoot on the Plum stock will be twice as hard and firm as the one on the Peach stock; but, Thirdly, and the most important reason is, that the Plum ceases to send up its sap early in autumn, causing the Peach to perfect its wood befordo the cold weartere sets in."

As the failure of this fruit of late years has elicited con-? siderable discussion and observation, which increasès in interest annually, I will offer an exposition of my views on the subject, by a comparison between vegetable and animal matter, which I humbly conceive bear a striking analogy to each other. If the reader should deem my arguments visionary, or speculative, I would remind him that the grave importance of the subject fully justifies this or any othes attempt at elucidation.

Having, in article Nectarine, shown the error of deep planting all descriptions of trees and plants, I would here observe, that a tree brought into a state of disease, by which the circulation of its nutrimental juices is impeded, and its hark injured, is very similarly situated to a timber post inserted in the soil; which every one knows will rot between earth and air, however sound its other parts may be.

In venturing a comparison between vegetable and animal matter, I would first reter the reader to article Chestnut, where I have shown that a chestnut tree has been known to live over a thousand years; and that its timber, cut in proper season, is supposed to be in durability commensurate with the age of the growing tree. It is also recorded in history, that animal subjects preserved on the Egyptian principle, 
have been known to keep as long as the most durable tim. ber; while daily experience shows, that corrupt animal and vegetable substances, not only become a prey to the most noxious insects and reptiles, but will generate them in incal culable numbers.

It is also evident, that a tree deprived of its functions or means of growing luxuriantly, is in a similar situation to a diseased animal. If disease be not checked before the juices of the tree become putrid, it will not only die, but will contaminate the earth in which it is planted, to the destruction of its neighbouring inmates of the garden or field. All experienced rurserymen admit this to be the case with diseásed Peach treès," and șome have actually abandoned their

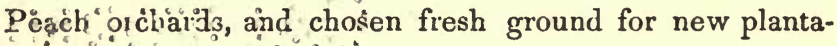
tions.

It is precisely the same with smaller vegetable plants. A diseased Cabbage, for instance, by its excremental and corrupt juices being spent in the ground, will render the cultivation of the same or allied species a casualty; and daily observation teacheth, that young and thrifty plants often fall a prey to worms and reptiles which were generated by a previous crop.

It is, moreover, evident that all those enemies of the vegetable family feed on the same descriptions of vegetable matter which first generated them; hence the Peach insects feed on its fruit in embryo, as well as in a state at, and even beyond, perfection; the Cabbage worms prey on plants of the same genera or species; and I have no duubt but the cotton worms prefer the same description of vegetable matter which gave them birth, and that when these insects and reptiles cannot obtain the parts which are the most palatable to them, or congenial to their nature, they will feed upon diseased trees, plants, or any other matter which contain similar juices or nutriment. I again repeat, that the best security against their depredations is health and soundness. A good sound healthy tree, planted and cultivated upon cor- 
rect principles, may be justly considered as invulnerable to the attacks of insects and reptiles, as any species of healthy animal creature in existence.

As I have been more familiar with the cultivation of vegetables than fruits, I would state farther my views relative to the Cabbage tribe. On New-York Island, in the vicinity of the city, it is customary with gardeners to cut their Cabbages gradually as they are required for market, and often to leave their roots standing; these by some are ploughed under, where they not only feed, but geverate their peculiar species of insects. Some gardeners take their roots and leaves to the cattle yard or dung heap, and return them back to the garden the ensuing season in the shape of manure. As a consequence of such practice, good Cabbages are very seldom obtained, even after a routine of other crops, for two or three years.

With a view to illustrate the evil of deep planting, I would observe farther, that when Cabbage plants are transplanted in proper season and on good fresh soil, they generally prove uniformly good; whereas, if it should happen, as it sometime does for want of suitable weather, that the plants cannot be transplanted until they get crooked and overgrown, so as to require deep planting to support them in the soil, such plants, like diseased Peach trees, decay first in the bark, between earth and air, and then, from being deprived of a natural circulation of the vegetable juices, die, and discharge their putrid matter in the earth, to the destruction of such other plants as may be inserted in their stead. I have frequently known a land of Cabbage plants filled up half a dozen times, and the crop at last scarcely worth gathering, whereas, could the plants have been set out while dwarfish, and inserted their proper depth in the ground, the cultivator would have been rewarded a hundred fold.

I dislike tautology, but cannot avoid repeating my humble opinion, that deep planting and injudicious culture are the causes of most of the diseases and failures of fruit trees; and 
in this way $I$ account for Peaches being less plentiful than they were when left almost to nature, which was the case, I am informed, in the beginning of the present century. That this malpractice in horticulture is very general, the most superficial observer may discover, by comparing the thrifty growth of those trees scattered by nature in our highways and byways with many of those aided by the art of man. If any of my readers should require proof of my assertions, I can show them from the window of the room where this article is being written, scores of living, or rather dying evidences of the evil of deep planting.

All the varieties of the Peach produce their fruit upon the young wood of a year old, the blossom buds rising immediately from the eyes of the shoots. The same shoots seldom bear after the first year, except on some casual small spurs on the two years' wood, which is not to be counted upon. Hence the trees are to be pruned as bearing entirely on the shoots of the preceding year, and a full supply of regular grown shoots must be retained for successional bearers. Cut out the redundant shoots, and all decayed and dead wood, and reduce some of the former bearers, cutting the most naked quite away.

A Peach Orchard may be planted at any time after the bud is established, until the trees are three or four years old, which may be placed from fifteen to twenty feet from each other, or from any other spreading trees. The dwarf kinds may be introduced into the kitchen garden, and trained against fences, as directed for the Ápricot, or as espaliers, or dwarf standards. 


\section{SELECT DESCRIPTIVE LIST OF PEACHES.}

\section{FREESTONE PEACIES.}

Astor. An excellent variety, originating in the city of New-York; the fruit is above medium size; skin pale yellow, with red cheek ; flesh melting and pleasant flavoured; juice sweet and plentiful; ripe the latter end of $A$ ugust and early in September.

BuERs's RED RARERIPE, Middleto:"n late Red Rareripe. Fruit very large, of oblong shape; skin nearly white, with a red cheek; flesh firm, juicy, and high flavoured. This variety originated with Joseph Beers, of Middletown, New-Jersey; it ripens there from the middle to the end of September, and is represented as a good market fruit.

Belle de VITRY, Admirable Turdive, Bellis, Beauty of Vilry. A large fruit, of fine red colour next the sun, on the opposite side a yellowish white; flesh white, stained with red at the stone; firm, juicy, sweet, vinous and excellent; ripe early in September.

Bellegrade, Galande, Violette Hative, Noire de Montreuil. Smooth Leaved Royal George of some. The tree is vigorous and productive; fruit above medium size, globular; skin greenish yellow, and on the sunny Eide rich deep red, with dark purple streaks ; flesh pale yellow, very melting, saccharine and juicy; a first rate fruit, early in September.

BUONAPARTE. A fine early variety, introduced by Joseph Buonaparte, and recommended by Caleb $R$. Smith, of Burlington, New-Jersey, as being the best market fruit known at that place; its colour is red, mottled with yellow; flesh melting; juice sweet and delicious, in August.

Brevoort's Seedi ing Melter, Brevoort's Morris. A superior Peach, raised by Henry Brevoort, Esq., of New-York; skin of a dingy white colour, with red cheek; flesh white, firm, rich, and sugary; ripe by the middle of August.

Columbia. Fruit of medium size; skin rough and thin; colour dull red; flesh yellow, fibrous, similar to a pineapple, juicy and rich. It is supposed that this Peach originated with Mr. Cox. It is a singular variety.

Cooledge's Favourite, Cooledge's early Red Rareripe. A large handsome globular fruit; skin red, tinged with crimson; flesh very melting, juicy, and of delicious flavour, in August. The tree is vigorous and very productive.

Crawford's Early Melocoton, Early Crawford. Fruit large, oblong; skin yellow and red; flesh yellow, juicy, sweet, with an agreeable acidity. It originated with Mr. Crawford, Middletown, New-Jersey. The tree is a great bearer, and the fruit is considered one of the most marketable varieties, in August and September.

Crawford's Late Malacatune. Fruit very large, round; skin yellow and red; flesh yellow, sweet, juicy, and excellent. It is highly estimated at Middletown for its productiveness and adaptation for market; in Septemiber and October.

Doubl.e Montagnw, Sion, Eearly Double Mountain, Montauban. A beautiful and excellent Peach of middle size; skin greenish white, but sof red, marbled with a deeper red next the sun; flesh white and melting juice plentiful and highly flavoured; ripe in August. 
Eardy Orange, Orange Freestone, Yellow Rareripe, Yellow Malacaton, Golden Rareripe, Eurly Yellow. Fruit undex a medium size, inclining to the oval shape, apex full, with a small tip; akin greenish yellow; flesh a fine yellow; juice rich and sweet, but not plentiful; ripe in August and September. There are several varieties under the same name, some of which are inferior to the true Orange Peach.

Early Royal George. Red Mugdalen of Prince. A superior variety, of medium size, and rather globular furm ; skin yellow, with red cheek ; flesh melting and delicious; in August. There are several varieties cultivated under this name, differently described.

EAstburn's Chorce. Fruit large, nearly round ; skin pale yellow, with a red blush ; flesh yellowish white; juice exceedingly pleasant and sprightly ; in September and October. The tree is represented as hardy, luxuriant and vigorous, by the Editor of Hoffy's Orchardists' Companion of Philadelphia, from whence this description is taken.

Emperor of Russia, Serrated Leaf, New Cut-Leaved Unique. The fruit of this species is deeply cleft, one half of it projecting considerably beyond the other; the skin is downy, of a brownish yellow and red colour; flesh melting ; juice sweet and delicious; towards the end of August. This sort was found by Mr. Floy, in New-Jersey, 1S09, and all the stoncs of this fruit are said to produce plants with jagged leaves.

George the Fourth. An excellent Peach, of medium size and globular shape; of pale yellow colour in the shade, and dark red next the sun; flesh yellow, but red at the stone, from which it separates; a fruit of very superior flavour when at maturity, which is early in September. It originated in the garden of Mr. Gill, Broad-street, New-York.

Green Nutmeg, Early Anne, Avant Blanche. This early variety is said to have originated in Berkshire, England. The fruit is small; its colour yellowish green; its pulp melting, juicy, of very pleasant flavour, and ripens in July and August. Murray's Early Anne is a variety raised from the seed of this. It is esteemed for its early maturity.

Grosse Mignonne, Veloutee de Merlet, Grimu'ood's Royal George, Large French Mignonne, Vineuse, according to Lindley; and the following synonymes are added by Kenrick: Belle Beaute, Smnoth-leaved Royal Gearge, Royal Souveruin, Pourpre de Normandie, Royal Kensington, Early Vineyard, Transparent, and Morris's Red Rareripe. One of the most beautiful and delicious varieties in cultivation. Fruit large, depressed, hollow at the summit, with a deepish sature; skin rather downy, of rich deep red, thickly mottled on a yellowish ground; flesh pale yellow, rayed with red at the storse melting, juicy, and of a rich vinous flavour, when in perfection, which is early in September.

HeAth FreEstone, Kenrick's Heath. This variety was first obtained from the late General Heath, of Roxbury, near Boston. The fruit is very large, oblong and beautiful, frequently weighing half a pound; colour pale yellowish green, with crimson or violet next the sun; its flesh is melting, juicy, rich, vinous, and agreeably acid; ripens in September and October.

Hoffman's Pound, Morrison's Potınd, Hoffman's Favmırite. This fruit is by some called the Morrissania, from its having been first obtained by Mr. Floy from Governeur Morris; but it originated with Martin Hoffman, Esq., of New-York. The fruit is very large; skin brownish white 
and red; flesh yellow, firm, very juicy and delicious, parting from the stone; greatly esteeemed from its ripening late in September and October.

Late A durable, Royale, Rıyul, Bourdine. Tetim de Venus of Prince and Downing. Fruit large, roundish, inclining to oblong; sature deeply impressed along one side, having the flesh swelling boldly and equally on both sides, with a slight impression on the summit; skin downy, of pale green colour, streaked with dull tawny red; flesh white, delicate, melting, juicy and high flavoured; a magnificent Peach, ripening in September.

Malta, Peche Multe, Belle de Paris, Multe de Nurmandie, Italiun Peach. Fruit above the medium size; colour pale yellowish green, marbled with purplish red; flesh yellow, juicy, rich, vinous, and of superior flavour; ripens at the end of August.

Madelein s de Courson, Madeleine Rouge, Rouge Faysanne, Red Magdalen. Royal George, and New Royal charlotte of some collections. An excellent fruit, of large size ; colour yellow and red; ripens at the end of August ; flesh firm, white, but red at the stone; sugary and rich.

Monstrous Lman, Largest Lemon. This variety was first discovered in the garden of Mr. Tiebout, now Union Place; the fruit is of the largest size, and in the gardens of two persons in New-York. has weighed seventeen ounces, as stated by Mr. Prince, who says that the tree requires a sheltered situation, and that the fruit is late in ripening; October.

Morris's Red Freestone, Red Rareripe. Grosie Mignonne, and Royal Kensington according to Prince. Fruit nearly round, of large size, apex a little sunken; skin greenish yellow, with red cheek; flesh delicious and melting; a first rate var.ety ; ripe toward the end of August.

Morris's White Freestone, White Rureripe, Luscious White Rareripc, Philadelphia Freestone. Lady Ann Slewart of Downing and Prince. Fruit large, and inclining to the oval form, sature even, but not deep; apex a little sunken; skin white or rather yellowish; flesh white, juicy, rich and sweet; ripe in September.

Neil's Early Purple, Early Purple of Miller, Johnson's Purple Avant, Padley's Early Purple, Veritable Pourpree Hative, Peche du Vin. One of the most beautiful of Peaches, of medium size ; skin yellow, but on the sunny side of a fine deep red and purplish colour; it ripens by the middle of August; flesh melting, juicy, with a rich vinous flavour; an excellent fruit.

New Royal Chartotte, Queen Charlotte, New Early Purple, Kew Éarly Purple. A delicious Peach, rather above medium size; skin pale greenish white, with deep red next the sun; flesh greenish white, rich and agreeable; ripe in $\Lambda$ ugust.

Noblesse, Mellish's Fuvourite. Vanguard of Prince and Winter. The tree is of a vigorons growth, and very productive; fruit large, somewhat oval, of a pale red colour, marbled with different shades; pulp juicy, rich, and melting when at maturity, which is in A ugust and September.

Prnidient This variety originated at Bedford, on Long Island. It is a rich, melting. juicy fruit. of large size. roundish, with a shallow sature; skin very downy, dull red next the sun. pale yellowish green in the shade; the surface covered with small red dots; a first rate Peach; ripe in September.

Prince's Late Yer.low Freestone. A beautiful fruit, of a greenish yellow colour, tinged with red; flesh firm and rich. A partially ripe speci- 
men of this variety was exhibited by Mr. Prince in the Horticultural room of the American Institute, October 24th, 1843.

RARERIPE Y Elzow, Yellow ard Red Rareripe. Red Velvet, Large Yellow Nutmeg. M.rie Antinette of some. This variety is large; skin yellow and red; flesh firm, rich and delicious, in August and September. It is considered one of the most valuable market varieties.

Red Chef Malacatune. Huga's Milacitan, Alberge Incomprable, Lady Gallutin. Prubyn Peach. The fruit of this variety is of large size and oval form; its colour is yellow, with a red cheek on the sunny side; the flesh is also yellow, melting, rich, juicy, and luscious. 'There is another variety of this fruit, which originated with Mr. Polls, of New-York, said to bu very productive, and of excellent quality; ripens in September.

Rominson Cresoe, Eurly Rubinson Crusoe. Fruit large, round, and handsome; skin pale red, marbled with d.urk red; flesh juicy, sweet, and delicions; ripe in September. The stone from which this variety was raised, by Dr. Coxe. of Philadelphia, was brought by Lieutenant Coxe from the fur-famed Island of Alexander Selkirk, or Robinson Crusoe.

Sмоск Frгe, Smock's Freestone. An esteemed market variety, at Middletown, New-Jersey, where it originated, in Mr. Smock's orchard. Some specimens of the fruit have measured twelve inches in circumference. It is of oblong shape; skin pale yellow and dark red; flesh juicy, a little acid, nnd very palatable; in september and vetober.

Sweer W This variety is said to have originated at Flushing; its form is round, and its colour whitish green, with a red blush at maturity, which is early in August. The tlesh is very tender, melting, rich and jucy.

Teton de Venus. Ruyale of some collections. There are two or three varieties bearing this llame; the fruit of the best variety is large, globular, of a pale yellowish green colour, marbled with red; fiesh greenish yellow, but red at the stone; a delicious flavoured Peach; ripe in September.

VAN ZANDT'S SUPERB, Waxen Rareripe. This variety criginated with Mr. Van Zandt, of Flushing; its form is oval; its skin smooth, somewhat mottleit, and of a beautiful waxen appearance; flesh melting, and of excellent thavour; in August and September.

WAlter's EARI.Y. Fruit large; colour white in the shade, and red next the sun; flesh red, very juicy and delicinus. It is considered one of the most productive and early Peaches cultivated at Middletown, NewJersey, where it ripens abont the middle of August.

Washington РЕАсн, Bıyce Peach, Washington Freestone. Early $\boldsymbol{R}$ ise of some. A first rate Peach; colour a pale yellow in the shade, but pale red next the sun; flesh very juicy and delicious; ripens toward the end of August. A peculiar trait in this Peach, is its rapid growth; it will, while ripening, in about ten days, nearly double its ordinary size; weighing over half a pound.

Whit: Blossox, Willow Peach, Snow Peach, White Blossomed Incomparable. This variety originated on Long lsland; the fruit is perfectly white, of an oval form and handsome appearance; the flesh is also white, melting, juicy and pleasant; it is much used for preserves when not over ripe, and is at full maturity in september.

Yellow Admanee, Abricotee, Admirable Jaune, Peche d'Orange, Grosst Jaune, Peche de Burai, Sandalie, Hermaphrodite, Apricot Peach. 
The fruit of this variety is large; yellow while immature, but laved with red when ripe; flesh firm, yellow; flavour similar to the Apricot; ripe late in september.

Yellow Ar.Brige, Alberge Jaune, Peche Jaune, Roussanne, Saint Laurent Jaune, Petite Ruussanne, Rosanna. Purple Alberge, and Gold Fleshed of Winter \& Co. A middle sized globular fruit, of a yellow colour in the shade, with deep red next the sun; the flesh deep yellow, but red next the stone; melting, juicy, rich, sweet, vinous and excellent; in August.

\section{PAVIES, OR CLINGSTONE PEACHES.}

Brood Cring, Claret Clingstone, Red Velvet. Sanguinole of Prince. Bliod Peach of Winter \& Co. Fruit large, oblong, of a dark violet or crimson colour; flesh blood red to the stone; highly valuable for preserves, and by some deemed preferable to the Quince. The tree is very productive.

CATHarine. Rodman's Red, and Red Catharine of some catalogues. Fruit large,-round, variable; colour a beautiful red next the sun, marbled and dashed with darker shades; pale greenish yellow in the shade; flesh white, tinged with yellow and red; juice abundant, and of very rich and sweet flavour; tree a good bearer; its fruit ripens in September.

Congress Clingstone. Mr. Manning describes this as a fine large round Peach; skin yellowish white, marbled with red; flesh melting, juicy, rich and excellent ; in September.

Early Newington, Smith's Newington, New-York Early Newington. A much esteemed fruit; its colour in the shade is white, but next the sun red; its form is globular; its flesh is juicy, rich and high flavoured. The tree is productive, and the fruit matures in August.

Henth, Henth Clingstone, Late Heath, Late October. Mr. Prince says, that the original tree of this variety was discovered growing wild on the farm of the late Judge Willet, of Flushing, and took its name from its being found in a barren field. The fruit is very large, of oval or oblong form; the skin is downy, nearly all white; the flesh is peculiarly rich and highly flavoured, tender, melting and juicy. There is another variety mentioned by Mr. Kenrick, and called by the same name, said to have been raised from a stone brought by Mr. Heath from the Mediterranean,

Hrslop's Clingstone. The trees of this variety are vigorous and pro. ductive. The fruit is large; skin a yellowish white, with red cheek; flesh melting. juicy, sweet, vinous, and excellent ; it ripens in October, and will keep good till November.

Incompara ble, Late Admirable, Pavie $1 d$ mirable. The fruit of this esteemed variety is large and roundish; the skin pale yellow colour, shaded with scarlet or deep crimson next the sun; flesh pale yellow; juice sugary and well flavoured; ripe in September.

Lemon Chingstone, Kennedy's Carolina, Pineapple Clingstone, Hoyte's Lemon Clingstone, Lemon Largest, Large Yellonv Pineapple. This fruit is of large size and oval shape; yellow in the shade, but bright red next the sun; it resembles a lemon, having a nipple at the apex; some have weighed twelve ounces; its flesh is firm, and is at maturity in New-York by the end of September. 


\section{Monstrous Pavie on Pomponne, Gros Melecoton, Gros Perseque Rouge} Pavie Minstreux, Pavie Cornu. Fruit very large, roundish, with an obtuse nipple : skin downy, of a fine red and greenish white colour; flesh white, deep red at the stone, juicy and vinous, excellent for preserving; in Seplember and October.

New-York White Cringstone, Williams's New-York. New Neuington of some cataligues. Fruit large, round, with a pointed apex; skin white, tinged with rose ; flesh yellow, melting or soft, but adhering closely to the stone; juice very plentiful, sweet, luscious, and high flavoured; ripe in September.

Ord Mixon Clingstone. Of all clingstone Peaches, this is considered the most delicious; the skin is yellow, with a bright red cheek, marbled; flesh red at the stone, rich, juicy, swect, and high flavoured; the fruit ripens gradually in September. This variety is cultivated in Massachusetts, under the above name; but Mr. Manning says that he ha; cultivated this fruit with the Old Newington, and the Catharine, and could never perceive any difference in the fruit or trees.

Old Newington, Newington. The fruit of this variety is large, rather globular, of a fine bright red and pale yellow colour, marbled with dashes and streaks of a deeper colour; the flesh is yellowish white, but red at the stone; also juicy, rich, sweet and well flavoured; the tree is very productive ; in September.

Orange Cling, Round Alberge. A beautiful native Peach, of round shape, and bright yellow or orange colour; flesh orange colour, aromatic, rich, and juicy. The tree is a great bearer, and from the beauty of its fruit, which ripens in September, is entitled to extensive cultivation for the market.

Pavie Madelerne, Pavie Blanc, Melecoton, Myrecoton, Merlicoton, Persique a Gros-Fruit Blanc. The fruit of this variety is of medium size, somewhat broadly globular; skin pale yellowish white and marbled red; flesh yellowish white to the stone; juice sugary and of an agreeable flavour; towards the end of August and september.

Prince's Climax. Fruit very large, oval; skin yellow, mottled with crimson; flesh yellow, and of rich pincapple flavour; ripe in September, and good in October.

Selby's Cerng. Fruit large, highly esteemed; skin white and red; flesh melting, juicy, and of peculiar rich flavour; ripe in September and October.

Surock's Clingstone. Fruit very large, obłong; skin yellow and red; flesh juicy, rich, a little acid; it ripens in October at Middletown, NewJersey, and is considered one of the most productive and profitable late market fruits.

Tippecanoe Prach, Hero of Tippecanoe. This variety originated with George Thomas, of Philadelphia, and the fruit has been much admired at the Pennsylvania Horticultural exhibitions; it is of large size, of a beantiful yellow colour, with a fine red blush; flesh yellow, firm and juicy, possessing an agreeable acidity; it ripens late in September. A faithful description of this fruit, accompanied by a beautiful coloured plate, taken from nature, may be seen in Hoffy's Orchardists' Companion, No. 4. 


\section{PEAR.}

\section{Poirier. Pyrus.}

The Pear tree, in its wild state, is thorny, with upright branches, tending to the pyramidal form, in which it differs materially from the Apple tree. The twigs, or sprays, hang down; the leaves are eliptical, obtuse, serrate; the flowers in terminating, villose corymbs, produced from wood of the preceding year, or from buds gradually formed on the several years' growth, on the extremeties of very short protruding shoots, technically called spurs. It is found in a wild state in England, and abundantly in France and Germany, as well as in other parts of Europe, not excepting Russia, as far north as latitude 51. It grows in almost any soil. The cultivated tree differs from the Apple, not only in having a tendency to the pyramidal form, but also in being more apt to send out tap roots; it being, as a seedling plant, longer in coming into bearing; and when on its own root, or grafted on a wild Pear stock, much longer lived. In a dry soil, it will exist for centuries, and still keep its health, productiveness, and vigour. The Romans had thirty-six varieties in Pliny's time : there are now several hundreds in the French and British nurseries; the London Horticultural Catalogue contains the names of upward of six hundred varieties. Professor Van Mons, of Brussels, and M. Duquessie, of Mons, fruited about eight thousand seedling Pears, from which they obtained nearly eight hundred sorts worth cultivating, (Neil's Hort. Jour.) The varieties are divided by the French into different classes of fruits, which are desig. nated as Beurrees, Crevers, Poiree, \&c.

Criterion of a good Pear.-Dessert Pears are characterized by a sugary, aromatic juice, with the pulp soft and sub-liquid, or melting, as in the Beurrees, or Butter Pears, or of a firm and crisp consistence, or breaking, as in the 
Winter Bergamots. Kitchen Pears should be of a large size, with the flesh firm, neither breaking nor melting, and rather austere than sweet. Perry Pears may be either large or small; but the more austere the taste, the better will be the liquor; excellent perry is made from the wild Pear.

Pear trees are propagated by grafting in the spring, or budding late in the summer, and also by seed taken from the best sorts for the purpose of obtaining new varieties. In raising Pear stocks, the wild Pear is preferred in Europe, as being calculated to produce plants more hardy and durable than the cultivated sorts; and for dwarfing and precocity, the Quince is preferred.

The Pear is a much handsomer upright growing tree than the Apple; more durable, and its wood hard and valuable for the turner and millwright; but its blossoms being white, are less showy than those of the Apple.

A Pear Orchard may be planted at any time after the trees are two years' old from the graft; and as some varieties of trees from young stocks will not come into full bearing until ten or twelve years old, they will bear removing with care at any time within that period. They may be planted at from twenty to thirty-five feet distance from each other, according to the nature of the tree. The dwarf varieties may be planted in the kitchen garden, and trained either as espaliers or dwarf standards.

Standard Pear trees will require but little pruning after the heads are once formed; in doing which, the branches should be permitted to extend on all sides freely. Several years may elapse before any cross-placed, very irregular, or crowded branches, require pruning; yet there are sorne kinds whose form of growth resembles the Apple; such will need frequent pruning. "The Pear tree," Mr. Phail says, "does not produce blossoms on the former year's wood, as several other sorts of trees do. Its blossom buds are formed upon spurs growing out of wood over one year old, and, consequently, projecting spurs all over the tree must be left 
for that purpose." In some Pears, Knight observes, "the fruit grows only on the inside of those branches which are exposed to the sun and air; in others it occupies every part of the tree." Withering says, that " the French make perry, or poive, from the fermented juice of the Pear, which is little inferior to wine; and that even the bad eating kinds, pared and dried in an oven, will keep several years with or without sugar.

Before I introduce the descriptive list of Pears, it may be necessary to inform my readers that a controversy has lately existed among justly celebrated pomologists and nurserymen, with regard to some of the old varieties of l'ears and other fruits ; the consequence of which has been, that several cultivators are for an indiscriminate rejection of all the oldest varieties, while others contend that in some districts the old fruits are as good as they were ever known to be, and consequently deserving of cultivation as heretofore. It is recorded in 'Loudon's Encyclopœdia,' that the Autumn Bergamot for instance, has been cultivated and highly esteemed in England since the time of Julius Cæsar, nearly nineteen centuries. This fact is my apology for retaining such of the old varieties of the different fruits in my descriptive list, as have been most celebrated. The following extracts are from the catalogue of Messrs. Winter \& Co., proprietors of the old Linnæan Botanic Garden and Nurseries, Flushing, Long Island :

"That some of the fine old varieties of the Pear have deteriorated in some parts of the country, is unquestionable; this is ascribed to various causes; first, that the varieties have run out, as it is termed; second, to the use of diseased stocks, or scions from diseased, or aged, or unthrifty trees, or both; third, to the deleterious influence of the salt air, near the seaboard; fourth, to the want of proper attention to soil and culture. We cannot subscribe to the soundness of the reason first assigned; there are too many instances of varieties of fruit whose origin is so remote that it cannot be 
traced, still continuing in full vigour; and the kinds which bave deteriorated in some sections of the country, still maintain their celebrity in the interior, and more especially in the virgin soil of the west. Which of the other causes as signed, has tended to deteriorate the fine kinds alluded to, we will not undertake to determine; one or more of them may have had their influence, but we think that proper attention to propagation, soil, and culture, may in general, if not in every instance, restore the valuable old varieties to their pristine excellence; and in this vicinity there is decisive evidence of the improvement of that superior old variety the White Doyenne, Saint Michael, or Virgalieu."

The last line of the above extract leads me to remark, that so celebrated has been the Pear therein alluded to, that it has been cultivated throughout the civilized world for centuries, under numberless different names. In 'Lindley's Guide to the Orchard and Fruit Garden,' fifteen synonymes are added to the general head, White Doyenne; some of which names are still retained in the catalogues of those who profess to denounce the old fruits as "outcasts." In fact, the various catalogues are become so complicated from the above causes, that I have, to avoid discrepancy, occasionally adopted some of the names as synonymes, of what, to me, appeared to be distinct varieties; and with a view to lead the reader to judge for himself in such cases, I have appended the names of the different nurserymen to the articles, who being practical men of good judgment, and integrity, are entitled to such distinction. These remarks are intended to apply, not only to Pears, but to other species of fruit in the various descriptive lists. 


\title{
SELECT DESCRIPTIVE LIST OF PEARS.
}

\author{
SUMMER FRUIT.
}

Aн' Mon Dreu. A beautiful Pear, introduced by J. B. Mantel, of Bloomingdale, New-York. It is depicted in 'Hoffy's Orchardists' Companion, by a handsome coloured plate, accompanied by the following description: Size medium ; form handsome ; colour rich yellow, with bright red cheek; flesh juicy; flavour sweet and perfumed. Tree vigorous and productive, the fruit growing in clusters of fuur or five together.

Amire Joannet, Early Sugar. This fruit is described by Mr. Manning as small, of oblong form ; light yellow skin, with a small portion of red; flesh white, and when not overripe juicy and good. It ripens in July, about ten days before the Petit Muscat, to which it is superior in flavour.

Belle de BruXelles, Beauty of Brussels, Cours Complet. A large early Pear of pyramidal form; skin a beautiful clear yellow, with red cheek; flesh white, fine, and of an agreeable flavour; ripe early in August.

BeURRE D'Amanlis. A fine early Pear, imported from France by J. B. Mantel, of Bloomingdale, New-York; and described as follows, in 'Hoffy's Orchardists' Companion :' Size large; form large bellied; colour green, changing to yellow, with a fine blush when fully ripe, and russet spots; flesh melting. juicy, sweet and excellent; ripe in August and September. Tree vigorous and productive.

Bloodgood Pear, Early B.urre. Fruit large ; form nearly oval; skin a dull yellow, covered with dark russet spots; flesh tender, melting, and pleasant. Mr. Manning says, "It comes early into bearing and produces abundant crops every year ; in August."

Crawrord, Early Craifford. A fine early Scotch Pear, of medium size, round at the eye, diminishing at the stem; the skin is entirely of a light yellow; the flesh juicy, tender, and good. Mr. Manning says that the tree comes into bearing young, and ripens its fruit in A ugust.

DEARBORN'S SEEDLING. This variety originated in the garden of the Hon. H. A. S. Dearborn, of Roxbury. The tree is of vigorous growth; fruit of medium size, rounded at the crown, and regularly diminishes in a parabolic manner to the stalk; the skin is smooth, thin, green, with russet spots; at maturity it turns to a delicate yellow; flesh very melting, and of the finest flavour; in August.

EARt.y Rousselet, Rousselet hatif, Early Catharine. This is a small Pear, with a long curved neck; skin yellow, with brownish russet; flesh very fine, rich, and high flavoured; in August and September. The treo yields immense crops.

Honey Pfar, American Honey. This Pear in size and shape resembles the Seckle; the skin is yellow, with a large portion of dull red; the tlesh sweet, juicy and good. Mr. Manning says the tree bears young, and bids fair to be very prolific.

Jargon rlle, English, Beau Present, Saint Sampson, Grosse Cuisse Madame, Saint Lambert, Poire des Tables des Princes. Fruit rather large, oblong, of a pale green colour, a little marked with red; flesh melting, juicy, with a slightly acid, rich and agreeable flavour. It ripens early 
in A ugust, is one of the most productive of all Pears, and the very best in its season.

Julienne of Coxe, L'Archiluc d'Ele, Summer Beurre, Summer Duyenne, Summer St. Michael, of Boston. Bloodgood Pear of some collections. Fruit medium size, smooth, bright yellow at maturity, with a faint blush next the sun; form rather ovate. tapering toward the stalk; flesh perfectly melting, rich. and juicy. The tree bears young, and most profusely, and matures its fruit in $\Lambda$ ugust and september.

Madeleine, Magdalene, Citron des Curmes, Eırly Chaumontelle. This Pear is of medium size, pale yellow, with an occasional blush next the sun ; flesh white, melting, perfumed. A fine early fruit, ripening in July and August. Mr. Manning considers this a very good Pear; he says the tree bears well every year.

Rousselet dE Rheims, Musk or Spice Pear. Fruit small, pyramidal, greenish yellow at maturity, but brown red next the sun, with russetty spots; flesh half beurre, fine, very perfumed. Good to put in brandy, and to dry; in August and September.

Sabine d'Ete, Bellissime d'Amour, Epargne of the French. English Red Cheek. This Pear is of pyramidal form, terminating in a round blunt point at the stalk; colour yellow, but fine scarlet next the sun; the whole surface smooth, regular, and polished; flesh white, melting, juicy, and highly perfumed; the tree is an abundant bearer, and ripens its fruit in A ugust.

Stevens's Genesee Pear. A specimen of this Pear was fnrnished the Orchardists' Companion, from Wm. Reid's Nursery, at Murray Hill, NewYork. It appears by the plate, to be a beautiful Pear, of large size, and rather of an oblong form; its colour is mellow green, with russet blotches; its flesh is represented as white, juicy. and melting ; flavour sprightly, rich, and very delicious. Time of ripening, toward the end of August.

Skinlrss Pear. Puire sans peau, Fleur de Guignes. A small oblong Pear; the skin, which is very smooth and thin, is pale green, marbled with red and yellow ; flesh crisp, sweet, and of pleasant flavour. The tree is very prolific, ripening its fruit in August.

Summer Francrial, Fruncreal d'Ete, Fondante, France Cannel, Gros Micet d'Ete, Milun Blanc, Prebles Beurre. Fruit above medium size; shape oblong; thickest about one-third from the eye; skin yellowish green; flesh melting. rich and excellent; ripe early in September.

Summer Melting. Sunimer Beurre, Fondant d'Ele. An excellent summer Pear, of pyriform shape; colour yellow, tinged with brownish red ; flesh soft, melting, and sweet. The tree bears young, and ripens its fruit in A ugust.

Summer Rosi, Thorny Rose, Epine Rose, Poire de Rose, Rosenbirne Kraft. A Pear of medium size, in form resembling an Apple; the skin is dull yellow, spotted with russet, and marbled with red; a very productive variety, ripening its fruit early in A ugust. Mr. Manning pronounces this a beautiful fruit. and the tree a great bearer.

Wricams's Boschretien, Bartlet. Williams's Early, Autumn Superb of Prince. This fruit originated with a Mr. Whetler, at Aldermaston, in Berkshire, England, but was subsequently extensively propagated by Mr. Williams, near London; hence its name. The fruit is large, oblong; the stalk thick and fleshy, an inch long; the colour at maturity yellow 
tinged with red; flesh whitish, very melting, and delicate; juice perfumed, sweet and abundant. Tree very productive, and fruit ripe early in September.

\section{AUTUMN FRUIT.}

ANDREws, Amory, Gi3son. Fruit oblong; skin yellowish green, with a dull red cheek; flesh melting, juicy, and high flavoured. Mr. Manning represents it as "a very valuable pear, producing its fruit early and abundantly." Ripe in September and October.

A Utum Bergamot, Common Bergamot, York Bergamot, Bergamotte d'Aulomne, Andreios. Fruit globular, depressed; skin rough, yellowish green, and du!l brown. with greyish spots; flesh pale, melting, juicy, sugary and perfumed; ripe in September and Octuber. This variety has been cultivated in England from the time of Julius Cæsar, and is still considered by unaryy a first-rate Pear in its seasor.

A UTUMn scrers. This is a large Pear, full and round at the eye, diminishing to a point at the stem; the skin is yellow, mixed with dull red; the flesh melting and good. Mr. Manning says it bears young; and that the fruit ripens in October.

Bect.e ex Bonne, Belle d'Flanders, Schone und gute, Gracieuse. Fruit very large, globular, depressed; the stalk long; skin greenish yellow, but next the sun yellow, with spots of russet; flesh white, sweet, exceeding rich and ayreeably perfumed. The tree is very productive, and the fruit ripens in September. This variety has been cultivated under the erroneous names of Charles 'A'Atriche, Belle De Bruxelles and Bergamolte Crussunne, which are distinct fruits.

Beice Lucrative, Fondante d'Automne. A beautiful Flemish Pear; middle sized, roundish, tapering at the stalk; skin yellow, slightly russetted, and tinged with pale red; flesh melting, sweet and juicy, with a sliglt musky perfume; early in October. Mr. Manning considered this variety as worthy of a place among the choisest collections.

Brunre Bosc, C'alebasse bosc. Fruit large and very long; terminated with a crown, near three inches in diameter; somewhat calabash-formed; skin gray fawn colour, but russetty yellow at maturity; flesh white, melting, highly flavoured, and delicious; it ripens in October.

B̈LEKer's Mendow, Large Seckel, of Prince. Meadow Pear of Winter \& ( $\%$. A native fruit of medium size, roundish form, and of a yellow colour, tinged with dull red; the flesh melting. juicy, sweet, musky, and of delicious flavour; ripe in October. A prolific bearer.

Brown Bevr Roi, Beurre d'Ambitse, Isımbert, Red Beurre, Golden Beurre, Poire d'Amboise. This was formerly considered the best of all Pears in its season. Fruit rather large, of greenish yellow, and dusky red colour, covered with thin russet; flesh melting, buttery, rich and excellent; at perfection in October and November.

CApiamont, Beurre de Capiaumont, Calebasse vass. This variety is much esteemed in the vicinity of Boston. Fruit of medium size; skin yellow, tinged with fine red or cinnamon; flesh yellowish, melting, verv rich and high flavoured; in September and October. 
Carshear. A medium sized Pear, much cultivated near Providence, Rhode Island; the shape is rather globular; skin a light cinnamon russet; flesh white, melting and juicy. The tree bears well, says Mr. Manning, and the fruit ripens in October.

Charles d'Autriche, Gracieuse. Charles of Austria. A fine and beautiful fruit, large, three and a half inches long, and three inches broad; colour greenish yellow, with brown spots, and partially russetted; flesh white, melting, juicy, and delicious ; ripe in October, and good in Novem. ber.

Cumbrrland. A native fruit from Cumberland, Rhode Island, of large size and oblong shape; skin orange colour, with bright red cheek; the flesh melting, juicy and good ; ripe in October. The tree is of vigorous growth, says Mr. Manning, and bears abundantly.

Cushrng. A native fruit from Hingham, Massachusetts; of medium size and oblong shape; skin, when ripe, smooth, of a light yellow, mottled with dull red on one side; flesh white, melting, sprightly and good. $\mathrm{Mr}$. Manning says it comes early into bearing, and produces plenty of fruit in September and October.

Delices d'ARden pont, Delices d'Hardenpont de Toulouse. Beurre d'Ardenpont of some. Fruit above medium size; oblong, pyramidal; skin yellow at maturity, and partially covered with a thin cinnamon coloured russet; flesh yellowish white, nearly melting; juice pleasant, sweet, and abundant ; in October and November. The tree is a good bearer.

Dix. A native variety originating in the garden of Mr. Dix, in Boston; fruit large, oblong; skin, when ripe, yellow, with a blush of red; flesh melting, juicy and rich ; in October and November.

Doyenne Santelete. A new, fine, handsome Flemish Pear; fruit above the middle size, pyramidally oblong; skin pale green, speckled with grcy russet; flesh white, a little gritty, but tender; juice saccharine, with a slight musky perfume. The tree is hardy, and ripens its fruit early in October.

Duchess of Angouleme, Duchesse d'Angouleme. A rear of first-rate excellence. Form roundish, oblong, tapering towards the stalk; skin dull yellow, with broad russet patches ; flesh white, rich, melting, very juicy, and high flavoured, with a most agreeable perfume. Specimens of this fruit have been shown in England, weighing twenty-two ounces; at perfection in October and November.

Fremish Benuty, La Belle de Flanders. Imperatrice de la France. Brilliant, Bosch, Bouche Nuuvelle. A fine Flemish Pear in great repute; it is of large size, obovate, obtuse at the stalk; greenish yellow russet, tinged with crimson; flesh rather firm, yellowish white, sweet, rich, and excellent ; it ripens in October.

Frenerick of Wurtemberg, Roi de Wurtemberg, Capiaumont of some collections. A large and splendid Pear, of pyramidal form and fine yellow colour, covered with beautiful crimson on one side ; flesh melting, and of delicious flavour. The three bears while young, and very abundantly.

Fultor. A fine Pear of medium size, raised from seed by Mr. Fulton, of Topsham, Maine; shape roundish turbinate; skin dark yellow ; russetted; flesh melting, juicy, and of delicious flavour; ripe in September, 
and lasts a mnnth. The tree is a great and constant bearer, and highly deserving of cultivation.

Gansel's BERgamot, Broca's Bergamot Ives's Bergamot, Bonne Rouge. Fruit varying from middle size to large; ovate flattened; colour dull green, slightly red noxt the sun; flesh white, melting, sweet, rich and high flavoured. A deliciuus Pear; ripe in October, and good till Christmas. Mr. Manning says that this variety was introduced in 1766 , and as yet shows no sign of decay.

GOLdEN BEURRE OF BILBOA. This variety was imported from Bilboa, by Mr. Hooper, of Marbleltead; the original name being unknown. Fruit of medium size, oblong; colour a bright golden yellow, with patches of russet; perfectly melting, and of fine flavour. A beautiful Pear tree, a great bearer, and worthy of cultivation; ripe in October.

Gor E's HкAтнсот. A native variety, highly esteemed in Massachusetts. Fruit of medium size; form long; skin of a uniformly light yellow; flesh melting, juicy, and high tlavoured. The growth of the tree is handsome and vigorous, producing abundant crops in September and October.

Green Syı.vange, Sylvange Vert, Bergamotte Sylvange. A most superior Pear, of medium size, skin rough and green, speckled with grey or black. The flesh is greenish near the skin, whi'e in the centre, soft, saccharine and juicy; fruit in perfection from October to Christmas. The tree is a great bearer, and specimens of the fruit bave been known to weigh thirteen ounces.

Hacon's Incomparable, Norfolk Seelling. Downham Seelling of Winter \& Co. Fruit nuiddle sized, of pale yellow colour, mixed with grcen, partially covered with orange russet; flesh yellowish white, slightly gritty, but very tender, juicy, sweet and rich; and possessing a high musky and pertumed tlavour. The tree is a great bearer, and the fruit excellent; in November and December. A silver medal was given to the originator of this fruit, as a prize, in England, 1830.

HarVard, L'Epergne, Buston Epargne. This variety is highly prized in the Bustọn markets; fruit above medium size; oblong, swollen at the crown; skin russetty yellow, tinged with red; flesh white, juicy and melting ; in September and October.

Henry the fourth, Henri Quatre. Fruit of medium size; oblong, skin a dull yellow, mixed with brown and green; flesh yellow, rather gritty, juicy and meiting, with a peculiar rich flavour; ripe in september and Uctober. Mr. Manning says the tree bears while young, and abundantly.

Long Green of Autumn, Verte Longne, Mouthwater. Mr. Manning says that this is one of the best of the old varieties; its form is very long; skin at maturity a light green; flesh white, melting. and rich flavoured The tree is of vigorous growth, bears well, and the fruit is ripe in September and October.

MARIE Lourse, Marie Chretienne. Fruit oblong, tapering towards both ends; size varying from medium to large; skin nearly smooth, yellowish green, and cinnamon coloured russet; flesh white, melting. juicy, and rich. It ripens in October and November, and is an excellent fruit in its season.

Moor Fow EgG. Fruit rather small, globular, ovate, swollen in the middle; skin orange brown next the sun, with spots of russet; flesh yel- 
lowish white, a little gritty, but tender and mellow, juice saccharine, a little perfumed. This is a hardy Scotch variety; ripe in September, and good in October

Na Poleon, Medaille, Sauvagenn Liart. Roi de Rome, and Wurtemburg of Prince. Fruit large, form of the Colmar; skin smooth; colour bright green, but at maturity pale green; flesh very melting. with an unusual abundance of rich agreeable juice. At perfection in October and November

Puincesse or Orange, Princess d'Orunge, Princess c mquetle. 'The fruit is roundish; the skin bright reddish orange russet; flesh yellowish white, sugary and rich, in some seasons pertectly melting, but occasionally a little gritty. A beautiful Pear, and of good quality ; in October.

SEckLE, Neu-York Red Chtek, Red Cheek Seckle, Sycle. An excellent native fruit, in size rather small; colour varying from yellowish to brownish russet, but bright red next the sun ; flesh melting, spicy, and of a most extraordinary rich flavour. This frnit grows in clusters, in great abundance, and is at perfection in September and October.

Swan's Egg, Muor Fulul Egg if Boslom. Fruit small, of an oval, turbinate figure; colour yellowish green, and dull russetty brown ; Hesh tender and melting, with a rich, sacharine, musky flavour. An excellent fruit; ripe in October. The tree is remarkably tall, upright, vigorous, and productive.

URBANISTE, Beurre du Roi. The fruit is of mediam size. pyramidally ovate; skin pale green, inclining to yellow, with green streaks; flesh white, but reddish yellow next the core; it is quite melting, juicy, and very sweet, with a little perfume; it ripens from the niddle of september to November.

W Ashrngton. A native fruit from New Jersey, of medium size and oval form; the skin is light yellow, covered with small brown spots, with a tinge of red; the flesh melting, and of excellent flavour. Mr. Manning says the tree bears well, and is worthy of general cultivation; fruit ripens in September.

Whrte Doyenne, Doyenne Blanc, Beurre Blanc, Bonne ante, St. Michael, Carlisle, Citron de Septembre, Kuiserbirne, Poire a conte q'ıeue, Poire de Limon, Poire de Seigneur, Poire Munsieur, Vultercia, White Beurre, Virgulieu of some collections. Fruit pretty large; roundish ob. long; skin pale citron yellow, with cinnamon russet, speckled; flesh white, juicy, very buttery, and delicious; ripe in September and October. An old, and once celebrated variety, still admired by many, although excluded from some nurseries, or cultivated under new names.

WIIxinson. A native Pear from Cumberland, R. I. The tree bears young, and is very fruitful; size above medium; form oblong; skin yellow, with a brownish blush near the sun; flesh white, juicy, and melting; at perfection in October and November.

\section{WINTER FRUIT.}

Beurre D'Arembero, Beurre d'Arembert, Duc d'Aremberg, Poire ¿Aremberg, Beurre Deschamps, Beurre des Orphelins of Deschamps, Colmar Deschamps. The English and French writers speak of this Peas 
as one of the best in cultivation. The tree is a great bearer, comes early into cultivation, and the fruit will keep till March. Fruit large, turbinate skin of a delicate pale green, dotted with russet, which becomes of a deeper yellow at maturity ; flesh whitish, fine, very juicy, perfectly melting, and rery extraordinarily rich, stveet, high flavoured and excellent.

Brunke Dren, Diel's Bulterbirne, Dorothe Royale, Beurre de Yelle, Beurre Royule, Pivire de Melon. Beurre Inconiparable of some. This ranks amongst the best of Pears. The tree is of vigorous growth; fruit, when in perfection, four inches long, and three inclies broad; the skin at maturity is bright orange, with reddish russet ; flesh clear white, melting, juicy, and of a delicious aromatic flavour; from November to January.

Beurre Rance, Beurre Epine, Hurdenpont de Printemps. This is said to be a frot-rate Pear. The tree is vigorous, and a good bearer; fruit mid. dle sized, oblong; skin deep green, with russetty specks; flesh green, melting, having a rich delicious flavour, with very little acid. It shrivels in ripening, but will keep till April.

Bezy VAet, Bezy de Saint Vurst. A most excellent Pear, somewhat the shape of the Swan's. Egg, but larger; skin dull green, covered with russetty spots; fleslı yellowish; perfectly melting, sweet and agrecably perfumed; at perfection in November and December.

Catrllac. Fruit very large, rather turbinate; pale yellow, stained with red; flesh firm and breaking; its flavour astringent; an excellent baking Pear; from November to April. Specimens of this variety have been known to weigh upward of two pounds.

Chaumonter, Bezy de Chaumontelle, Poire de Chaumontelle, Beurre d'Hiver. This noble old variety is a fruit varying in size, from large to very large; its colour at maturity yellow, tinged with brownish red next the sun; its form variable; flesh melting, juicy, sweet, musky. excellent : in season from November to February.

Colman, Colmar Souverain. Poire Manne, Bergamotte Tardive, Incomparable. This fruit is rather large; skin smooth, of a green colour, changing to a yellow at maturity; form pyramidal; flesh melting, juicy, saccharine, and of excellent flavour. The fruit is in perfection from November to February.

Columbra, Columbian Virgalieu. A large native pear of oblong or pyramid form, and fine yellow colour, tinged with red; flesh rich, firm, juicy, and excellent; from November to January. Tree pruductive and of very handsome form.

Easter Beurre, Bergamotte de la Pentecote, Beurre d'Hiver de Bruxelles, Doyenne d'Hiver, de Bruxelles, Bezi Chaumontelle Tres Gros. OP all the late keeping Pears, this is considered the best (for England.) Fruit large, roundish, oblong; colour green, but yellow at maturity, with specks of russet brown; flesh yellowish white, perfectly buttery and melting, also extremely high flavoured; it is eatable in November, and will keep till May ; it is a most profuse bearer, on a quince stock.

Echassery, Bezy de Chassery, Bezy de Landry, Poire d' $E$ uf, Ambrette, Walnut, Tilton of New-Jersey. Fruit middle size, of a roundish turbinate figure, something like a Citron, or the Ambrette; skin smooth, greenish yellow, with grey specks; flesh melting, juicy and delicious; from Decem. ber to March. 
Glout Morcenu, G'oux Morceaux, Beurre d'Aremberg. Roi de Wurtemburg, Gloria. Colmar d'hiver of Prince, and Beurre de Hardenpont of Downing. A very large Belgic variety, of great excellence; fruit of ovalish form, pale green colour, inclining to yellow, with russetty specks and blotches; flesh whitish, firm, very juicy and excellent; in perfection from November to March.

LEwIs. This variety originated on the farm of Mr. I. Lewis, of Roxbury, Mass. The size is medium; form somewhat globular; skin, when ripe, a greenish yellow; the flesh is white, very melting, juicy and excellent; froin November to March. The tree grows quick, and bears abundance of fruit.

Louise Bonne de Jersey, Loutse Bonne d'Avranckes. A large Pear ; oblong; a good substilute for the old St. Germain; skin yellowish green, sometimes tinged with red; flesh extremely tender, and full of an excellent saccharine, well flavoured juice. A first-rate fruit, from October till after Christmas.

Newtown Vergaleav. A large Pear, of a yellow colour, with a very short stalk; the tree grows very crooked and of an irregular form, bending by the weight of its fruit, which is excellent to preserve, or for baking $i$ from November to January. Its productiveness renders it desirable in an orchard.

Passe Colmar, Fondante de Panisel, Passe Colmar Gris dit Precet. Poire Precel, Passe Colmar, Epineux, Beurre Colmar Gris dit Precel Beurre d'Argenson, Present de Malines, Colmar souverain, Ch"pman's A most valuable Pear, of medium size, conical, flattened next the eye; skin at maturity yellowish, sprinkled with russet, a tinge of red next the sun; flesh yellowish, melting, rich and excellent. The tree is a good bearer, and the fruit is in perfection from November to February.

Pound Pear, Black Pear of Woreester, Parkinson's Warden, Grande Munarque, Livre, Groote Mogul, Gros Ruteau Gris, Love Pear. Winter Bell of Downing. Fruit very large, of a roundish turbinate figure; skin rough, covered with dull russet; flesh hard and coarse, but excellent when baked or sterved in winter. Grafted on a Pear stock, the tree bears so abundantly, as to bend like a weeping willow. A specimen of this variety was exhibited at the sixteenth annual fair of the American Institute, October, 1843, weighing $33 \mathrm{oz}$.

Prince's St. Germain. Fruit about medium size; form obovate; skin russetty yellow, with dull red cheek; flesh melting and good. Mr. Manning says that its abundant bearing, and its ripening gradually in the house during winter, renders it a very valuable market fruit; good till after Christmas.

Surpasse Marie Louise, Pitt's Prolific Marie, Pitt's Marie Louise. A large Pear; oblong or calabash formed; green, covered with brown yellow russet; flesh melting and rich flavoured; ripe in October and November. It is a very prolific bearer.

Surpasse St. Germain. Fruit of medium size; round at the crown, tapering to the stem; it is of very irregular form; the skin is rough; colour yellow, mixed with dull brown; flesh coarse grained, sugary, and high flavoured; good from November till January.

Surpasse Vergaleav. Fruit large, oblong, some specimens nearly round; the skin smooth, its colour yellow with a light red cheek; flesh 
rich, juicy, and delicious eating ; in Oclober and November. Mr. Manning says the tree bears young, yields large crops, and is worthy of extensive cultivation.

Uvendale's St. Germain, Belle de Jersey. A large fine pyriform Bell Pear, of a hrownish green colour, with russetty spots; flesh firm, and high flavoured. It is considered a first-rate baking Pear, and will keep till March. Mr. Reid, of the Murray Hill Nursery, exhibited some fine specimens of this fruit at the sixteenth annual fair of the American Institute, October, 1843.

Vicar of Winkfield, Bourgmestre of Boston, Monsieur Le Cure, Dumas, Clion if Buston, according to the catalogue of Winter \& Co. Flushing. Fruit oblong, or yyramidal ; skin russetty yellow, with ruddy colour on one side; flesh firm, sweet, and rich; good as a table fruit, from December to Fcbruary. This variety is deserving extensive cultivation, for its beauty, large size, keeping qualities and productiveness.

Winter Nelis, Nelis d'Hiver, La Bonne Mulinorise, Spreeuu. All accounts agrec that this is a most excellent Winter Pear; its size is above medium, somewhat oval; its skin green and russetty, full of grey dots; flesh yellowish white, melting, high flavoured, with a musky perfume; at perfection in December ond January.

\section{PERRY PEARS.}

BARI.AND. This variety took its name from the original tree, growing in a field called Bare Lands, in Herefordshire, England. The fruit is smallish, of ovate form; skin dull green, russetted with grey. It is deemed excellent for perry. Specific gravity of its juice 1070 .

Holmore. Fruit small globular ; skin of a dingy yellowish green, tinged with red. Excellent perry is made of this variety in Herefordshire, England. Specific gravity of its juice, 1066.

HuFrcap. There are several varieties of Pears bearing this name, but the best perry is madc of the true Herefordshire Huffcap. The fruit is middle sized, of pale green colour, marked with grey russet. Specific gravity of its juice 1070.

MoNARch. A new Pear, considered by Mr. Knight as without a rival. The tree is of rapid growth, and an abundant bearer; fruit large, of an extraordinary musky flavour, and deemed excellent for perry ; good also for the table; from October to December and January.

Ordfield. Fruit below the medium size, of pale green colour, with russetty spots. An excellent perry fruit. Specific gravity of its juice 1067 . From this variety is made the celebrated Ledbury Perry.

Longland. Fruit very handsome, much like the Swan's Egg in shape; skin bright gold colour, tinged and mottled with a russetty lively orange; specific gravity of its juice 1063. The tree is handsome and upright, and much cultivated in Herefordshire for perry.

Trixton Squash. Fruit middle sized, of angular shape; skin a muddy russetty green, marbled with dull orange, interspersed with ash-coloured specks. It originated in Teinton, Gloucestershire. and the perry made from this fruit is of the very highest quality, something approaching in colour and briskness to champaigne, for which fine samples of it have sometimes been sold. 


\section{PLUM.}

\section{Prunier. Prumuls.}

Tre Plum tree rises fifteen feet in height, branching into a moderately spreading head; the leaves are ovate, serrated, and on short petioles; petals white. The natural colour of the fruit is generally considered to be black; but the varieties in cultivation are of yellow, red, blue, and green colours, and of different forms and flavours. There are several good sorts that grow wild in the hedges of Britain, and also in America, but its original country is supposed to be Asia ; and according to Pliny, it was taken from Syria into Greece, and from thence into Italy. There are many varieties cultivated in France; and in the Iondon Horticultural Garden there are about three hundred sorts kept under name. The Green Gage is considered the best dessert Plum, and the Egg Plum for sweetmeats; but the Damson is the best baking Plum.

The Plum is said to succeed best in a lofty exposure, and may yield well in the mountainous parts of the United States; it yields well near Albany, but the fruit is by no means plentiful in the vicinity of the city of New-York. Like the Nectarine, it is subject to the attacks of the Curculio, and other insects.

It has been observed that Plum trees growing in frequented lanes or barn-yards, are more generally fruitful than those cultivated in private gardens, or secluded situations; this circumstance is by some attributed to the jarring of the trees, by cattle and swine rubbing against them; thus causing the defective fruit to fall on the ground. Geese kept in orchards or fruit gardens, often prove beneficial; as they, by devouring the defective fruit and other corruptible matter, prevent the possibility of insects getting into the ground, so as to perpetuate their existence, or multiply their species.

Cobbett attributes the scarcity of Plums in New-York to 
neglece In his American Gardener, paragraph 320, he asks, "How is it that we see so few Plums in America, when the markets are supplied with cart-loads in such a chilly, shady, and blighty country as England ?"

I would answer this query by informing the reader, that the inhabitants of our parent country, with a view to derive the full benefit of the sun's rays for the cultivation of Plums, Peaches, Nectarines, and such other fruit as require extra heat, train their trees against walls, fences, or trellis-work; and from their having these mearss of support, gardeners have no inducement to plant them deeper than is necessary; whereas, from the circumstance of the American climate being sufficiently warm to ripen thise fruits on standard trees, they are generally so cultivated. Many persons, to save the trouble of staking, or otherwise supporting their trees, plant them too deep, and thus defeat the operations of nature. That this is a prevalent error, has been shown in the articles Nectarine and Peach, to which the reader is referred for a more concise view of the subject.

New varieties of the Plum are produced from seed; and the old kinds are generally propagated by budding on stocks of free-growing Plums, in preference to grafting, because Plum trees are very apt to gum wherever large wounds are made in them. All the sorts produce their fruit on small natural spurs rising at the ends and along the sides of the bearing shoots of one, two, or three years' growth. In most sorts, new fruit branches are two years old before the spurs bear. The same branches and spurs continue fruitful, in proportion to the time which they take to come into bearing.

After the formation of the head is begun, it takes from two to six years before the different sorts come into bearing. Standards must be allowed to expand in free growth, occasionally pruning long ramblers and irregular cross branches. In annual pruning, thin crowded parts, cut away worn out bearers, and all decayed and cankery wood. The Plum 
may be cultivated in small gardens, trained as espaliers, or to a close fence, like the Apricot, \&c.

The tree is of farther use than for its fruit as a dessert, \&c.; the bark dyes yellow; the wood is used by turners; and the dried fruit, or prune, is formed into electuaries and gentle purgatives. Prunes were originally brought from Damascus, whence their name.

\section{SELECT DESCRIPTIVE LIST OF PLUMS.}

American Yellow Gage, American Wheat. A beautiful medium sized oval Plum; of a bright yellow colour, when fully ripe; its flavour is rich, equal to the Green Gage. The fruit is not apt to crack nor to be attacked by insects. It is a very suitable varicty to cultivate for the market; it ripens in August and September.

A Pricot Plum, Prune Abricute, Abricnte de Tours. A large freestone Plum; its form is globular, depressed, divided by a deep sature ; whitish yellow, but faint red next the sun, and covered with bloom; its llesh is firm, juicy, sweet, musky and excellent; it ripens in August and September.

Bingham, Bingham's Yellow Cling. A delicious clingstone Plum, of large size and oval form; skin bright yellow, spotted and blotched with red; flesh J'ellow, rich, and delicious; ripening in August and September.

BLEEKER'S GACE. This fine freestone Plum is stated to have been raised by the Rev. Mr. Bleeker, of Albany. from the stone of a German Prune; it is a large globular fruit, of excellent quality ; skin dark yellow, with red spots and blotches; the flesh is rich, saccharine, and juicy; in September.

Coe's Gozden Drop, Coe's Imperial, Bury Seedling, Golden Gage, Fair's Golden Drop. Raised by Mr. Coe, Bury St. Edmond's, Suffolk. England. The tree is vigorous; fruit oval, of large size; skin greenish yel low, spotted with violet and crimson; the flesh, which separates from the stone, is of gold colour, rich and excellent; the fruit ripens at the end of September, and will keep several weeks. A first-rate fruit, and worthy of general cultivation.

Coe's Late Red, Saint Martin, Saint Mrrtin Rouge. An excellent freestone Plum of medium size, in form almost round; its colour is violet purple, with a partial degree of bloom; flesh rich, saccharine and high flavoured. It is one of the best of late Plums, ripening in October and November.

Col.umbra, Columbian Gage. A beautiful native clingstone Plum, of light purple colour: the flesh is firm, of a greenish hue, with an abundance of rich flavoured juice. 'The tree is a great bearer, and ripens its fruit in August.

Cooper's Large Red, Cooper's Large American, La Delicieuse. This 
Plum is of extraordinary size, measuring within an eighth of two inches in each direction; the skin is of a fine dark purple colour ; the flesh is yellowish green, rich, juicy, and of pleasant Havour ; the fruit makes excellent preserves, if gathered in August ; its great defect is an inclination to rot, if left long on the tree.

Diamon Plum. Some consider this as the largest Plum known; its colour is a dark purple; in form it resembles the Magnum Bonum, but its flavour is considered rather superior; it ripens in September, and the flesh separates clear from the stone. The tree, which grows vigorously, originated with Mr. Hooker, Kent, England.

Downing's Emerald Drop. A beautiful clinostone Plum of medium size, oblong form, and green colour; flesh firm and of delicious flavour; this variety originated at the Nursery of A. J. Downing \& Co., Newburgh, State of New York.

Downton IMPERATRICE. A superior late Plum, of medium size, shaped similar to the blue imperatrice; skin dark yellow, and very thin; the flesh yellow, soft, juicy, with a high flavoured acidity; at perfection in October and November.

Drap D'OR, Cloth of Goll, Myrabelle Double. Yellow Perdrigon of Winter \& Co. A small freestone Plum, of a roundish form, and bright yellow colour, marbled with red; flesh yellow, tender; juice sugary and excellent; ripe in July and August.

Duane's Frencu Purple, Dume Aubert Violet. Purple Magnum Bonum and Purple Egg of some c'llections. A very superior clingstone Plum, of large size, and oblong form; the skin dark purple; flesh sweet, juicy, rich and excellent; ripe in September. This variety, from being inported by Mr. Duane, of New York, was named after him, as he had lost the original name.

Eanly Ohlahan, New Orleans, Early Monsieur, Monsieur Hatif. A fine frecstone plum, above medium size; form round; its sature deep; colour dark purple, covered with a fine bloom; flesh greenish yellow, of excellent flavour; sweet, combined with a pleasant acid; it ripens in August.

EARLY Tours, Precose de Tours, Early Violet. The tree is vigorous and fertile; fruit small, oval, dark purple covered with fine bloom; flesh greenish yellow, tender, juicy, and of very agreeable flavour; one of the best early varieties, and very productive ; ripe at the end of July.

ELFRY. French Cooper of Prince. A native clingstone Plum, highly esteemed in Pennsylvania and New-Jersey for its productiveness and other good qualities; the fruit is below medium size, of oblong shape and dark blue colour; flesh firm, very rich and delicious ; in September.

German Prune, Prune d'All magne, Damas Gros, Quetsche, Quetzen. The fruit of the Quetsche Plum is grown for the purpose of drying, and is considered the best for use as prunes; fruit below the middle size; of an oval figure; skin red and purple; flesh yellow; juice sweet, with a slight acid; ripe early in September.

Golratr, Goliah, st. Cloud, Caledonian. Wilmot's late Orleans. This fruit is very large, sometimes weighing four ounces; the skin is a decp reddish purple; the flesh pale yellow, firm, and well flavoured, but not rich, slightly adhering to the stone ; the tree is a great bearer, and the fruit is much used for cooking; ripe in September. 
Green GAGE, Great Queen Claude, Dauphine, Grosse Reine Claude, Abricot Vert, Verte Bonne, Gros Dumas Vert. A middle sized round fruit, of a yellowish green colour, and purplish russetty red next the sun; the flesh is of a greenish hue, melting, with an abundance of very sweet and highly perfumed juice, of an exquisite taste ; it arrives at maturity toward the end of A ugust.

Horse PlUM, Large Sweet Damson. Fruit of medium size, oval, with a deep sature in the middle; skin dark red, inclining to purple when ripe; flesh greenish yellow; juice acid but agreeable. Quantities of these Plums are sold in the New-York markets in August and september, for sweetmeats. The trees are generally raised from suckers; and Peaches, Apricots, and Nectarines, will bud and thrive well on such stocks.

Hur.rng's Superb, Keyser's Plum. 'This Plum is of monstrous size, and has been known to weigh nearly four ounces; it is of roundish form, and of a greenish yellow colour; the flesh is sweet and excellent. It was raised from seed by Mr. Keyser, of Pennsylyania, and brought into notice by $\mathrm{Dr}$. Wm. Hulings, of that State.

ImPERATrice, Imperatrice Violette, Blue Imperatrice. Simiana of some collections. One of the best of late clingstone Plums; fruit medium size, oval; skin rich deep purple, covered with bloom; flesh yellowish green, a little firm, very sweet, rich and juicy; the fruit hangs long on the tree, and is at maturity in October and November.

Imperial Diadem, Red Iinperial, Red Diaper. A fine fruit, admirably adapted for culinary purposes ; shape oval; colour pale red, but dark when mature; flesh yellow, and separates from the stone; juice plentiful when perfectly ripe, which is early in September; it is of good flavour, and highly perfumed.

ITALIAN DAMASK, Damas d'Italie. This fruit is of medium size, nearly round, a little flattened at the base; its colour blue or violet, and covered with a purple bloom; its flesh is yellow, rich, and juicy, and the tree, which matures its fruit in $\Lambda$ ugust, is very productive.

KIRK E's Plum. This variety is said to be as hardy and prolific as the Orleans, as handsome as the Damask, and as good as the Green Gage ; fruit large, roundish; skin covered with a close, firm, azure bloom, through which appears a few golden specks; flesh greenish yellow, firm, juicy and rich; in perfection the early part of September.

La Royale, Riyale. A large and excellent freestone Plum, of a homely dull red colour, but concealed by a thick violet or azure bloom; flesh fine, yellowish green, firm, juicy, high flavoured and delicious; a superior Plum; at maturity early in September.

Late Purple Damson, Purple Winter Damson, Blue Damascene, Blue Damson. This variety is in great esteem for preserves, and generally commands a high price. It is of a dark purple colour, covered with bloom; the flesh has rather too much acidity for a table fruit, but this tartness gives it an agreeable flavour when cooked, and if the fruit remains on the tree until November, it becomes sweet.

Lawrence Gage, Lawrence's Favourite. A large round freestone Plum, of a yellowish green colour, tinged with red ; flesh firm, and of delicious flavour, similar to the Green Gage. The tree is very fertile, and yields an abundance of fruit in August and September.

Lucombe's Nonsuch. This Plum is large, compressed at the summit 
and base; its breadth is two inches; its colour at maturity, as well as its form, resemble the Green Gage, but more streaked with yellow; flesh firm, rich and juicy; at maturity in dugust; tree a good bearer.

Mrm's, Minm's Plum, Diuper Rougue. The fruit is very large, a little oblong; colour bright purple, covered with thick bloom; its flesh, which separates from the stone, is yellowish green, tencler, juicy, and very asreeably flavoured; ripe in September.

Monocco, Early Black Damask, Black Damascus, Black Morocco, Early Damusk, Early Murucco. This is considered one of the best of early llums. The tree is very hardy and productive; fruit middle sized, roundish; skin deep blackish purple, covered with a light blue bloom; flesh greenish yellow, juicy, rich, and high flavoured; ripe early in August.

Nectarine Plom, Caledonian, Hmvell's Large, Prune Peche, Jenkin's Imperiul. One of the most beaut:ful Plums known; large, nearly round; the skin at maturity varies from red to crimson, covered with azure bloom; flesh yellowish, coarse grained, astringent; juice abundant, and of a mild, pleasant flavour; at maturity in July and early in August.

New-York Purple, Breurorl's Purple Bolmar, Brevont's Purnle Washington. An excellent fruit, raised from a seel of Bolmar's Washing. ton Plum, that had been impregnated with the pollen of the Blue Gage. The fruit is very large; skin brown red, covered with purple bloom; flesh yellow, of a rich and brisk flavour, and adheres to the stone; ripe towards the end of August.

Octóer GAge, Frost Gage. A beautiful native fruit, a drawing of which has been taken from nature, and may be found in "Hoffy's Orchardist's Companion." Fruit of medium size; form oblong; colour dark brownish purple, covered with a black bloom; flesh firın and juicy; fla. vour sprightly and agreeable; ripe early in October.

Orleans Plox, Red Damask, Damas Rouge, Monsieur. A well known and productive Plum; of medium size, and somewhat oval form ; the skin is dark red, approaching to purple, with a thin blue bloom; tesh yellow, firm and good, separating freely from the stone; ripe in A ugust.

Pond's Puntes, Pond's Stedling. A large round purple clingstone Plum, a native of Massachusetts ; it is of peculiar rich flavour, not apt to crack, and is well adapted for the markets. The tree bears wonderful cropa, which ripen in August.

Prince's I mperial Gage, Flushing Gage, Superior Green Guge, Whife Gage. This tree was originated at the Flushing nursery, from a seed of the Green Gage. The fruit is one of the finest of its class; the skin at maturity is yellow, with a whitish bloom; the flesh is rich, luscious, and of excellent flavour. It makes fine preserves, if gathered loward the end of August; at maturity in september.

Prince's Orange kgg. A large splendid orange coloured clingstone Plum, of oval form, and of peculiarly rich flavour; ripe in August. The tree yields abundant crops of truly beautiful fruit, which is never attacked by insects, as many kinds are.

Prune Sursse, Simiana, Pruned' Altesse, Monsieur Tardif, Swiss Prune. Fruit very handsome, round, flattened; colour varying from bright amber to deep red, and covered with azure bloom ; flesh yellow, delicious, melting, and closely adheres to the stone; juice very abundant. An excellent fruit; ripening in September. 


\section{Purpee Gage, Blue Gage, Reine Claude Violette, Die Violette, Konigin} Clautia. This fruit is of medium size, almost round, and may be considered as one of the finest varieties; its skin is of a violet purple colour, with pale yellow dots, and covered with a light blue bloom; flesh greenish amber, rich, saccharine, and high flavoured : at maturity in August, and good until October.

Queen Victoria, Sharp's,Emperor, Dennyer's Victoria. An excellent freestone Plum, as large as the Red Magnum Bonum; of a roundish oval form, and red colour, covered with a fine bloom; the flesh is firm, rich, juicy, and delicious. The tree grows very strong, and yields abundant crops in september.

Red DiAPER, Diapree Rouge, Roche Corbon. One of the most beautiful Plums known; form oval, above medium size; colour bright red; flesh greenish yellow, soft and sweet, separating from the stone; the fruit makes excellent prunes, if gathered early in September, and like the Imperatrice, will hang some time on the tree.

Red Magnum Bonum, Red Imperial, Imperial Violette of the French. Purple Egg of Prince and others. A large, oval Plum, of deep red colour, covered with blue bloom; the flesh, which parts from the stone, is harsh and acid; consequently good for cooking, preserves, \&c.; in September and October.

Red Perdrigon, Perdrigon Rouge. An excellent Plum, of the first class; of medium size, oval shape, and fine red colour, with gold coloured dots, and a fine bloom; flesh bright yellow, transparent, and separates from the stone; juice sweet and delicious; ripe early in September. It makes excellent prunes, not inferior to the White Perdrigon.

RED QUEEN MOther. The Plum is of medium size, its colour bright red and yellow, somewhat spotted, and covered with pale bloom; its flesh is yellow, sweet and excellent. ripening early in September. A very productive variety, and highly deserving of cultivation.

ROYAL DE TOURs. The tree is of extraordinary vigorous growth; its principal stem rises vertically ; the fruit is globular, of medium size; red violet colour, and covered with azure bloom; flesh yellow, fine, good; juice abundant and sweet : ripens early in August.

Saint Catharine. A medium sized, oblong fruit; skin bright gold colour, spotted with red at maturity, and covered with bloom; flesh yellow, tender, sweet, and fine flavour; ripens early in September, and will hang some time on the tree. A good market Plum, for which purpose it is much cultivated.

Smith's Orleass. This variety is held in great esteem as a market fruit; the trees are free from gum and insects, and yields abundant crops of large freestone Plums, of an oval form and purple colour. The fruit ripens gradually in September.

Surpasse Monsieur. A large fruit, of oval form, and of a dark red purplish colour, raised by a Mr. Noisette ; it is said to be more beautiful and perfumed than the Monsieur, and the tree yields suckers, which produce fruit in all their beauty and excellence ; in September.

Virginale, White Virginal. This fruit ranks among the best of Plums; its shape is round; colour yellowish, touched with violet or rose, and covered with dense bloom; flesh melting, juice abundant, and very agreeable; it adheres to the stone; ripe in September. 
Washington, New Washington, Bolmar's Washingtun, Franklin. A very large, globular Plum, inclining to oval; colour greenish yellow, with crimson specks, covered with a rich bloom. This Plum has somet mes weighed over four ounces; its flesh is yellow, firm, sweet and delicious; in August. This variety originated in New-York, from suckers of an old root, the tree of which had been some time previously destroyed by lightning.

White Magnum Bonum, Yellou, Magnum Bonum, Gros Luisante, Imperiale Blanche, Egg Plum, White Mugul, White Holland. This fruit is of extraordinary size, oval; yellow, covered with pale bloom; the flesh yellow, firm, closely adhering to the stone; excellent fur cooking and preserves; in September.

White Perdrigon, Perdrigon Blanc. A middle sized, oblong fruit, of a pale yellow, with red spots, and covered with white bloom; flesh yellow, rich, saccharine and juicy, separating from the stone; it ripens in August and September.

\section{QUINCE.}

\section{Corgnassier. Cydonia.}

Tine Quince is of low growth, much branched, and geno. rally cronked and distorted. The leaves are roundish, or ovate, entire, above dusky green, underneath whitish, on short petioles. The flowers are large, white, or pale red, and appear in May and June; the fruit, a pome, varying in shape in the different varieties, globular, oblong, or ovate; it has a peculiar and rather disagreeable smell, and austere taste. The fruit takes its name from being a native of tho ancient town of Cydon, in the Island of Crete; some suppose it to be a corruption of Malus cotonea, by which the Latins designated the fruit. It is used as a marmalade for flavouring apple pies, and makes an excellent sweetmeat; and it has the advantage over many other fruits for keeping, if properly managed.

Of the several sorts, the following are in greatest esteem : 1. The oblong, or Pear Quince, with ovate leaves, and an oblong fruit lengthened at the base. 2. The Apple Quince, with orate leaves, and a rounder fruit. 3. The Portugal Quince, the fruit of which is more juicy and less harsh than 
the preceding, and therefore the most valuable. It is rather a shy bearer, but is highly esteemed, as the pulp has the property of assuming a fine purple tint in the course of being prepared as a marmalade. 4. The mild or eatable Quince, being less austere and astringent than the others. 5 . The Orange Quince, a very handsome fruit of peculiar rich fla vour. 6. The Musk or Pine Apple Quince, very large and beautiful.

The Quince produces the finest fruit when planted in a soft, moist soil, and rather shady, or at least sheltered situa tion. It is generally propagated by layers, and also by cuttings, and approved sorts may be perpetuated by grafting. In propagating for stocks, nothing more is necessary than to remove the lower shoots from the layer, so as to preserve a clear stem as high as the graft; but for fruit-bearing trees, it is necessary to train the stem to a rod, till it lias attained four or five feet in height, and can support itself upright.

When planted in an orchard, the trees may be placed ten or twelve feet apart. The time of planting, the mode of bearing, and all the other particulars of culture, are the same as for the Apple and Pear. The chief pruning they sequire, is to keep them free from suckers, and cut out decayed wood.

\section{RASPBERRY.}

Framboisier. Rubus, elc.

There are several species of the Rubus found wild in various parts of Asia, Europe, and America, some of which have upright stems, others prostrate; the American Stone Bramble, and also the common Blackberry, Dewberry, Cloudberry, \&c. are of this family. The Rubus idaeus, or common Rasjiberry, grows spuntaneously in the province of 
New Brunswick, and in various parts of the United States, but most of the cultivated varieties are supposed to have originated in England. Loudon describes the true Raspberry as having "stems which are suffructicose, upright, rising to the height of several feet, and are biennial in duration; but the root is perennial, producing suckers which ripen and drop their leaves one year, and resume their foliage, produce blossom shoots, flower, and fruit, and die the next. The leaves are quinate-pinnate; the flowers come in panicles from the extremity of the present year's shoots; they are white, appear in May and June, and the fruit forms about a fortnight afterward."

The fruit is grateful to most palates, as nature presents 1t, but sugar improves the flavour; accordingly it is much esteemed when made into sweetmeats, and for jams, tarts, and sauces. It is fragrant, sub-acid, and cooling; allays heat and thirst. It is much used in distilling. "Raspberry syrup is next to the Strawberry in dissolving the tartar of the teeth; and as, like that fruit, it does not undergo the acetuus fermentation in the stomach, it is recommended to gouty and rheumatic patients."

Nicol enumerates twenty-three species and varieties of the cultivated Raspberry, and twenty-one of the Rubus ronce, or Bramble; in the latter is included the American Red and Black Raspberry, the Long. Island and Virginian Raspberry; also the Ohio Ever-Bearing, and the Pennsylvania Raspberry. The English varieties are, early Small White; Large White; Large Red; most Large Red Antwerp; Large Yellow Antwerp; Cane, or smonth-stalked; Twice-bearing White; Twice-bearing Red; Smooth Cane, twice-bearing; Woodward's Raspberry; Monthly, or Four Season; Dwarf Red Cane; Victoria Raspberry; Large Red Franconia; Mason's Red Cluster; McKeen's Scarlet Prolific; Chili Red; Cornish Red; Cox's Honey; Brentford Red; Brentford White; Flesh-coloured; Barnet Red; Bromley Hill; 
Cretan Red; Prolific Red; Canada Purple; Rose-flowering, \&c.

The varieties can be perpetuated by young sucker shoots, rising plenteously from the root in spring and summer; when these have completed one season's growth, they are proper to detach with roots for planting, either in the autumn of the same year, or the next spring, in March or early in April. These new plants will bear some fruit the first year, and furnish a succession of strong bottom shoots for full bearing the second season. New varieties are raised from seed, and they come into bearing the second year. Some of the American species are cultivated by layers, which produce fruit the same year.

Raspberry beds are in their prime about the third and fourth year; and, if well managed, continue in perfection five or six years, after which they are apt to decline in growth, and the fruit to become small, so that a successive plantation should be provided in time. Select new plants from vigorous stools in full perfection as to bearing. Be careful to favour the twice bearers with a good mellow sril, in a sheltered situation, in order that the second crop may come to perfection.

When Raspberries are cultivated on a large scale, it is best to plant them in beds by themselves, in rows from three to five feet apart, according to the kinds. In small gardens, they may be planted in detached stools, or in single rows, in different parts of the garden, from the most sunny to the most shady aspect, for early and late fruit of improved growth and flavour. It is requisite to cut out the dead stems early in the spring, and to thin and regulate the successional young shoots; at the same time, the shoots retained should be pruned at the top, below the weak bending part, and some rotten dung worked in around the roots of the plants. Keep them clear of weeds during the summer, by hoeing between the rows; at the same time oradicate all 
superfluous suckers, but be careful to retain enough for stock in succeeding years.

The Antwerp and other tender varieties of the Raspberry are liable to be more or less injured by the severity of our vinters; to prevent which, they should be protected by bending them down to the ground late in autumn, and covering them with earth five or six inches, sloping it off so as to prevent injury from rain or snow.

\section{SELECT DESCRIPTIVE LIST OF RASPBERRIES.}

A mirican Brack. Black Cap. This fruit is of smallish size, and ripens I June and July. It is a favourite with some.

A merican Red, English Red, Conimon Red. This variety is much cultivated for the market. The fruit ripens in June and July, successively.

Antwerp Red Large Red Antwerp, Huwlind's Red Antwerp. Burley. This species is rather tender, on which account the branches must be bent down in autumn, and covered with soil. See Calentar. The fruit is large and beautiful, of delicious flavour, and quite fragrant; in June and July.

AnTWERP White, Yellow Antwerp. This is also tender or half hardy, but very prolific; the fruit is large. of a pale yellow colour, and much esteemed. It ripens in June and July.

Barnet, Cormuallis Prolific, Lord Exmonith, Large Red. This is considered a first-rate fruit, and yields abundantly ; in June and July.

BEE Hive. A new variety, introduced by Messrs. Winter \& Co., of the Linnæan Butanic Garden, Flushing. The fruit is large, of round shape and red colour; ripe in July.

Cornish, Large Cornish. A hardy and highly productive variety, yielding an abundance of Reil Berries in June and July.

Doubie Bearing Red, Tuice Bcaring. This species is very prolific, producing its first crop in July, and another in October.

Fiesh Coloured, Frambuisier couleur de chair. A new variety, imported by W. R. Prince \& Co.. from France. It is described as an highly flavoured and much esteemed fruit.

Franconia, Red Franconia. This variety is in great repute for its productiveness and the fineness of its fruit, which ripens gradually in July.

Monthly or Four Seasons, Perpetual Bearing. This species, if planted in a shady situation, will produce successional crops throughout the sunmer.

RED TAI.t CANE. There are several species of the Cane Raspberry, some of which are worthless. The Tall Red Cane produces fine fruit in July and August, and very frequently in autumn.

Victoria. This Queen of Raspberries has been imported by W. R. Prince, and plants are offered for sale at his nursery at Flushing, for twenty-five cents each. 


\section{STRAWBERRY.}

\section{Fraisier. Fragaria.}

This is a genus of fruit-bearing herbaceous plants, of which there are few in the vegetable kingdom that can equal the Strawberry in wholesomeness and excellence. The fruit is supposed to receive its name from the ancient practice of laying straw between the rows, which keeps the ground moist and the fruit clean. They are natives of temperate, or cold climates, as of Europe and America. The fruit, though termed a berry, is, in correct botanical language, a fleshy receptacle, studded with seeds. It is universally grateful alone, or with sugar, cream, or wine, and has the property, so valuable for acid stomachs, of not undergoing the acetous fermentation. Physicians concur in placing Strawberries in their small catalogue of pleasant remedies; as having properties which render them. in most conditions of the animal frame, positively salutary; they dissolve the tartareous incrustations of the teeth, and promote perspiration. Persons afflicted with the gout have found relief from using them very largely: so havo patients in case of the stone; and Hoffman states, that he has known consumptive people cured by them. The bark of the root is astringent.

In cultivating the Strawberry, an open situation and rich loamy soil, rather strong, is required for most varieties; and from their large mass of foliage and flowers, they must, till the fruit is set, have copious supplies of water. The row culture is best calculated to produce fruit; and frequent renewal insures vigorous plants, as well as large fruit. Some plant them in single rows, from twelve to eighteen inches apart, according to the sorts; others form a bed with four rows. If several beds be intended, a space of two or three feet may be left between each bed as a path; and in the second or third season, the paths may be manured and dug 
to admit of the runners taking root; by this means, a renewal may be made so often, and the old stools being taken away, leaves spaces between the beds as before. Or new plantations may be made every season; because, after the roots are fairly established, they multiply spontaneously, as well by suckers from the parent stem, as by numerous runners; all of which, rooting and forming a plant at every joint, require only removal to a spot where there is room for them to flourish. If taken off, and planted in rows in August and September, they will produce fine fruit the following season, and will bear in full perfection the second summer; some, however, prefer spring planting, which answers very well, if done in damp weather.

A plantation of the Alpine yields fruit the same year that it is made. The Wood and the Alpine are often cultivated from seed, which generally produces fine fruit. The other species are uniformly propagated by offsets, except the iutention be to try for new varieties. The Alpine and Wood species may be planted in situations rather cool and shady, in order that they may produce their fruit late in the season, which is desirable. The Strawberry, with a little trouble of choosing a succession of sorts, may be forced so as to be had at the dessert every month in the year; though, during the winter months, they have not much flavour.

Some gardeners lay straw an inch or two thick over their beds in March, and set fire to it, in order to promote a stocky growth of plants and early fruit; others recommend mowing off the tops of such as are not required to fruit early, while they are in blossom, with a view to obtain a crop of Strawberries late in the season.

The London Horticultural Catalogue contains the names of about one hundred and fifty varieties of all the species, which are classed according to their nature, colour, \&c. Class 1. Scarlet Strawberries; 2. Black Strawberries; 3. Pine Strawberries; 4. Chili Strawberries; 5. Hautbris Strawberries; Green Strawberries; 7. Alpine and Wood 
Strawberries. To select all the most esteemed from this, or any other extensive catalogue, is a difficult task ; the following description of species and varieties may serve to direct the choice :-

\section{SELECT DESCRIPTIVE LIST OF STRAWBERRIES.}

The Wood Strawberry, Fragaria vesea, with oval serrated leaves; the fruit red white, and green, which is round and small. A rative of Britain. Some of the varieties are in great repute, as they are very productive, and continue long in hearing.

The Scarlet. Fragaria Virginiana, with leaves like the preceding; the fruit roundish and scarlet-coloured. A native of Virginia. VarietiesMetlıven Scarlet, Knight's Scarlet, Austrian Scarlet. Early Scarlet, Wilmot's late, Common late, Wilınot's Early Scarlet, \&c.

The Roseberry. Fragaric, Virg var. An A berdeen seedling, introduced in 1810 . The plants have few roundish leaves, larger fruit than the scarlet. and are very prolific; continues bearing till August.

THF. BlACK var. Downtın, Dark Scarlet Strawberry, originated by Mr. Knight. The fruit is large, irregular, and cockscomb-like; plant hardy and prolific.

The Carolina. Fragaria Carolinensis; colour dark red; a native of America. There are several choice varieties of this fruit, as-EIton's Seedling. Keen's Seedling, Mulberry, Wilmot's Black Imperial, Blood Pine, North's Seedling, Knevet's Seedling, \&c.

The Musky, on Hattbors. Fragaria elatis, with oval, rough, javelinedged leaves. A native of Britain. Varieties-Black Hautbois, White Hautbois, Globe Hautiois, Conical Hautbois, Double or Twice Bearing, producing delicious fru $t$ in spring and autumn.

Tне Chls.r, Fragaria Chiliensis, with large, oval, thick. hairy leaves, and large flowers ; the fruit large and very firm; a native of South America. Wilmot's suberb. or Larre Cockscomb Scarlet. Knight's Seedling, and Greenwell's New Giant, are highly esteemed varieties.

KeEn's IMPERIAl, OR New ChII.I, Fragaria Chili var,, raised by Mr. Keen. of Isleworth, a most excellent bearer, ripening early. The fruit is very large; the flesh firm and solid, without any separate core: colour scarlet.

ThE A r.pre, or Prolific, Fragaria collina, commonly lasts from June till November, and in mild seasnns till near Christmas; the varieties of this fruit are red and white. Natives of the Alps of Europe.

Tue ONE-Leavr.D. Fragaria monophylla, the pulp of the fruit, pinkcoloured. A native of South America.

The following varieties have been lately propagated from some of the above species :- 
Brsuop's Orange, Bishop's Globe, Bishnp's New. Fruit large, of roundisn or connical firm; orange scarlet colour. and very delic.ous flavour; ripe early in July.

Garnstone Scakl.et. A fine, highly cstcemed scarlet variety, of large size, roundish form and peculiarly rich flavour, which ripens early in June.

ELros, Elton Pine Strawberry. Fruit very large; form heart shaped, or obtusely conical; colour bright dark scarlet ; flesh firm, rosy red; flavour very rich, spicy, aromatic and agreeable. A beautiful drawing of this fruit is given in "Hoffy's Orchardist's Companion," from whence the above description was taken.

Grove EN S Scarlet, Atkinson's Scarlet. A secdling raised by Wm. Atkinson, at Grove End, Marylebone, in 1820; fruit large, oblate, of a bright vermillion colour, and rich flavour; ripe by the middle of June.

Hovey's SEFDling. 'This favourite variety was raised by Messrs. Hovey \& Co., of Boston, in 1834. Fruit very large; form round, or slightly ovate, conical ; colour deep shining red, paler in the shade; flesh scarlet, and firm, abounding in an agreeable acid, and high flavoured juice, not surpassed by any other variety; ripe early in July.

Hunson's BAy, American Scarlet, Velvet Scarlet, Large Hudson. Fruit large, of ovate form; represented by Mr. Downing as the best for market; early in July.

Monthi.y Red Alpine. Fruit of medium size, and conical form ; continues bearing fruit moderately from June till winter.

Myatr's Rritish QueEn. The fruit of this celebrated variety is said to be of monstrous size; in form roundish, and in quality first-rate ; about the iniddle of July.

Mratr's Pine. A medium sized fruit of ovate form, and very rich flavoured; ripening in July.

Prince A I.BERT. A new variety lately raised in London, represented as a large fruit of ovate form, very splendid in appearance, and delicious in flavour; ripe in July.

Prince's New PINe. An excellent seedling variety of large size and ovate forın. Raised by Wm. R. Prince, of Flushing; ripe early in July.

Roseberry Montevideo, Montevideo Early Scarlet. An improved American seedling. from the common Roseberry : of large size, conical forın, and fine tlavour; ripe early in July.

Swainstone's SEEDling. This variety is described as large, ovate, and of the very first quality, ripening one crop early in June, and a second crop in autumn.

Victoria, Higgins's Seedling. The fruit of this variety is greatly esteemed : it is extra large, of roundish form, and exquisite flavour; early in July.

WARREN's SEEDIINo, Wurren's Methven. This is represented as a peculiar fruit, being of large size, and in form nearly flat; it is moreover of rich pine-apple flavour, and yields abundantly throughout the month of July.

White Bush Alpine, New White Alpine. A medium sized berry, of ovate form and agrceable flavour: the plant has no runnerz, and ripens its fruit in June and July. 
All the species and varieties of this fruit are highly estimated in Britain, where they are cultivated in great perfection. Berries have been known to weigh from one to two ounces, which have been grown to the circumference of eight inches and upward. It may be gratifying to the lovers of this excellent fruit to be informed that some of the best kinds are attainable here. The late Jesse Buel, Esq., of Albany, informed us, in the Albany Argus, of June 23, 1830, that he had grown the Downton, (a variety of the Chili, crossed by Mr. Knight,) two years in succession, 43 inches in circumference. He said, that " he picked a pailful that morning of the Methven Scarlet Strawberry, which had an average circumference of three inches each. Several measured four inches, and one four and a quarter inches. Sixtythree, divested of the calyx, weighed a pound, which is a trifle more than four to the ounce." Several of the choicest kinds have been lately transplanted from the London Society's Garden into the American Nurseries, and some fine native seedlings have been lately propagated, which will bear comparison with many of the best foreign varieties.

\section{WALNUT}

\section{Noyer. Juglans.}

From the circumstance of our having an abundance of the fruit, from the many species of this genus of trees growing spontaneously around us, it is presumed that the culture of the Juglans regia, commonly called English Walnut, or Madeira Nut, has been neglected by many of our citizens. It is a native of Persia, and is cultivated in France, England, and in other parts of Europe, both as a fruit and timber tree. The fruit, in England, is mnch used in a green state for pickling, and also as an adulteration of soy sauce. In France, an oil, which supplies the place of that of Almonds, 
is made from the kernel. In Spain, they strew the gratings of old and hard nuts, first peeled. into their tarts and other meats. The leaves strewed on the ground, and left there, annoy moles, or macerated in warm water, afford a liquor which will destroy them. The unripe fruit is used in medicine for the purpose of destroying worms in the human body. Pliny says, "the more Walnuts one eats, with the more ease will he drive worms out of the stomach."

The timber is considered lighter, in proportion to its strength and elasticity, than any other, and therefore cornmonly used in England for gun stocks. It is used in cabinet work in most parts of Europe; the young timber is allowed to make the finest coloured work, but the old to be finest variegated for ornament. When propagated for timber, the nut is sown ; but when fruit is the object, inarching from the branches of fruit - bearing trees is preferable. Budding is also practised by some; the buds succeed best when taken from the base of the annual shoots; ordinary sized buds from the upper part of such shoots generally fail.

Walnut trees that have not been grafted or budded, may be induced to produce blossoms by ringing the bark, that is, cutting out a streak of the bark around the body or main branches of the tree. Walnut trees seldom yield much fruit until fifteen or twenty years old; it is produced on the extremities of the preceding year's shoots. The trees should stand forty or fifty feet apart, and they may be permitted to branch out in their natural order. They need but little pruning, merely to regulate any casual disorderly growth, to reduce over-extended branches, and to prune up the low stragglers.

Lest any of our native Walnuts should be neglected or abandoned by any, I annex a description of the different kinds :

Juglans catharticus, is known under the name of Butternut. Oilnut, and white Walnut; these nuts are used by the Indians as a medicine. 
Juglans nigra, the black Walnut, is a tree of large size; its fruit is known to be excellent.

Juglans olivaformis, Pecan, or Illinois nut, is delicious. The nuts of Juglans sulcata, which is called thick shell bark, Hickory, and Springfield, and Gloucester nut, are large and well-tasted. The shell bark Hickory, shag bark, or scaly bark Hickory, Juglans alba, is so called on account of its bark, which is torn lengthwise in long loose strips, as in $\mathbf{J}$. sulcata. The Juglans tormentosa, the Mucker nut, white heart Hickory, or cummon Hickory, and most of the other kinds enumerated, are worth preserving; or cultivating where there is none, for its timber for mechanical purposes; and that of the Juglans glabra, or Hog nut, is useful for brooms, \&c. 


\section{CALENDAR AND INDEX.}

\section{JANUARY.}

THE clear icicle shines in the sun's faint beam, Cungealed is the river, the lake, and the stream, The trees are all leafiess, while sullen winds roar, And Nature benumbed, seems her fate to deplore.

As the weather at this season of the year is generally unfavourable to any employment in the Orchard or Fruit Garden, I cannot occupy a few pages more appropriately than in directing the reader's atteution to subjects connected with improvements in the several species and varieties of Fruits; for it must be admitted that there is no kind of fruit, however delicious, that may not be deteriorated, or however worthless, that may not be aneliorated, by particular modes of management; so that after a given variety shall have been created, its merits may be either elicited or destroyed by the cultivator. In this place those practices only need be considered that tend to improvement.

It is an indubitable fact, that all our fruits, without exception, have been so much ameliorated by various circumstances, that they no longer bear any resemblance in respect of quality to their original. Who, for instance, would recognize the wild parent of the Green Gage Plum in the austere Sloe, or that of the delicious Pippin Apples in the worthless acid Crab? Or, what resemblance can be traced between our famous Beurre Pears, whose flesh is so succulent, lich and melting, and that hard, stony, astringent fruit, which even birds and animals refuse to eat? Yet these are undoubted cases of improvement, resulting from time and skill patiently and constantly in action. But it would be of little service to mankind that the quality of any fruit should be improved, unless we adopt some efficient and certain 
mode of multiplying the individuals when obtained Hence there are two great objects which the cultivator should aim at, viz Amelioration and Propagation.

In planting seed for the purpose of procuring improved varieties, care should be taken not only that the seed be selected from the finest existing kinds, but also that the most handsome, the largest, and the most perfectly ripened specimens should be those that supply the seed. A seedling plant will always partake more or less of the character of its parent, the qualities of which are concentrated in the embryo, when it has anived at full maturity. As this subject has been already discussed in the second part of this work, page 133, I shall direct the reader's attention to the operation of Cross Fertilization.

This is effected by the action of the pollen of one plant upon the stigma of another. The nature of this action is highly curious. Pollen consists of extremely minute hollow balls or bodies; their cavity is filled with fluid, in which swim particles of a figure varying from spherical to oblong, and having an apparently spontaneous motion. The stigma is composed of very lax tissue, the intercellular passages of which have a greater diameter than the moving particles of the pollen. When a grain of pollen comes in contact with the stigma, it bursts, and discharges its contents among the lax tissue upon which it has fallen. The moving particles descend through the tissue of the style, until one, or sometimes more, of them finds its way, by routes especially destined by nature for this service, into a little opening in the integuments of the ovulum or young seed. Once deposited there, the particle swells, increases gradually in size, separates into radicle and cotyledons, and finally becomes the embryo,- the part which is to give birth, when the seed is sown, to a new individual. Such being the mode in which the pollen influences the stigma, and subsequently the seed, a practical consequence of great importance necessarily follows, viz., that in all cases of cross fertilization, the new 
variety will take chiefly after its polliniferous or male parent; and that at the same time it will acquire some of the constitutional peculiarities of its mother. Thus the male parent of the Downton Strawberry was the Old Black, the female a kind of Scarlet. In Coe's Golden Drop Plum, the father was the Yellow Magnum Bonum, the mother the Green Gage; and in the Elton Cherry, the White Heart was the male parent, and the Graffion the female.

The limits within which experiments of this kind must be confined are, however, narrow. It seems that cross fertilization will not take place at all, or very rarely, between different species, unless these species are nearly related to each other: and that the offspring of two distinct species is itself sterile, or if it possesses the power of multiplying itself by seed, its progeny returns back to the state of one or other of its parents. Hence it seldom or never has happened that domesticated fruits have had such an origin. We have no varieties raised between the Apple and the Pear, or the Plum and Cherry, or the Gooseberry and the Currant. On the other hand, new varieties obtained by the intermixture of two pre-existing varieties are not less prolific, but, on the contrary, often more so than either of their parents : witness the numerous sorts of Flemish Pears which have been raised by cross fertilization from bad bearers, within the last thirty years, and which are the most prolific-trees with which gardeners are acquainted; witness also Mr. Knight's Cherries, raised between the May Duke and the Graffion, and the Coe's Plum already mentioned. It is therefore to the intermixture of the most valuable existing varieties of fruit that gardeners should trust for the cmelioration of their stock. By this operation the Pears that are in eating in the spring have been rendered as delicious and as fertile as those of the autumn; and there is no apparent reason why those very early, but worthless sorts, such as the Muscat Robert, which usher in the season of Pears, should not bo brought to a similar state of perfection. 
Lindley recommends the operation of cross fertilization to be performed early in the morning of a dry day; about sun-rise is a good time to begin, and before the blossom is entirely expanded; the pollen being at that time humid, is closely attached to the anthers. The blossoms must be carefully opened and the anthers extracted by delicate scissors, care being taken not to wound the filaments or any other part of the flower. This being done, the matured pollen from another variety must be carefully placed on the blossom which it is intended to fertilize, and from which the anthers have been extracted; and this operation must be repeated twice or three times in the course of the day. By shaking the blossoms over a sheet of white paper, the time when it is perfectly matured will be ascertained. It is necessary to protect the prepared blossom from bees and other insects with thin book-muslin, or gauze, till a swelling is perceived in the germ. When the process has been successful, the pollen which has been placed on the stigma becomes so attached that it cannot be removed with a hair pencil; it changes form and colour, and soon disappears, and the blossom will soon wither and fade; but when the process has been imperfect, the pollen is easily detached from the stig$\mathrm{ma}$, its appearance is unaltered, and it remains visible with the duration of the flower, which will continue a long time.

For further information on these subjects, see Outlines of the First Principles of Horticulture, pages 120 to 140 of the second part of this work. 


\section{FEBRUARY.}

Without 'tis a desert, too bleak for a ram,

Within we have one-merely Apples and Jam,

Preserved for the season, with skill and with care,

By the hands of the thrifty, the good, and the fair !

As the season for pruning fruit trees and vines commences in the various parts of our country at different periods, according to the climate, I would submit a few general remarks on the subject, with a view to prepare the gardener for the performance of the work in a skilful manner, and at the proper season; for be it remembered that untimely or injudicious pruning may produce injury instead of benefit, and in many cases defeat the real object of the operation.

Having given ample directions for the cultivation of the various species of fruit, I would recommend the novice to peruse every article before he enters upon the work of the garden; he will there discover that no single rule will apply to every lind of fruit; first, because the mode of bearing is different in almost every distinct species; secondly, because the sap rises earlier and continues longer in the branches of some species than in others; and thir.dly, because some trees, as the Plum for instance, is apt to gum, if pruned too soon in the season, and the grape vine to bleed if delayed too long. For the above, and other reasons that may be given, the gardener should examine all his firuit trees frequently in this month, with his implements at hand, and if circumstances will not admit of a general pruning, he may cut off dead branches, and clear trees from moss and canker, also search for the nests of insects, and destroy them while in a torpid state. This will assist the natural efforts of the trees, in casting off the crude and undigested juices, which if confined in them will in a short time destroy them, or some of their branches.

As soon as the severity of the winter is over, the hardy 
and half hardy grape-vines should be judiciously pruned, by cutting out old branches which produced fruit the preceding year, as well as all superfluous and weak young shoots, leaving the strong summer shoots for bearers the coming season, which should be judiciously trained as recommended in articles, pages 21 and 72.

In pruning all descriptions of trees, some general rules may be observed. In cutting out defective branches, prune close to the healthy wood, and also shorten such shoots as have been injured by the winter, to the full extent, or even a few inches beyond, where damage has been sustained.

In pruning healthy young trees the limbs should not be too closely pruned, because this would occasion more lateral shoots to put forth than is beneficial to the tree; which, if not rubbed off in the summer, while quite young, and as it were herbaceous, they will form crowded branches, which may not yield good fruit. In doing this disbudding, howcver, care must be taken to leave shoots in a suitable direction, sufficient for the formation of an open and handsome head to the tree, according to its kind.

It may be observed, farther, that in the event of young trees, taken from the nursery, being deficient in fibrous roots, as is sometimes the case, close pruning may be necessary to maintain a proper equilibrium between the roots and the head, but it should be borne in mind, that foliage is as essential to the maintenance of the roots, as roots are necessary to the promotion of the growth of the head; because the secretion of plants being formed in leaves, it follows that secretions cannot take place if leaf buds are destroyed.

As vegetation makes rapid progress in our climate after the frost is out of the ground, the gardener should employ himself in unfavourable weather, in providing implements and materials for the performance of the work of the garden every fine day, in order that his pruning and planting may be done before the too rapid advance of the sap. 
By such management, he will not only promote the welfare of his fruit garden, but will save himself much anxiety and labour as the season progresses. For some appropriate hints, relative to the employment of this month, see the Calendar for January and February, in the first part of this work, pages 148 and 149 , also page 53 of the second part, and pages 21 and 34 of the third part.

Toward the latter end of this month, it will be time to prune and train grape vines in many situations. Provide shreds or strips of woollen cloth about half an inch wide, or list from broad cloth, which is still better; also small sharppointed nails to use in training vines and such fiuit-frees as require training.

If any removals are contemplated, or if fresh trees or vines are required, arrangements should be made to have them planted as soon as the ground can be brought into good condition. See pages from 9 to 11 , also pages 93,101 to 104 .

If the kernels of the Apple, Pear, and Quince, and the pits of the Apricot, Cherry, Peach, and Plum were not planted last autumn, as directed, let it be done as soon as the earth can be brought into tillable condition, because exposure to frost is essential to their vegetating.

\section{MARCH.}

The Gard'ner at work, ere the birds pipe a tune, Each fruit-tree inspects, then commences to prune;

The insects destroying, on brancles or root, That injure the blossom, or live in the fruit.

If the weather be mild this month, considerable work may be done in the fruit garden and orchard, before the ground can be brought into suitable condition for ploughing, digging, or planting.

Prune grape vines early in this month, if not done last month, but withhold the knife until you have surveyed the 
plant, and selected a full supply of the last summer shoots at regular distances from each other, for bearers the coming summer; cut out the superabundant, with most of the last year's bearers, and naked wood. Prune so that a young shoot will terminate each branch, and shorten the reserved shoots; the smallest to three or four joints, and the strong ones to ten or twelve. Fasten the vines to trellises as soon as pruned, with list, or shreds of woollen cloth, arranging the general branches from ten to twelve inches' distance, more or less, according to the size of the vines and space allotted for them to grow in. Preserve all strong shoots to make cuttings with, to be planted next month, which will produce vines fit to set out next year. See Observations on Training and Pruning, page 21; also, article Grape Vine, 72 to 88.

Prune Apple trees, 38; Cherry, 52; Pear, 112; Quince, 132; also, Currant bushes, 59; Gooseberry, 71; cutting out all crowded branches, worn-out bearers, and decayed wood. If not done in the autumn, plantations may be made this month of all the above species.

Cut out and destroy all the old stems of Raspberry shrubs, reserving three or four of the strongest young shoots on each stool; shorten them at the top, and take away all others, the strongest of which may be transplanted to form a new bed. Lay the trailing varieties for propagation, 134 .

In transplanting trees, care should be taken that the collar, or that part from which emanate the main roots, be not inserted too deep in the soil, as this injures the bark, and, consequently, impedes the natural circulation of the juices. A medium sized tree may be planted one inch deeper than it was in the nursery bed, and the largest should not exceed two or three inches, 9, 93, 101 and 125.

Plant cuttings and suckers of Gooseberries and Currants, also, of such fruit trees as produce them, in order to raise stocks to bud and graft upon; fruit stones and kernels may also be planted for the same purpose.

Young trees, shrubs, and vines may be obtained at public 
nurseries, in different stages of growth, suited for general planting; and others sufficiently advanced for immediate bearers; these should be carefully taken up, and replanted. For full information on this subject, the reader is referred to the article, 'On the Choice of Fruit 'Trees in the Nursery,' page 32.

Toward the end of the month is a good time to prepare for the cultivation of Cranberries; they thrive best in a wet soil, but will grow on almost any land, by giving it a topdressing of peat, bog, or swamp earth. As soon as such ground can be brought into tillable condition, get plants that were produced from layers of the last season, and set them out in rows about two feet apart; they will soon cover the ground by their runners, which, on being layed, will produce an abundance of plants well adapted for additional plantations in succeeding years. See page 57.

Provide Cedar or Chestnut stakes for the purpose of driving into the ground, to protect newly planted trees from injury by the wind.

\section{APRIL.}

No advocate he for a long morning nap, Waking early, he plants ere the rise of the sap; Whilst glee and good humour enliven his face, More happy, by far, than his Lordship or Grace.

Frnish pruning hardy fruit trees the early part of this month; also Apricot, 47; Almond, 51; Fig, 63; Mulberry, 90 ; Nectarine, 91 ; Peach, 104; Plum, 125; not forgetting such trees, vines, and shrubs as may have been left undone last month. At the same time manure and dig the ground around every fruit tree that requires it.

Prepare the ground for planting, by digging, trenching, and manuring, either generally, or in such particular places as are allotted for the trees to be planted in, page 9. 
This is the most proper season for planting the Apricot, Almond, Fig, Grape, Mulberry, Nectarine, Peach, and all such fruit trees, vines, or shrubs as originated in warm climates. Apple, Cherry, Pear, Plum, Quince and other hardy fruit trees, may also be planted with safety early in this month; but autumn is considered the most favourable season for planting all trees, vines, or shrubs of northern latitude, 10, 93, 101 and 125 .

Those who have a variety of soil should accommodate all the varied kinds of fruit to that which has been proved to be the best adapted to its culture; and due attention should be paid to situation and aspect, in planting a fruit garden $o$ orchard, 12.

Use means to destroy insects while in a torpid state, to prevent their spreading, and also the larvæ of insects ; directions for which will be found in the article headed, 'Observations on Insects, and Diseases to which Fruit Trees are liable,' 13.

Grafting may be performed on fruit trees in general, 27; prune and plant Currant bushes, 59 ; Filbert, 65; Gooseberry, 70; Raspberry, 134. Plant cuttings and suckers from these shrubs; also of such trees as produce them, in order to get a supply of stocks to bud and graft upon, as well as some for bearing. Fruit stones and kernels of various kinds may be planted for the same purpose.

This is a good season to plant cuttings of Grape Vines, and the vine may also be propagated by layers, that is, by bending a young shoot down into the earth a few inches, and pinning it down with a forked stick. The top may be tied to a small stake, to keep it perpendicular; 76 and 81 . The tender vines that were laid down in autumn, should be taken up, and fastened to trellises or stakes.

Uncover and raise up the Antwerp and other tender varieties of the Raspberry, and prune them, before the buds shoot, at the same time cultivate the ground around them, and drive in stakes for their support. In order to obtain a 
good supply of Raspberries in the autumn, cut down some of the twice bearing varieties close to the ground, which will occasion strong suckers to shoot up, that will yield an abundant crop of fruit at a season when other varieties are not attainable, 134.

Strawberry beds that were protected with leaves or litter through the winter, should be uncovered, and the plants carefully cultivated; some lay straw over their beds, an inch or two thick, and set fire to it, 187.

As the warm weather progresses, the gardener should be on the alert, in order to conquer the various kinds of insects. Burn damp litter, stubble, leaves, weeds, \&c., near fruit trees, and sow the ashes over the ground, 18 and 91.

\section{MAY.}

The Gooseberry green the first fruit of the year,

In pudding or pie, affords exquisite cheer,

But e'en should the season their pleasure forefend.

In such a dilemma, green Rhubarb's a friend.

Finish planting trees, vines, and shrubs as early in this month as possible; those planted last month should be kept watered in dry weather, and stakes should be applied to such as may be exposed to the wind, 93, 101 and 125.

Finish grafting early in this month. Apples, Pears, and other late-shooting kinds may still succeed, 27.

Strawberry beds may be made early in this month, and if the transplanting is well done, and the plants frequently watered, they will produce some fruit this year, and a plentiful supply the next season. Hovey's American Seedling is worthy a place in every good collection for its productiveness, and the superiority of its fruit. The Methven Scarlet, and Mulberry or Pine, are large and yield plentifully. Kean's Seedling, and also the Downton, are of superior flavour. The Elton Seedling, Southborough Seedling, Myatt's 
Seedling, and Bishop's Orange, are in great repute where cultivated. The old Scarlet, being one of the earliest, should not be forgotten. The Wood and the Alpine Straw berry will produce fine fruit from seed sown in the spring. For names of other varieties, mode of planting, \&cc., see article, page 136.

If frost prevail when fruit trees are in blossom, those trained on trellises, or against walls and fences, may be protected by hanging matting or sheets of tow cloth over them; some defend them by sticking bunches of evergreens between the branches, as cedar, laurel, pine, \&c. The object in doing this, is not so much to keep out the frost, as to break off the sun's rays in the morning after a frosty night, because the sudden transition from cold to heat does more injury than the cold itself.

Propagate Fig trees by layers, cuttings, suckers, and by grafting, 62.

If any webs or larvæ of insects appear on the leaves of fruit trees and vines, pluck off and destroy such leaves before the insects become quickened, which may be a means of preventing any depredation to the advancing leaves and buds. The trees of Plum and other stone fruit are very apt to gum and canker at this season of the year: in such cases the defective parts should be pruned closely off, and whale oil soap applied to the wound. A little soot also should be rubbed on while wet. In large fruit gardens and orchards, means should be used to destroy insects by fumigation, washing, \&c. For various remedies, see Observations on Insects, and Diseases to which Fruit Trees are liable, page 13; see, also, article page 30 .

Divest young budded and grafted trees of all shoots from the stocks, below the bud or graft, as they appear; also rub off all useless buds in early-shooting wall trees, as Nectarine, Apricots, \&c., 48.

To protect Gooseberries and other fruits from mildews sprinkle the leaves with soap-suds; and while they are wet, 
sow sulphur lightly over them. This may be done two or three times a week if necessary, as it is better to use a little of the ingredients frequently, than too much at once. A solution made of saltpetre and stone lime is also a good remedy; but it must be used with caution. See pages 14 and 71 .

\section{JUNE.}

The Cherry, the Currant, and Strawherry red,

To the rich and the poor their refreshment have shed;

Pornona has scatter'd her blessings abroad,

The full-bearing branches bend down with their load.

THE principal business of this month in the fruit garden is summer pruning, which is generally performed with the finger and thumb, by detaching all superfluous shoots and buds; and also to thin the young fruit of Apricot, Nectarine, and other choice trained trees, where it sets too thick or in clusters. The Apricots, so thinned off, and the first principal green fruit, will make excellent pies and tarts. See pages 48 and 92 .

Cherry trees of the finest sorts may be defended from birds, with nets, particularly those trained as espaliers, 52 .

Currant and Gooseberry shrubs of choice late varieties, trained as espaliers or standards, if very crowded with shoots of the year, should be pruned, and the Gooseberry fruit thinned, to promote its growth and ripening in full per. fection, 59 and 71 .

All trees on espaliers require attention; cut off such superfluous shoots as are not required to be trained in, leaving well-situated middle-sized shoots to supply the place of any old branches that it may bo thought necessary to sut away, 23.

Grape Vines should be looked over every week. Cut off all the tendrils and useless young shoots, and stop the shoots before the bunches of fruit. Train up the shoots for bear- 
ing next season, and to a proper length, before you stop them, 86.

Newly planted trees should be watered in dry bot weather; an occasional hoeing around them will also be bene ficial, but care must be taken not to injure the roots.

The trained trees and espaliers should be examined frequently, and cleared of dead leaves and insects; which can be done by the hand, with very little trouble. For the destruction of Rose Bugs on Grape Vines and Fruit Trees, see article Grape, page 84.

Those who have plenty of Strawberry beds, may, by mowing the tops from some of them while they are in blossom, obtain a supply of fruit at a season when Strawberries are scarce. The beds will require to be hoed, and watered in dry weather, 136 and 137 .

\section{JULY.}

The Margaret Apple, the pride of our clime, With the Apricot, Raspberry, true to their time, Are pleasant companions, as summer e'er met, Though others, as welcome, are coming on yet.

Tris the fruit of Apricots, which will be good for pies anu tarts; thin Nectarines; also such Peaches and other fruits as may be desired in full perfection, 48 and 92 .

Defend choice fruit from birds and insects, such as wasps, flies, \&c.; the birds may be kept off by nets, and the insects may be decoyed and drowned, by placing phials of strong liquor, honey, or sugared water near the fiuit.

If annoyed with ants, place cuttings of reed, hollowed elder or anything of a tube-like kind, in which they will harbour, and may be destroyed by dipping the tubes in hot water.

If mildew appear on Grape Vines, syringe them with water, in which a small quantity of saltpetre and stone lime has been infuserl, (it need not be over strong.) To prevent 
any injurious effects from the lime, the vines may be syringed alternately with the liquid and pure water, each two or three times a week. A little sulphur dusted over while the leaves are wet is also a good remedy, 14 .

Look over your trained Fruit Trees and Grape Vines; stop the shoots before the bunches of fruit, and train up such shoots as are reserved for bearing next year. Nip off curled and dead leaves, and destroy insects, 22 and 86.

Fig Trees against fences or on trellises will require attention; train up as many young shoots as will be required for bearers next year, and if the leaves are thick, take some off, with a view to expose the fruit to the influence of the sun, which is essential to its ripening with good flavour, 62 .

Toward the end of this month is the proper season for budding the Nectarine, Peach, Plum, and other species of stone fruit. The Peach stock is often budded when only a year old, but the Plum stock is generally kept in the nursery two or three years 25 .

Apple and Pear stocks may be budded when two or three years old, but those fruits are generally propagated by graft. ing early in the spring.

A judicious pruning of Peach, Nectarine, and other kinds of young trees is necessary at this season. To prevent the long, straggling growth of limbs which are frequently bare of shoots for some distance from the body of the tree, such limbs should be shortened, which will cause the production of lateral shoots. An annual summer pruning is essential to the well being of a tree, as by shortening the wood of the preceding year's growth, a symmetrical tree containing a good supply of bearing wood may be formed. By this treat ment the longevity of a tree will be promoted, provided the work is done with judgment and care, so as not to render the tree impervious to the influence of the sun and air; for, be it remembered, that the head of a tree must always be kept moderately open, for the purposes of giving the fruit the best possible chance of ripening perfectly, 21,34 and 48 . 


\section{AUGUST.}

The Peach, plump and ripe, brings us excellent fare, Let the Nectarine, too, in this eulogy shareTheir flavour how grateful-their juices how fine, Inequall'd in taste by the fruit of the vine.

Finsis all that remains to be done of summer pruning of all trained fruit trees and vines, as in the last two months; destroy all irregular and unnecessary after-shoots, and train in a requisite supply of well-situated shoots, for bearers next year, 48 and 86 .

Examine the fruit trees that were inoculated last month, and wherever a bud has failed, insert another upon the smooth part of the bark. Budding generally succeeds well if done by the middle of this month, 26 .

Keep Raspberry beds clear of all straggling suckers; tie up such shoots as are adapted for next year's bearers to neat stakes, and keep the ground clear of weeds, 134.

Strawberry beds should be kept clear of weeds, and the runners may be taken from some kinds to make new plantations with, 137.

If $\mathrm{dry}$ weather prevail, as is generally the case at this season, hoe frequently between such young trees, shrubs, \&c., in the nursery beds, as are well rooted; and water those which were recently transplanted.

As numerous species of insects are engendered by the excessive heat which generally prevails at this season of the year, efforts should be made to destroy them. By a general search every morning and evening, the increase of some species may be checked, and by perseverance, they may be totally eradicated. See pages from 18 to 21 of the first part, and pages 13, 30, 84 and 156 of the third part, for directions how to proceed.

Many of those reptiles that take up their abode in the earth may be annoyed by frequent sowings of compost over the surface of the land. The various kinds of bitter and 
acril substances recommended in the chapter containing ' Observations on Insects and the Diseases of Fruit Trees,' page 13, are not only adapted to the destruction of insects, but the use of them in this way, will produce an incalculable benefit to the land, and in many cases preclude the necessity of using any other manure.

The ingredients alluded to consist of ashes, charcoal dust, plaster of Paris, tobacco dust, lime, salt, soot, pepper, potash, saltpetre, snuff, and sulphur. The proportions may be as follows: Of the first four articles, half a bushel of each; of the next three, a peck of each; and of the last five, say one pound of each; which will make together three bushels of compost.

As all land possesses inorganic matter, which contains more or less of the elements comprised in the above remedies, and as some land contains more of one element than another, a judicious choice may be made from the above list, with a view to suit all the various kinds of soil; thus, in locations open to sea breezes, which replenish the earth with salt, that article may be dispensed with, and another substituted; and on land which is not susceptible of being improved by lime, perhaps the salt may be beneficial; but it is presumed that in most cases a compost made of all, or as many of the different articles as are attainable, would produce a lasting benefit to land in general, by sowing, say at the rate of a bushel per acre, once a week, at those seasous of the year when it will avail most in the destruction of reptiles and insects; and as the primary object of using the compost is to prevent our fruits from being destroyed, it would prove most effectual if sown out of a wagon, from which, in passing between the trees, the leaves could bo dusted. See pages 19, 89 and 104, of the first part. 


\section{SEPTEMBER.}

The Peach and the Pear tree have still ample store, And the Plum, most inviting, "makes urchins adore ;" A bountiful feast is spread over the land, For great is the Giver, unsparing His hand.

Prantations of Strawberries may be made this month, either with runners or seedling plants, 137.

Protect your Grapes and other fruit from wasps and other insects; either decoy them with honey or sugared water, or hang nets over the fruit; some take the trouble of putting the bunches into crape or paper bags.

Grape Vines and espalier trees in general should be attended to, as directed in the previous summer months; by depriving them of all useless shoots and suckers, training in those branches intended for the next year's bearers, and destroying the eggs of insects, curled leaves, \&c., 85 .

Stone fruit, which will now be continually ripening, should be gathered while in full perfection, and not suffered to get over-ripe, so as to lose its peculiar flavour.

Ground allotted for the planting of fruit trees and vines the coming autumn, should be prepared this month, by digging, trenching, and manuring, where necessary, 8 .

With a view to conquer the various kinds of insects and reptiles, persevere in the use of the remedies recommended last month. Gather up all fruit which falls from the trees, or turn geese enough into the orchard to eat it up, by which means the reptiles and their food are devoured at once. Hogs are the best scavengers, but they are too apt to do injury by rooting; they may, however, be let into the orchard a few hours each day, and watched, 13 and 124.

Besides the ingredients already recommended, there are others which may be used in various ways. Some may be dissolved in a hogshead allotted for the purpose, which on being kept filled with water. makes a solution well calculated to sprinkle on the leaves of trees, by means of a syringe or 
a portable garden engine. Others may be prepared of the consistency of paint, and applied to the body and limbs of trees with a brush; and some may be made into a composition, and used as an ointment at the time of pruning. The articles alluded to are beeswax, burdock leaves, cow dung, decoctions of elder, lamp-black, ley, soap-suds, soft-soap, tar, tallow, turpentine, urine, vinegar, walnut leaves, and whale oil soap, to which may be added such of the dry materials in our previous list as are dissoluble. See page 18 of the first part, and page 30 of the third part.

If any of my readers, from the prevailing prejudices alluded to in page 113, should feel disposed to abandon or root up any of the fruit trees which have been nurtured and esteemed by their forefathers, they are recommended before doing so to apply some of the preceding remedies, and also to follow the advice given in chapter the 13th and verse the 8th of St. Luke's Gospel, in reference to the barren fig tree, namely, "dig about it, and dung it." If after this, it should be necessary to "cut it down," get some scions of the same varieties from vigorous and healthy trees, and in-giafi them on stocks, carefully raised, by which means the old fruits will have the same chance as the new varieties; but it will be generally admitted that a new broom sweeps clean, and that old things in general are too apt to be neglected. I would here avail myself of the opportunity of remarking, that so strong is the propensity of some persons to adopt novelties, that they often abandon some of the best productions of the garden in order to find room for other plants, merely because they are new, and which they cultivate with peculiar care; whereas, if the same attention was bestowed on the old inmates of their garden, they would prove the most worthy of being cultivated and perpetuated. 


\section{OCTOBER.}

Oh Bacchus! thy Grapes now in bunches hang down; Some press them too freely their "sorrows to drown;" Let " Temperance in all things" be ever our guideNo evil can flow from the generous tide!

Prepare the ground for planting all kinds of hardy fruit trees this month, by digging, trenching, and manuring, 8 .

Gather such varieties of Apples and Pears as are in full growth, both of autumn-eating and winter-keeping kinds; do it on dry days ; let the keeping sorts lay in heaps, to discharge their redundant moisture; after which convey them to a ronm adapted for preserving them through the winter; lay each kind separate, and cover them up with dry straw, a foot or more in thickness, according to the warmness of the room, which will preserve them in good order.

Prune Currant and Gooseberry bushes; make new plantations, and plant cuttings from these shrubs, prepared as directed in pages 59 and 70.

Plant the stones of Cherry, Peach. Plum, \&c., in drills about two inches deep, for the purpose of raising stocks and for new varieties; and in temperate climates, kernels of Apple, Pear, Quince, \&c., may be scwn in drills about an inch deep for the same purpose. Plant, also, cuttings of hardy trees, suckers of Filberts, \&c., 38 and 62.

Strawberry beds which were planted last month should be kept free from weeds, and if dry weather prevails, they should be occasionally watered, 136 .

Plantings of hardy trees may be commenced toward the end of this month, or sonn after the leaves show indications of decay, whether fallen or not, 10.

Toward the end of this month, or early in the next, all the tender shrubs and vines must be protected, by laying them down and covering them with earth, or by entwining straw or matting around them, 63,80 and 135 .

In gathering grapes for the dessert be careful not to bruise them or disturb the vine; to aroid which cut off each bunch with a pair of small scissors. 


\section{NOVEMBER.}

And now we've arrived near the close of the year, Winter Apples and Cranberries bring up the rear; All are good of their kind, and we freely declare, Not one of the Fruils we would willingly spare.

Apple, Pear, Plum, Cherry, Chestnut, Mulberty, Quince, Walnut, and other hardy fruit trees may now bo planted; use caution not to injure them in taking up or removing them; let holes be dug somewhat larger than is sufficient to admit the ronts in their natural position, and of sufficient depth to allow of some good rich compost or pulverized earth to be thrown in before the trees are planted. See pages 9, 34, 103 and 125, and read the article headed 'Observations on the Choice of Fruit Trees in the Nursery,' page 32.

Finish gathering late varieties of Apples, Pears, Grapes, \&c.; do it in dry weather, and stow them away out of the reach of frost, as recommended last month.

Cranberry, Currant, Filbert, Gooseberry, and Raspberry shrubs may be planted this month; at the same time cut out all crowded branches, superfluous suckers, worn-out bearers, and decayed wood, 58, 60, 65, 70 and 134 .

Strawberry beds made in August and September, as well as those of greater age, may be covered up with leaves, light manure, salt hay, or other litter.

Protect the beds where fruit seeds and cuttings were planted last month, by a covering of light manure, compost, or leaves of trees.

Winter pruning may be performed this month on some species of hardy trees, shrubs, vines, \&c., and continued at all opportunities throughout the next month, 23.

Fig Trees, Tender Grape Vines, as well as the Antwerp and other half-hardy Raspberry Shrubs, must be protected from the effects of frost, which is done by bending them down to the ground and covering them with earth five or six inches, which should be sloped so as to carry off the rain. Some of the trained Vines and Fig Trees may be protected with wickers of straw or matting, 63,80 and 135 . 


\section{DECEMBER.}

Let sober Reflection, the Tiller employ, The sound seeds of Virtue will spring to his joy ;

To the Ruler of season's, let gatitude's voice, In $\mathrm{H}$ is love and $\mathrm{His}$ wisdom for ever rejoice.

If any of the work recommended to be done in the last month was not accomplished, let it be done with all possible despatch this month, as we know not what a day may bring forth.

Protect the stems of newly-planted trees. Cover with litter the roots of Grape Vines and Figs against walls, and cover the branches with mats, \&c. In temperate climates prune Apple, Pear, Quince, and other hardy fruit trees; cut out rotten and decaying branches, 23 and 63 .

To destroy insects on the fruit trees, and prevent them from creeping up and breeding on them, do as follows:-

Take a strong knife with a sharp point, and a sharp hooklike iron made for the purpose; with these scrape clean off all the moss and outside rough bark, and with the knife pick out or cut away the cankered parts of the bark and wood, in such a slanting manner that water cannot lodge in the sides of the stem of the trees. Having cleared the trees in this way, make up a mixture of lime, soot, and sulphur; put these ingredients into a pot or tub, pour boiling water upon them, and with a stick stir and mix them well together. When this strong mixture becomes cold, and about the thickness of white-wash, take a brush, dip it in the mixture, and apply it to the stems and large branches of the trees, dabbing it well into the hollow parts of the bark.

The pruning of hardy fruit trees and hardy shrubs may be performed at all favourable opportunities through the winter, 21 to 24 .

For farther information on the winter management of Fruit Trees, the reader is referred to the articies corstmeris. ing pages $7,13,21,30$ and 32. 


\section{TO THE PEOPLE}

\section{OF THE \\ UNITED STATES OF AMERICA.}

\section{FELLOW-CITIZENS :}

Ax application having been made to your Representatives in Congress to vote a sum equal to five cents from each individual in the United States, OR ABOUT A MILLION DOLLARS OF YOUR RESOURCES, to the promotion of an improved system of "Terra-culture," as described in Senate, Document No. 23, of the third session of the 25th Congress, I hereby direct your attention to a few extracts taken from the applicant's preamble; copies of which were forwarded to each member of the 26th Congress, in session, November 30,1839 , by Russcll Comstock.

From the Poughkeepsie Eagle, of January 25, 1840.

\section{PRESERVATION OF FRUIT TREES, PLANTS, \&c.} GREAT DISCOVERY.

"To the Hon. Perry Smith, Chairman of the United States Senate Com. mittee on Agriculture of the 25th Congress. "With the consent and by the advice on the $23 \mathrm{~d}$ inst., of the chairman of the United States Senate Committee on Agriculture of the 25th Congress, I forward to each member of the 26th Congress the accompanying document dated the 14th inst.; the object is to show you some of the pronf that a discovery of vital importance to civilized man has been made, which in several letters from different members of the present and last Congress is valued at HuNDREDS or rrLLIONS OF DAYS' LABOUR, AND WORTH MORE THAN ALL THE DISCOVERIES OF THE PRESENT AGE COMBINED-THE APPLICATION OF STEAM NOT EXCEPTED.

"For what purpose would all the owners of the public lands more freely or gratefully consent to give one hundreth part of those lands, or the proceeds thereof? Would they nut be grateful to those members of Congress, who assist in giving the owners of the public domain the desired information, and reverence them as benefactors of human kind.

"For the honour of the Republic, for the honour of the age, and for the interest and comfort of the living, as well as the unborn, let not that discovery which may cause two seeds to ripen where one now does, which prevents the premature death of all cultivated trees, which has been searched for in vain during the history of all civilized society, die with the discoverer for want of the action of the United States Congress."

Our patriotic discoverer "claims the following five discoreries as his, besides other discoveries which are stated in his memorial to the 25 th Congress : 
1st. "That various diseases, universally supposed to be destructive to plants are only symptoms that a particular error in cultivation has been committed; and that many other injurious effects have been produced by the same error, which are attributed to other causes.

2d. "That the error is UNIVERSAl.LY commitTED, to a greater or less extent, throughout the states, and that he has seen an excess of it whereever he has been, which is in the Atlantic States, from Georgia to Massachusetts, inclusive.

3d. "That the Peach and Nectarine are more easily injured by the error than most other Fruit trees, and the cause of their being more easily unjured by it; and that this error causes them to be barren, or short-lived.

4th. "That the application of two known laws in nature demonstrate the reality of his discovery and its application to the whole vegetable king dom; and that by them, his discovery, (if publicly known,) must be per petuated, and his practice more easily introduced : and that by these two laws the occasional success of common remedies is explained.

5th. "That the said error is the obstacle which has discouraged experimenters, and lamentably retarded improvements in the scienee and practice of agriculture; and that he has discovered facts and made himself acquainted with knowledge sufficient to reduce them to practice."

We are farther informed, "that it is neither climate, nor soil, nor insects, nor worms, that are the cause of many of the disastrous effects that have been attributed to them, but that those effects are produced by error in cultivation, which diseases the smallest plant or largest tree."

Our modest and patriotic fellow-citizen admits, in the course of his preamble, "that the practical part of his discovery is So EXTREMELY SIMPLE and economical, that it costs no more to prevent the diseases than it does to produce them ; and that it is so different from the established theories and habits of the people, THAT UNLESS A LARGE AMOUNT BE APPROPRIATED, many will be unwilling to try it, and therefore the pUBLIC Good seems to require that a large amount should be appropriated." He moreover asserts, that "there are two known laws in nature, by which the reality of his discovery, and its application to the whole vegetable kingdom, are demonstrable in less than thirty words."

That this invaluable secret, whatever it may be, is not strictly speaking a new discovery, is demonstrable by numerous living witnesses which have inhabited the fields of the old world for over a thousand years ; and our discoverer freely admits, and in very emphatic language, that there are thousands of trees in our own country on which, what he terms " the common error" bas never been committed; and also, that several of the fifteen gentlemen to whom he communicated his secret, "confidently for ever," have some such trees on their own domains.

Hear him-" The Senator from Missouri, (Mr. Linn,) said, that the most flourishing and healthy Peach tree in his possession had never had what I call the common error in cultivation committed upon it."

"The Senator from Pennsylvania, (Mr. McKean,) said, that he had long supposed that what I call the common error. was an error, but that he had no idea of such extensive evils arising from it."

"The Senator from Maryland, ( $\mathrm{Mr}$, Spence,) said, that in his district it was a universal custom to commit what $I$ call the common error in cultivation, on the fruit trees, and that it was common to have no Plums perfect 
and free from worms, excepting on a few of his, on which the error had not been committed for twenty years, if ever; and those few (four) continued to bear abundantly annually; that he had no recollection of ever seeing an imperfect wormy Plum on either of these four trees, but that he had never supposed that to have been the cause of their perfection."

The Senator from South Carolina, (Mr. Calhoun.) to whom I am indebted for pointing out one symptom of the error, and for a valuable suggestion in the culture of plants, said, "while examining the defective trees around the Capitol, that the principle when exhibited was very plain and simple, that it was philosophical, and in his opınion it could not be neglected without injury to the health and growth of trees and plants, and deserving of public patronage."

"The Vice President of the United States, (Mr. Johnson,) said, that my discovery was perfectly cunsistent with the laws of nature; and (when observing a few trees near the Capitol, which had been injured by the error, and were recovering.) farther remarked, that my theory was essentially correct and obvious to the most superficial observer."

"The member from New-York, (Mr. Jackson,) said, that he had reared an orchard on which he had carefully avoided an excess of what I call the common error, and that it had been admired as the most flourishing and fruitful orchard in the neighbourhood; and that he had recently seen a field of Indian corn, which yielded more than one hundred bushels of shelled grain to the acre, in which an excess of the error had been avoided, while the success was attributed to quite a different cause."

From the preceding extracts. it is evident that this inestimable treasure lays near the surf.ce; and from the disclosure having been communicated to rational and intelligent minds, it is preposterous to expect that those gentleman can, in the pursuit of their rural avocations, act directly contrary to knowledge and sound judgment; they must, therefore necessarily and unavoidably communicate the secret by their example, which will eventually disseminate in proportion as mankind take an interest in the merits of the alleged discovery.

But lest the full benefits of this invaluable remedy should be withheld from the community for want of the action of the United States Congress, I have submitted an exposition of $m y$ views of the particular points adverted to in the preamble, which may be found under the heads, Nectarine, Peach, and Plum, pages 91,98 and 124 of the third part of the present edition of the Young Gardener's Assistant; and I would furthermore remind my readers that the directions heretofore given in this and previous editions of the work are in strict accordance with the same doctrine; and that although the error alluded to is admitted to have been very generally committed, I am not aware that any writer has ever taught or encouraged the error, either direct or indirect; I confess, however, that I have heen induced to expatiate on this mal.practice in horticulture from the subject having elicited the grave consideration of enlightened legislators of these United States.

And lest these my voluntary disclosures should prove to have no bearing on the alleged discovery, I would prepare the public mind for its reception by an exhortation to TEMPERANCE AND MODERATIon, as the omly sufe course that can be considered applicable to the cultivation of all the varied species of plants, which cumprise "the whole vegetable kingdom." In 
articles page 26 of the first part, and pages 16, 25 and 97 of the second part, I have shown that the various species of plants whicls occupy our greenhouses, gardens, and fields, require each their peculiar aliment-they having been collected from all the diversified regions, climates, and soils through earth's remotest boun!s ; they consequently comprise natives of mountains and rocks, as well as of plains, valleys, and water courses. The most essential aliment for natives of warm climates and dry soils being HEAT, artificial means are used in cool seasons, and urpropitious climates to produce it. Natives of temperate climates require salubrious AIR, hence they are cuitivated to the greatest. perfection in our Northern States in spring and autumn; and in our Southern states in the winter; see page 147 of the first part; and natives of humid climates, as also amphibious plants in general, require a more than ordinary share of Morsture, and grow best in wet soil; but these THREF ELEMENTS collectively constitute the fond of plants in general, and should be judiciously imparted to the various species, in due proportions, according to circumstances. See pages 49,64 and 67 of the first part, for a more precise view of this subject. I have also shown that the roots of various species of plants require each their peculiar aliment, which is not to be found in all descriptions of land; this is demonstrated by roots of trees being frequently discovered spreading beyond their oruinary bounds in quest of salutary foud.

Although it has teen admitted that excessive deep planting of trees and plants is injurious, and in many cases fatal to their very existence, it does not follow that all annua's and biennials are injured by the same means; on the contrary, the earthing up of particular species of plants in a late stage of growth is calculated to promote early maturity, which constitutes the most essential art in gardening for the market; because the earliest crops are always the most profitable. It is moreover a necessary practice in climates where the seasons for gardening are short-as without such practice. many kinds of vegetables could not possibly be matured in due season for gathering before winter.

I would here take the opportunity of proving this last position, by reminding the reader that the effects of deep planting. the Peach tree for instance, is discoverable soon after the error is committed, by its fruit ripening prematurely, and this is often the case for a year or two prior to its fnal decease, and should operate as a salutary lesson against planting perennial plants and trees too deep.

In conclusion of this article, which is intended as an appendage to my works on gardening, I would urge gardeners and cultivators to consult the operations of nature in all their rural pursuits; and with a view to aid them, I subjoin the following rules, which are farther illustrated under the different heads :

1. In transplantiug fruit trees, let the collar, or that part from which emanate the main roots, be near the surface. A medium sized tree may be planted an inch deeper than it was in the nursery bed; and the largest should not exceed two or three inches See pages 93,101 and 125 of the third part of the present edition of the Young Gardener's Assistant.

2. In the cultivation of such plants as are transplanted. or grown in hills or clusters, as Indian Corn, \&c., keep the earth loose but level around them in their early stages of growth, by frequent hoeing, ploughing, or culti- 
vating; and to promote early maturity, throw a moderate portion of earth about the roots and stems at the last or final dressing.

3. In the sowing of seed, remember that IN UNITY THERE IS STRENGTr, and that from the gerrninative parts of a seed being weak and diminutive, it cannot be expected to perforate through the soil, solitary and alone. To insure a fair chance plant your seed moderately thick, and thin out tho surplu; plants while young. In planting seed in drills, which is the most eligible plan, the size of the seed and strength of its germ should be considered; large seed, producing vigorous roots, require deeper planting than diminutive seed, producing delicate roots and slender stalks.

4. In the chnice of compost for exotic or greeuhouse plants, imitate the native soil of each peculiar species as nearly as possible, by a judicious mixture of maiden eurth, loain, sand, leaf, swamp, and rock mould, decomposed manures, and such other composts as ase recommended under the different heads. Remember, that although strong manure is essential to the growth of some plants, it is poisonuus to others. Pursue, then, A MEDIUM course. From your soil not being too stiff or too light, too rich or too poor, too cool or too warm, too close or too porous, if not positively salutary and congenial to all, it must render the situation of each endurable. I again repeat, that temperance in the use of aliment, is as essential to the welfare of the vegetable family as it is to the health, happiness, and longevity of mankind.

New-York, March 4, 1840.

\section{T. BRIDGEMAN.}

Since this address has been in press, I have seen another article in the Poughkeepsie Eugle, dated February 29, 1840, wherein our modest and patriolic discoverer gratuitously pronounces his knowledge as superior to that of "all Botunical and Agricultural known uriters!" As I have anticipated the merits of this second valuable discovery in my books, I have nothing more to say than to remind the reader that this uncalled for attack on the brethren of my fraternity, fully justifies not merely the publication, but the most general circulation of these my voluntary disclosures.

\section{RETROSPECTIVE VIEW.}

This summary view of estimates is annexed, in order to aid the Seedsman and Gardener in making out a bill of seed for the purpose of planting any given quantity of ground, under the regulations suggested in tho Vegetable Department of the Young Gardener's Assistant, to which the reader is referred for a more concise view of the subject.

Artichoke; an ounce of seed will produce 600 plants, $\quad$ - $\quad$ - $\quad 31$

Asparagus; one ounce will be sufficient for 1000 plarits _ $\quad$ - 35

Beans, English Dwarf; one quart of seed will be required for every sixty feet of row, - _ _ _ _ _ _ - _ _

Beans, Kidney Dwarf; one quart of seed will plant from 350 to 400 hills, or from 230 to 260 feet of row, - . . . . 42 
Beans Pole, or Running ; one quart of Lima, or large running Beans will plant about 300 hills, or 250 feet of row, - _ _ _ 43

Beet; one ounce may be allotted for every perch, or pole, - _ 45

Borecole, or Kale, an ounce will produce 4000 plants, $\quad$ - $\quad 46$

Broccoli; one ounce is sutficient for 4000 plants, - _ . . 50

Cauliflower; an ounce of this seed will produce 4000 plants, $\quad$ - 53

Cabbage ; one ounce will produce 4000 plants, - _ _ - 55

Cardoon Artichoke; an ounce will produce 600 plants, _ - o

Carrot; half an ounce may be allotted for every pole, - $\quad$ - $\quad$ - $\quad 59$

Celery ; an ounce of seed will produce 10,000 plants, - _ $\quad$ - 60

Corn Salad, or Fetticus; one ounce of seed will sow about two poles

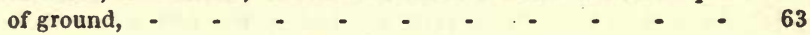

Cucumber; one ounce of seed is sufficient for 200 hills, $\quad$ - $\quad 65$

Egg Plant; an ounce of seed will produce 4000 plants, - $\quad 67$

Endive, or Succory; an ounce will yield 5000 plants, - _ _ 63

Leek; one ounce of seed may be allotted for 3000 plants, - $\quad 71$

Lettuce; an ounce will produce, say 10.000 plants, _ _ _ _ 73

Melon; one ounce of seed will produce from 120 to 150 hills, - $\quad 74$

Melon, Water; an ounce will plant from 40 to 50 hills, - - 75

Onion; one ounce of seed may be allotted for every pole, - $\quad$ - 78

Parsley ; two ounces may be allowed for three perches, - $\quad 80$

Parsnip; two ounces may be allotted for three perches, _ $\quad 81$

Pepper; one ounce of seed will produce 3000 plants, - ? $\quad$ - 82

Peas; one quart will plant from 150 to 200 feet of row, $\quad$ - $\quad 84$

Potatoes; from twelve to sixteen bushels may be allotted for an acre, 85

Potatoes, Sweet; half a peck of seed, properly managed, will produce

15 bushels,

Pumpkin; one quart of field Pumpkin will plant from 500 to 600 hills, and one ounce of the finest kinds will plant from 50 to 80 hills,

Radish; four ounces will do for every three perches, if sown broadcast, and about half the quantity if sown in drills, - $\quad$ - $\quad$ - $\quad 89$

Salsify ; two ounces of this seed will plant three perches, $\quad$ - $\quad$ - $\quad 93$

Shallots; four bushels of bulbs will plant forty poles, - _ - 9S

Spinach; if cultivated in drills, four ounces will plant five perches of land. If broadcast, it will require double the quantity, - $\quad$ - 99

Squash; an ounce of seed will plant from 50 to 100 hills, according to sorts and size, _ _ _ _ _ _ - _ - 100

Tomato; one ounce of seed will produce 4000 plants, $\quad$ - $\quad$ - 101

Turnip; one pound of seed is sufficient for an acre of land, _ $\quad 105$

QUANTITY OF GRASS SEED SUITABLE TO THE ACRE. Clover, sown alone, - 12 pounds. Timothy, ...... 1 peck. Herds Grass, ..... 1 bushel. Lucerne, ...... 8 pounds.

For a pasture for grazing, the following mixtures of seed would be found oxcellent, viz : 6 pounds of clover seed, 1 peck of herds grass, and half a bushel of Orchard grass seed-or 6 pounds clover, lialf a bushel of rye brass, and half a bushel of tall meadow oat seed. 


\section{COMMENDATORY NOTICES.}

"The first edition of "The Young Gardener's Assistant" has been favourably noticed in France :- "One of the leading articles of the Annales de l'Inslitute Royal Horticole de Fromont, is a long notice of "The Young Gardener's Assistant," by Mr. Thomas Bridgeman, of this city. The editor, Le Chevalier Soulange Bodin, speaks of the little work in very commendable terms." - New York Farmer.

Extract of a review of this work in the Magazine of Horticulture, Botany,

\&c., published by Hovey \& Co., Boston :

"The work is written in plain language, easily to be understood by the young beginner in gardening, who will find it a great help ; and its value, even to the experienced person, is by no means of an ordinary character. IT IS ADAPTED To our CLIMATE, and unlike compilations from English works, the novice is not led into disappointment by following the rules there laid down, as he generally is. when following the advice of the latter. We repeat, that as far as the book pretends, IT Is IVORTH ALL OTHEJS OF A SIMILAR CHARACTER THAT HAVE EVER BEEN PUBIISHED IN TIIS COUNTRY ; and its cheapness slould place it in the hands of all new beginners."

"No work ever published has been so studiuusly written to give plain useful information. By being arranged in the form of a catalogue, you can turn in a moment to any name you desire, where the time of sowing, depth, soil, after treatment, \&c. \&c., is clearly defined. The Calendarial Index, giving a summary of work for every month, is itself worth the whole price of the book. and must have cost the author much research and laborious thought. Mr. Bridgeman is not a theorist, but is in the daily practice of what he writes, and of course well qualified to direct all beginners in the profitable and delightful employment of cultivating a garden, ' a profession and an employment for which no man is too high or too low.' "-Geriessec Farmer.

' It will, we are persuaded, be found, what the writer intends it shall be, ' generally useful to such as may wish to superintend, or take the management of their own gardens.' Mr. Bridgeman is a gardener himself, in the Bowery road, and his dírections are therefore applicable to our climate-an advantage of no little monient."-Americun.

"Among the plants for the cultivation of which 'The Young Gardener's Assistant' contains directions, are a number of culinary vegetables not generally introduced in the United States. The introduction and successful cultivation of useful foreign vegetables add to the resources of our country. We recently saw, for instance, in Mr. Bridgeman's garden, several varieties of Broad Beans, Vicia faba, in a most vigorous and thrifty growth. They occupied a clayey spot of ground that was not suitable so early in the season for any other vegetable. They put forth a beautiful blossom, and would serve as an ornament for the flower garden."-New York Farmer. 
“Bridgeman's Gardenfr's Assistant.-The fourth edition of this useful little manual is published, and is rendered of increased value by the addition of several matters not contained in either of the former editions. Among these is a short and convenient calendar to assist the gardener's memory."-Evening Post.

"No work on the subject of Kitchen Gardening ever published in this country has met witl so very general approbation and extensive sale. $\mathrm{Mr}$. Bridgeman is well kuown as one of our best gardeners, and writes from hia own experience."-Duily Express.

"That work which teaches us how to create and to improve this most innocent and useful source of pleasure, is surely worthy of applause and patronage ; and such we consider 'The Young Gardener's Assistant."' Mrning Herald.

"The work is calculated to be of immense service to those engaged in Agriculture, 'far from the busy haunts of men,' and to the disciples of Flora, in the city. Mr. Bridgeman is a practical gardener and seedsmau, and has lived many years on both sides of the Atlantic."-Old counfryman.

"From what we gather from the tenor of Mr. Bridgeman's book, we should suppose that he paid but little attention to the mere on dits or dictums of any, but that he pursued that course which his judyment pointed out; and in this particular, we value his book-leading the young gardener to depend more on his own judgment than on the rules of custom." Anerican Farmer.

"All those who are desirous of a work on the subject of Gardening. and one which will convey the best information on the management of Hotbeds, Asparagus beds, best mode of raising all sorts of Esculent Vegetables, Pruning, Grafting and Budding Fruit Trees, Training the Vine, Preserving the Fruit from Mildew, \&cc., should procure this. No work on the subject ever published in this country has met with half as extensive a sale, or decided public approbation, as this valuable compendium. Mr. Bridgeman fully understands the subject on which he treats. The very rapid sale of the eight former editions is quite a sufficient recommendation."-G. $C$. Tharburn, in the Evening Star.

"We can assure gardeners and farmers that they will in times and ways almost without number, be amply compensated by purchasing the book. Mr. Bridgeman bestows great l.bour on his productions of the pen, not only as to practical matter of fact, but to the various excellences of style particularly to clearness, and the avoiding a redundancy of words. The amount of useful information in the book constitutes its value; and all this information is adapted to this country, and its climate and its soil."American Gardener's Maguzine.

"From the cursory examination we hive been enabled to give "The Young Gardener's Assistant,' we should judge that it embraces a greater amount of practical information, applicable to our climate, than can be found in any similar work. The list of fruit trees has been selected from the best authorities, both foreign and American, and is sufficiently exten. wive for any cultivator in this country." -Newark Daity Alvertiser 
- The author is an experienced practical gardener and seedsman, and his book is an excellent manual and guide for the beginner, whether old or young, in horticultural pursuits."-Gazetle.

"From the systematic arrangement of the parts, under appropriate heads, and the plain and practical nature of the instructions, it must be an invaluable manual for those who may wish to superintend the management of their own gardens. - Albany Argus.

Extract of a letter from Alex'r Walsh, Esq., Lansinburg :

Dear Sir:-You will see by the next month's New-York Farmer, if you have not already seen by the Albany papers, that several copies of the Young Gardener's Assistant have been given as premiums, by the State Agricultural Society. Mr. D. B. Slingerland and myself were on the committee for awarding premiums, and thouglit your work was deserving encouragement; and that even in this small way we might be of service in bringing it before the public as worthy of being given as premiums." *

"Written with a good deal of practical knowledge of the subject on which it treats. The directions given, the author say's, are the result of twenty years' experience, and we dare to say. that though submitted in an unpretending form, they will be found as useful, if not more so, than those in more costly and expensive works."-Courier \& Enquirer.

"We have undoubted authority for pronouncing this work as worth all others of a similar character that have ever been published in this country, from its adaptation to all the climates in the United States." $-N$. Y. Sun.

"That this is a useful work is evident from the number of editions through which it has passed. There is scarcely any employment in life more pleasing than the cultivation of a Garden with Fruits and Flowers. Those who have the opportunity to indulge themselves in this gratification, we have no doubt will derive much assistance from this publication." $-N$. Y. Tribune.

" Every one that cultivates a garden should possess the work, as it is a complete dictionary for young beginners in the delightful field of Horticulture."-Working Man's Advocute.

"No work on the subject ever published in this country has met with half as extensive a sale or decided approbation, as this valuable compendium. Mr. Bridgeman fully understands, from practical experience, the subject on which he treats. The Calcndarial Index arranges the work for every montl, and refers to the various parts of the book how to proceed. This of itself is worth the price of the whole work, and cost the author immense labour. The rapid sale of the former editıons, together with the commendation of every $\Lambda$ gricultural and Horticultural Journal in America, and several in England, is quite sufficient recommendation. The present edition both explains and fully makes known what was thought to be a great discovery (as great as steam) on the preservation of Fruit Trees, Plants, \&c., and which, to make known to the people of these United States, an application was made to the 25th Congress to vote the supposed

- The Amcrican Institute has also awarded several copies cf this work as premiums for superior specimens of garden products 
author of the discovery a sum equal to five cents from each individual in the United States-or about a million of dollars. Mr. Bridyeman has clearly proved this discovery from his long observation of the course of nature and treatment of 'Trees and Hlants, and which only occupies some four or fivo pages of the work." $-N$. Y. Commercial, by G. C. Thorburn.

"THE FluRIST's GuIDE.-A delightful little book, which we advise erery body to purchase-at least every body that has the least liking for the pleasing occupation on which it treats." -Courier \& Enquirer.

"The Florist's Guide," like its companion, "The Young Gardener's Assistant," is a useful work, which every Gardener and Florist may consult to advantage. It gives minute directions concerning plants of various species; the names and characters of each being alphabetically arranged, makes it an invaluable manual for those who may wish to superintend tho management of their own gardens."-Newark Daily Advertiser.

"This is one of the best works on the subject ever published in any country: it contains Practical Directions for the Cultivation of Annual, Biennial, and Perennial Flowering Plants, of different classes, Herbaceous and Shrubby, Bulbous, Fibrous, and Tuberous-rooted, including the Double Dahlia, Greenhouse Plants in Rooms, \&c. \&c.

"A work of the above kind has been long wanted; hitherto, it required an expenditure of some three or four dollars to get any kind of readable directions for snall gardens. window gardening, plants in rooms, \&c., which, when procured, were so full of botanical foppery, that plain, honest people, after wading through some three or four hundred pages, were as wise as to knowing how to set about their gardening, as when they com. menced their book. The present little work obviates all these difficulties. The author is well known as one of our practical gardeners, and it may be truly said he has rendered the ladies in particular (for whom the work was projected) an essential service; the directions for the care of the Camellia Japonica, the Double Dahlia, the sowing and treatment of Annual Flower Seed, \&c., are alone worth double the price of the book; so is the Calendarial Index, which, by the untiring industry of Mr. Bridgeman, is made to include in some half dozen pages, more viluable information than is to be found in some ponterous octavos on the same subject."-G. C. Thorburn, fiom the N. Y. Commercial.

"The style is free, and the language appropriate; the plan is judicious, and the contents embrace mucl well arranged practical information, unencumbered with disquisitions foreign to the object of the work. We very cheerfully recoumend it to our readers as a chcap and useful book." Gardener's Magazine.

The Florist's Guide has also been very favourably noticed by the editors ot many other very respectable periodicals, as a work cminently calculated to promote a love for the cultivation and correct management of fowersthe study of which, remarks one of the:e writers, "refines the taste, and imparts just and ennobling views of the wise provisions of nature." 


\section{I N ES}

SUGGESTED BY THE AWARD OF A GOLD MEDAL TO THE AUTHOR OF 'THE YOUNG GAKDENER'S ASSISTANT,' AT THE FOURTEENTI ANNUAL FAIR OF TIE AMERICAN INSTITUTE, 1S41, FOR ITS GREAT PRACTICAL UTILITY.

BY D. MITCHELL.

As VAloR's meed, and Honor's brightest test, I've seen a MrDAL on a Warrior's breast;

But to my mind it brought sad scenes to viewThe sweeping carnage of red Waterloo-

Th orphan's tear-the widow's drooping head, For slaughter'd heroes on false glory's bed The earth made desolate, its fruits despoil'd, By mad Ambition, fearless and unfoil'd !

Not so the Token thou hast gained from Peace, Thou lov'st to see fair iFature's wide increase, And the "Young Gard'ner," in thy fertile book, Finds an "Assistant" not to be mistook ! Thine is the pleasing art to cultivate, Fill Plenty's horn, and better man's estate ; 'Thine is the wish the Cotter's life to mend, And teach him that a garden is his friend: That Virtue smiles-sheds blessings on his head, And makes him happy in his humble shed, Who tends his " little patch" in well spent hours, A mid his kitchen treasures and his flowers; That Vice ne'er mars a lovely scene like thisThe consummation of the poor man's bliss ! Health, my firm friend, long life and health to thee, Health to the scions from the parent tree; Well may thy trophy be a source of pride, May they preserve it, whatsoe'r betide:

'Tis a memento for imparting good, More nobly won than that for shedding blood! 


\section{A P P E N D I X,}

CONTAINING REMARES ON THE ALLEGED DISEASE OF THE POTATO.

As I have not in the article Potato, page 86 , attempted to give its nistory, I would here inform the reader, that the Potato was cultivated in Britain, by Gerard, the English Botanist, in 1590, and was soon afterwards recominenled by Sir Walter Raleigh as a nutritious vegetable; but although first discovered on this continent, it spread so slowly, that nearly a century elapsed before this excellent root had become a regular dish on the Farmer's table in New England. The following account of the early reception is too good to be lost. It is recorded in the N. Y. Farmer and Mechanic that two brothers, named Clarke, settled in Connecticut, early in the 18 th century, and purchased a farm near Chatham. "On a hill which still bears the name of Clarke Hill, half a peck of potatoes were planted, and after the balls had ripened on the vines, it was proposed to gather some with a view to taste the wonderful product; some balls were accordingly picked and boiled, and being placed on the table, were approached with great caution. It was at length concluded that an old negro should first taste of this rare vegetable, whose report was by no means satisfactory; others also tasted, and the dish was condemned as unworthy their table and attention; the negro was therefore directed to go and destroy the vines; in doing so, he pulled up some potatoes with the tops; and, amazed at the sight, soon elicited the discovery that the real fruit was to be looked for at the root end of the plant."

As this vegetable is now considered one of the most important productions of the earth, upwards of one hundred millions of bushels being raised in the United States in a single year, a deficient or defective crop is acknowledged by all to be such a serious calamity as to incite the most diligent enquiry into the nature and cause of the defect, or deficiency.

As the seasons of 1843 and ' 4 were unfarorable to the growth and preservation of late potatoes, the American Institute encouraged an investigation and discussion of the subject amongst the members of the 
Farmers' Club; the result of which was published in the "New-York Farmer and Mechanic," vol. ii., November, 1844, from which I have selected the following extracts:

" That the disease may proceed from some chemical action in the atmosphere, or from peculiar location, as high or low, new or old lan l, and that some varieties are more liable to disease than others," page 290 .

"That the potato disease was imported from Great Britain two or three years ago; and that a gentleman, from microscopic examination, discovered in the tubers a growth of fungus, a plant analagous to the mushroom family. These fungi seeds although invisible to the naked eye are readily carried about by the winds, and will penetrate wherever air will. Bing once introluced from Europe, their extensive dissemination here is very easy. These seeds falling on the potato in favourable circumstances as to moisture, \&c. cause the disease," 291.* The application of common salt to the soil, previous to planting, is suggested as a remedy. Lime and charcoal dust sown on the ground after plant ing is also recominended.

Anothar corresponden', asserts, "that the disease is an old one, having been long known in Germany, as well as in England, and that there are in fact two distinct distempers, one of which is called dry rot, and the other wet rot; the dry rot often appears in a whitish surface; if the wet rot sets in, it is black, and soft worms are to be found in the putrifying parts. The direct origin of the disease is a fungus, the remote origin is something else. One of the most fertile causes of this disease is the habit of using farm yard manure in a state of fermentation. $\dagger$ Plants, in a healthy growing state, are rarely attacked by the fungus; probably, therefore, soine change takes place in potatoes before the fungus begins," page 307 .

\footnotetext{
- If it be true that an infectious disease exists amongst the potatoes of that country, wnich cont ins a less quantity of land than one of our largest States, it may be asked, how a proportion could be shipped here in an eatable and plat table condition, after rescrving a sufficiency 'For a population of upwards of twenty millions of inhabitants, who raise them for their cattle as well as for table use.

It is upwards of thirty years since I commensed cultivating potatoes, which, according to the seasons. has been attended with variable success. In $1820 \mathrm{my}$ potatoes were so bad as to be scarcely eatable, I however planted some of them for seed the year following, on land situated near the Bowery, where Third street now is, which was manured with livery stable dung; and the pr:sluct was the best I ever eat. Last season sereral of my acquaintance raised their early and late crops from the same lot of seed, with different results. Those planted in A pril or duced an abundance of excellent potatoes, while the product of those planted in June and July were represented as diseased and scarcely worth digging. The difference in all those cases m'ist have been occasioned by the weather and not by the seed. A change of soil however, will sornetimes cause a difference in the quality of potatoes.
} 
“That the disease in the potato arises from a small fly which lays Its eggs in the vines shurtly after they come up, which turn into maggots and pass through the tube of the vine into the potato. A table spoonful of poudrette to each plant is in this case recommended as a preventive," page 324.

Others contend that as every plant cultivated in the same soil for a long periol is liable to become deteriorated, a new generation of plants from seel of a healthy crop is essential to preserve their pristine excellence. A gentleman present, however, informed the Club, that his seedlings were found in a decayed state the same as others," page 290

As it is not my intention to discourage a farther investigation of this subject, I shall not pass censure upon the ileas above advanced, but offer a few remarks founded on observation and the study of nature, which, I trust, will prove acceptable to the public.

I have, in several pages of " the Young Gardener's Assistant," reminded my readers that the various species of plants which are cultivated in our gardens and fields, require each their peculiar aliment, they having been collected from all the diversified climates and soils in our globe; and I would here add, that it is a matter of astonishment, that so large a proportion of the fruits of the earth should be produced in perfection in any one climate, especially in unfavourable weather, to which every part of the earth is at times liable.

In page 26 of the first part, I have furnished a classification of the most important vegetables cultivated in our gardens, in which I have shown that the most essential aliment to natives of warm climates is heat, and of temperate climates moisture, and that the three elements HEAT, AIR, and MoISTURE, constitute the food of plants in general. I bave also recommended my readers to make choice of the seasons best adapted to the various articles they may wish to cultivate, as it is an indubitable fact that the element essential to the production of some vegetables is destructive to others, which in realily cannot be raised at all under unpropitious circumstances. In proof of the above assertion, I would remind the reader that various kinds of fruit are deficient in unfavourable seasons. Cherries for instance, in the event of a single week's rain, in a certain stage of growth, will rot on the trees; and it must be admitted that other fruits deteriorate, or lose their most essential flavour in the absence of suitable aliment. Why, then, I would ask, should we expect potato crops to be uniformly good every year.

It would be difficult to name any production of the earth, that yields full and perfect crops annually; on the contrary, it is well known that 
famine has been of frequent occurrence in many populous countries, through short or defective supplies of the necessaries of life.

It is conceded by the generality of those who have investigated the subject of disease in potatoes, that the tubers soon become defective after the tops cease to grow; and common observation teacheth that when plants of a succulent nature are deprived of their functions or means of growing luxuriantly, they continue to deteriorate until their juices become so corrupt, that they not only die, but contaminate the earth in which they were planted, to the destruction of their neighbouring inmates of the garden or field; and even potato tubers, after being taken from the earth, will injure those which come in contact with then by the emission of their corrupt juices

Mr. Teschemacher, in a communication published in " the New England Farmer," observes, "That the potato decays previous to the appearance of worms, and that worms are never found in the sound part of the potato either eating their way in, or depositing their eggs, nor have 1 seen the worms in that part of the potato in which the fungus have already commenced vegetating; it is only in the rotten part that the worms exist after the fungus has caused the decay. These worms are uniform, and appear to be of the same species from whatever cause the decay may arise."

It is precisely the case with other hinds of vegetables, and also with fruit; and it is evident that all those worms, insects, and reptiles which prey upon the vegetable family, are more partial to that particular kind of vegetable matter which first generated them, than to any other; hence the Peach insects feed on its fruit in embryo, as well as in a state of, and even beyond maturity; the Cabbage worms also prey on plants of the same genera or species; and when those enemies of the vegetable family cannot obtain the parts which are the most palatable to them, or congenial to their nature, they will feed upon diseased trees, plants, or other matter, which contain similar juices, or nutriment, in preference to any other description of fond.

It is generally allowed that the early planted potatoes have for the last two years, yielded as well as usual, and that they have been of very superior quality. It is only the late crops which are complained of. Now, it must be admitted that if the seed potatoes planted in June or July, whether raised here, or imported, had been diseased, they would have shown it at the time of their being cut and prepared for planting. as it is notorious that the discovery of defect is generally made at the time of gathering the crop, or soon after they are heaped together. 
It must, however, be conceded, that seed potatoes kept until July for the purpose of late planting, may have hecome deteriorated, because those roots being biennial cannot be expected to retain their bealth and vigour to so late a period; which, in some measure, accounts for early varieties being more seriously affected by the extreme heat than the late keeping red-skinned varieties, which will retain their vegetative properties even in dry seasons, so as to produce a good crop if not retarded by being over heated, to which they are liable, especially if placed in contact with acrid manure, which is destructive to all descriptions of plants in hot dry weather. New land without manure generally produces the best crops in dry seasons

It may be observed farther, that when the leaves or vines of the potato wither prematurely through extreme heat, the tubers become af fected to such a degree, that rain late in the season hastens their destruction instead of nurturing them, they consequently return to their native element.

From the above considerations, as well as from the knowledge I have acquired of the nature of plants in general, I have come to the conclusion that the alleged disease in potatoes was not occasioned by defective seed, but by the extreme heat of the Summer, followed by the excessive rain in Autumn.* In some instances the defect may have been accelerated by an injudicious use of acrid manure, and in others from their being planted in low undrained ground. It often happens that potatoes deteriorate from not being properly dried when taken from the ground, which on being heaped together, become heated, and consequently roL

All which is respectfully submilted.

THOMAS BRIDGEMAN.

NEw-YoRk, February 1st, 1845

- $\mathbf{s}$ this review was elicited by the discussions relative to the defect in potatoes the last two years, the conclusion has special reference thereto. It must, however, be acknowiedged, that the extremes of HEAT, COLD, and MOISTURE, are alike detrimental to vegetation in ail seasons; and that hot dry summers are often attendcd with results as fatal to vcretable productions as the coldness of winter. 


\section{SELECT DESCRIPTIVE LIST OF APPLES,}

\section{Continued from puge 46, Part III.}

Beautr or Kent. Fruit very large, roundish, but flat at the base; skin smooth, greenish yellow, with stripes of purplish red; flesh juicy, crisp, and tender, with an agreeable sub-acid flavour : in October and November.

Canadian Reinette, Reinette du Canada blanche, Portugal Apple, Grosse Reinette d'Angleterre, Pomme du Caen, Mela Janurea. Fruit large, broad, and flat; skin greenish yellow, tinged with brown; flesh yellowish white, firm, juicy, and of a high sub-acid flavour: from December to March.

Chandere. A native winter fruit of Pomfret, Comnecticut. Large, roundish, slightly flattened; skin thickly streaked with dull red on a greenish yellow ground with gray dots; flesh greenish white, tender, juicy, and rich.

Court of Wick Pippin, Fry's Pippin, Golden Drop, Wood's 'Transparent Pippin, Phillip's Reinette, Knightwick Pippin. An English wintervariety, well adapted for Canada or Maine. Fruit below the middle size, regularly formed, roundish-ovate; skin greenish yellow, mottled with orange and red at maturity ; flesh pale yellow, tender, juicy, and high flaroured.

Dutch Mignonne, Reinette Don'ce, Pcmme de Laak, Paterroster Arple. A winter fruit, large, roundish; skin dull orange, streaked and moitled with red, dotted with russet; flesh crisp; juice plentiful, with a delicions aromatic flavour.

Easter Pippin, Claremont Pippin, Ironstore Pippin, Young's Lomg Keeping, French Crab. Fruit middle size, somewhat globular; skin deep green, shaded with a pale livid brown; flesh very firm, and though not juicy, of a good, sub-acid flavour. This variety will keep sound two years.

Herefordehire Pearmain, Winter Pearmain, Royal Pearmain, Royale d'Angleterre. A fine winter dessert fruit above medium size, form oblong; skin russety green, mottled with red, and dotted with grayish specks; flesh tender, with pleasant aromatic flavour. 'Tree an abundant bearer.

Lyscum, Osgood's Favourite. A Massachusetts variety of merit. Fruit large, round; skin greenish yellow, mottled with red; flesh fine grained, exceedingly mild and agreeable in flavour: in use from September to November.

Lxman's Pumpkin Sweet. A very large apple raised by Mr. \$. Lyman, Manchester, Connecticut. Skin smooth, jale yellow; flesh firm, sweet, juicy, and excellent for baking : in the autumn. The tree bears prodigious crops.

Northern Spy. A native variety of the Spitzenburgh family. Fruit large, conical, considerably ribbed; skin smooth, yellow ground, nearly covered with rich dark red and purplish streaks; flesh yellowish white, and of a rich, aromatic, sub-acid flavour : good from December to May.

Peck's Pleasant. 'This variety resembles the Yellow Newtown Pippin, only it is larger; skin smootl, and when first gathered green, changing to yellow, with bright blush cheek and scattered gray dots; flesh yellowish, fine grained, juicy, and tender, with a delicious high aromatic flavour in winter.

Ross Nonpareil. A delicious Irish variety, approaching in fluvour to some kinds of pear; fruit below medium size, roundish; skin covered with a thin mellow russet, faintly stained with red; flesh greenish white, tender, and of a rich aromatic flavour: in perfection the end of October. Tree a profuse bearer, and worthy of a place in every amateur's garden.

Summer Sweet Paradise. A Pennsylvania fruit of large size; round, a littlo flatteued at both ends; skin rather thick, pale green, tinged with yellow, and sprinkled with large gray dots; flesh tender, crisp, juicy, and of a sweet, rich, aromatic flavour: ripe in August and September.

Sops of Wine, Rode Wyn Appel, Sapson, Sops in Wine. A handsome little autumn apple for the dessert; skin smooth, crimson, covered with a delicate light bloom: flesh white, with stains of a pinkish hue, firm, crisp, and juicy, 
Victuars and Drink, Big Sweet, Pompey. Fruit large, oblong, rather irregular: skin rough, dull yellow, marbled with russet; flesh yellowish, tender, breaking, and of a rich sprightly flavour: in perfection from October to March. The tree is a moderate bearer.

Winesap, Wine Sop. This is a good winter apple for the table, and one of the finest cider fruits; it is of medium size, rather oblong; skin smooth, of a fine dark red and yellow ground; flesh yellow, firm, with a rich high tlavour.

\section{SELECT DESCRIPTIVE LIST OF CHERRIES,}

Continued from page 56, Part III.

Allen's Sweet Montmorency, Late Montmorency. A seedling raised by J. F. Allen, Esq., of Salem, Massachusetts. Fruit of medium size, nearly round ; skin pale amber, mottled with red ; flesh yellowish, tender, sweet, and excellent. It is a good bearer, and ripens its fruit late in July.

Baumann's May, Wilder's Bigarreau de Mai. A very early variety imported by Col. Wilder; fruit rather small, oval heart-shaped; skin deep rich red; flesh, when fully ripe, sweet and good : ripe by the end of May.

Bigarreau China, Chinese Heart. A fine variety raised by the late Mr. W. Prince, of Flushing, L. I. Fruit of medium size, oval heart-slaaped, with a distinct suture line; skin, when fully ripe, glossy red, mottled with numerous light spots; flesh firm, and of a rich peculiar flavour: late in July.

Bigar reau Holnand, Spotted Bigarreau, Armstrong's Bigarreau. Fruit very large, of a regular heart-shape; skin pale yellow, mottled and spotted with bright red; flesh juicy, sweet, and excellent : towards the end of June.

Bigarreau 'Tardif de Hildesheim, Hildesheim Bigarreau. Fruit of modium size, heart-shaped; skin yellow, mottled and marbled with red; flesh pale yellow, firm, with a sweet and agreeable flavour. 'This variety ripens here in August, aud is considered by Thompson the latest sweet cherry known.

Downing's Red CheEr. An excellent seedling cherry raised at the nursery of A. J. Downing, Newburgh. Fruit rather large, regularly obtuse heartshaped; skin thin, white, with a rich dark crimson cheek; flesh yellowish, of a sweet and luscious flavour: about the middle of June.

Downton. A beautiful variety raised by T. A. Knight, of Downton Castle, England. Fruit very large, blunt heart-shaped; skin cream colour, stained and marbled with red dots; a delicious cherry early in July.

Early Purple Guigne, Early Purple Griotte. An early variety ripening towards the end of May, newly introduced from England. Fruit of medium size ; skin dark red and purple ; flesh rurple, tender, juicy, and delicious.

Manning's Mottled, Mottled Bigarreau. A beautiful heart cherry, raised by Mr. Manning from a seed of the Bigarreau; fruit above medium size, roundish heart-shaped; skin glossy amber colour, mottled with red; flesh, when fully ripe, yellow and tender, with a delicions juice : ripens late in June.

Transparent Guigne, Transparent Gean, Transparent. Fruit small, borne in pairs, and heart-shaped; skin glossy, thin, and nearly transparent; colour yellowish white, delicately mottled with fine red; flesh tender, melting, and sweet : ripe early in July.

\section{SELECT DESCRIPTIVE LIST OF FOREIGN GRAPES,}

Continued from page 78, Part III.

[Those deslgnated thus * will ripen in the open air. Those marked thus $\dagger$ require but little furcing in favourable seasons.]

* Black Chuster, Black Morillon, True Burgundy, Early Black, Aur 
verna. Bunches rather larger than those of the Miller's Burgundy; berries middle size, somewhat oval; skin of a very black colour; juice rich and sweet : the fruit ripens in the open air about the niddle of September.

Buack Damascus, Worksop Manor Grape. Bunches middle size; berries large, globular; skin thin, of a fine black colour; flesh delicate; juice rich, and of exquisite flavour when properly cultivated under glass.

† Black Frontignan, Black Frontignac, Violet Frontignac, Muscat Noir, Black Constantia of some. Berries of medium size, round, and grow close on the bunches; skin black; flesh tender; the juice of a rich vinous musky flavour: it ripens in October, in favourable seasons without fire-heat.

† Black Hamburgh, Warner's Black Hamburgh, Potier Bleu, Victoria of some collections. Bunches tolerably large, with two short compact shoulders ; berries pretty large, of an oval figure; skin rather thick, of a deep purple colour, nearly black; flesh tender; juice sugary and rich: a good and regular bearer. Wilmot's New Black Hamburgh is said to bear larger berries.

Black Lombardy, West's St. Peter's, Bunches long, with large shoulders; berries large, roundish oval; skin thin, very black at maturity ; juice plentiful and high flavaured : it requires a high temperature, and is then a great bearer.

Buack Muscat of Alexandria, Red Muscat of Alexandria, Red Frontignac of Jerusalem. Bunches large and shouldered; berries large, oval; skin thick, of a reddish colour, becoming black at maturity; flesh quite firm, with a rich vinous flavour: requires a vinery with fire-heat.

† Black Muscanine, Black Chasselas, Chasselas Noir. Bunches of medium size, compact; berries globular; skin black, covered with fine bloom; juice rich if well ripened: it requires a vinery.

† Black Princk. Bunches rather long; berries large, oval; skin dark blackish purple, covered with a thick blue bloom; flesh white, abounding with sweet well-flavoured juice: this variety will ripen here in the open air, and bear profusely in the vinery with the easiest culture.

Buack St. Peter's, Black Palestine, Suint Peter's. Bunches pretty large and long; berries rather large, almost globular; skin thin, of a black colour; flesh delicate, with a very excellent and well-flavoured juice : this is one of the best sorts for a vinery without fire-heat, and the fruit may be preserved on the vine for early winter use.

Chasselas Mosque, Musk Chasselas. Bunches of medium size; berries middle size, round; skin thin, yellowish white; flesh tender; juice rich and abundant : the highest flavoured chasselas known, having much of the flavour of the Muscat of Alexandria when properly forced.

Chasselas Rouge, Red Muscadine, Red Chasselas. The berries of this variety are something larger than those of the Black Muscadine, they are of a dark red colour, when highly ripened in the vinery ; juice sweet, and luscious.

* Early Black July, July Grape, Madeleine Noire, Maurillon Hatif. The earliest of grapes. Bunohes small and compact; berries small, quite round, of a black colour, covered with a blue bloom; flavour moderately sweet, but not rich or perfumed: it ripens here in the open air early in August.

* Esperione, Hardy Blue Windsor, Turner's Black, Cumberland Lodge. Bunches handsomely shouldered, and differing little in size from the Black Hamburgh; skin of a deep purple colour, covered with a thick blue bloom; flesh adheres to the skin, and is of a pleasant flavour : the vine is very prolific.

Grizzly Frontignan, Grizzly Frontignac, Muscat Gris. Bunches middle size, with small narrow shoulders; berries round, of medium size; skin thick, pale brown, blended with red and yellow; flesh very rich, musky, and high tavoured; this is one of the best varieties for the vinery. 
LoMbardy. Flame-coloured Tokay, Red Rhenish, Wantage. Bunches very large, frequently weighing six or seven pounds, being from twelve to eighteen inches in length; berries large, of somewhat oval figure ; skin of a pale red or flame colour; flesh firm, with pretty well-flavoured juice: this variety requires fire-heat to bring it to perfection.

* Miller's Burguindy, Miller Grape, Le Mennier, Morillon Taconne. Bunches short, thick, and compact; berries small, roundish, very closely set together; skin thin, with fine blue bloom; flesh tender, abounding with sweet, high-flavoured juice; each berry contains two small seeds.

* Pitmaston's White Cluster. A pretty hardy English variety. Bunches of medium size, compact, and shouldered; berries middle size, round; skin thin, light amber colour, occasionally shaded with russet when fully ripe; flesh tender, juicy, sweet, and excellent.

† Red Hamburgh, Warner's Red Hamburgh, Brovon Hamburgh, Gibraltar. 'The berries of' this are of a dark red or purple colour, with a thin skin, and juicy, delicate flesh. The size and figure of both the bunch and the berry are very much like the Black Hamburgh, except the latter being less oval, and growing more loosely on the bunches. When the berries are imperiectly ripened, they are of a pale brown colour, hence it is called Brown Hamburgh.

* Royal Muscanive, Amber Muscadine, Early White Teneriffe, Golden Chasselas, White Chasselas. Bunches large and shouldered; berrics round, larger than those of the Sweetwater; skin thin, at first greenish white, but turning to an amber colour when fully ripe; flesh tender, and of a rich flavour.

Syrian. Bunches enormously large, with broad shoulders; berries large, oval; skin thick, white at first, but amber colour when fully ripe; flesh firm, juicy, and sweet. A bunch of this variety was gathered in Mr. Speechly's vinery at Welbeck, England, four feet and a half in circumference, weighing nineteen pounds and a half. The syrian grape is suplosed to be the sort mentioned in Numbers xiii. 23.

Verdeclio, Verdal, Verdilhio, Madeira Wine Grape. Bunches rather small, loose, inclined to shoulder; berries oval, small, rather unequal in size ; skin thin, almost trausparent; juice, when fully matured in the vinery, of a rich saccharine flavour.

White Frontignan, White Frontignac, Muscat blanc, White Constantia. Bunches rather long, without shoulders; berries middle size, round, rather closely set; skin thin, of a greenisil yellow, covered with a thin bloom; flesh tender, very rich, aud of a high musky flavour, when cultivated in the vinery.

White Hamburgh, White Raisin, White Portugal, White Lisbon, Rai$\sin$ Muscat. Bunches large, loosely formed; berries large, of an oval figure; skin thick, of a greenish white colour; tlesh hard; juice sweet, and slightly acid. Bunches of 3 lbs. weight have been gathered, in vineries near Boston.

White Muscat of A lexandra, Jerusalem Muscat, Passe longue Musque, Malaga, Tottenham Park Muscat. The most delicious of all grapes, but requires to be grown under glass in this climate. Bunches large, and wellshouldered; berries large, oval; skin thick, of pale amber colour when fully ripe; flesh firm; juice of a sweet, musky, and most delicious flavour.

* White Melier, Melier blanc, Early White Malvasia, Early Chasselas. Berries middle size, somewhat of an oval figure; colour yellowish white; flesh sweet, juicy, and agreeable in flavour: ripens in Augnst.

White Nice. Bunches very large, with loase shoulders ; berries roundish, of medium size; skin greenish white, becoming yellowish when ripe; flesh crisp, and of good flavour. Mr. Mclintosh has gathered from his vinery in England bunches weighing eighteen pounds. 
* Whtre Sweetwater, Early White Muscadine, Early Swectioater. Bunches middle size; berries round, growing close; skiu whitish, sometimes shaded with a light russet; flesh sweet, watery, saccharine, and luscious : the fruit ripens in the onen air towards the end of August.

* Wrire 'Tokay, Gray T'okay, 'Tokai blanc. Bunches of medium size, compact ; berries oval, closely set; skin dull white ; flesh very delicate, sweet, and perfumed : good for wine and for the dessert. It will ripen in the open air.

\section{SELECT DESCRIPTIVE LIST OF NATIVE GRAPES.}

Duns. A seedling of the Catawba, raised by Mrs. Diana Crehore, of Boston. Fruit resembling the Catawba, but paler in colour; bunches loose; berries round, juicy, and fine flavoured: it ripens two weeks earlier than the parent.

Gilbert's White Shonga. 'This variety was found by Garret Gilbert, of the city of New York, on the Shonga Mountains in 1825, and planted in his garden. It is a great bearer, of similar labits with the Isabella, differing from that kind ouly in colour, and coming to maturity a little earlier.

LeNoIr, Sumpter, Clarence. This variety was introduced by Mr. Lenoir, of the santee river, Carolina. Bunches large, very handsome; berries small, round; skin purple, with a light bloom ; flesh tender, sweet, and excellent.

Mrssouri, Missouri Seedling. Bunches of medium size; berries small and round; skin blach, with a little bloom ; flesh tender, sweet, and pleasant.

Orio, Segar Box Grape, Longworth's Ohio. The cuttings from which Mr. Longworth's first stock originated, were left at his residence by an unknown friend, in a cigar box. Bunches from six to ten inches long; berries round and small; skin thin, purple ; flesh tender and melting: a good dessert fruit.

Shurtleff's seedung. Raised by Dr. \$. A. Shurtleff, of Pemberton Hill, Boston. Bunches large, often weighing a pound; berries oval, of medium size ; skin thick, light purple, with a grayish bloom; flesh firm, and of excellent flavour: the fruit is fit for the table in September.

UCheE Grape. A native grape found on the banks of the Uchee creek, Russell county, Alabama. The bunches are long, very compact, and of a jet black colour; the berries yield but little juicc, which is extremely rich, and makes delicious wine without sugar.

WiIte SCUPPERNon. Bunches short and close set; berries large, of a roundish figure; skin white, with some dark specks; juice sweet and rich: it is a great bearer, ripening its fruit early.

The Managers of the American Institute having at their nineteenth Aunual Fair, held at Castle Garden, in the City of New York, awarded premiums for Native Wine, I here insert a copy of the Judges' Report.

"Report on Native Wine tested October alst, 1846, by C. Henry HaLl, W. Niblo, and Adoniram Chandler, Committee of Judges on Wine."

The five kinds of wine described below, were sent by Mr. N. Longworth, of Cincinnati, Ohio, to whom a Silver Cup was awarded.

' No. 1.-A fine light wine, called 'Ladies' Wine,' with sugar added before fermentation; delicious in flavour, and will compete with foreign sweet wine.

"No. 2.-A light dry wine, from the Catawba grape: sound, of peculiar flavour, resembling that of Hock and of the Bouquet.

"No. 3.-A good dry wine, of pure juice, different vintage from the last described, but good sound wine, although not high flavoured.

"No. 4.-A dry wine from the pure juice of the Herbebont Grape. It is sound, of the peculiar flavour of the grape, and will without doubt be admired 
"No. 5.-From the Missouri Grape, five per cent. brandy. The wine is thin in body, and wanting flavour, perhaps arising from our not having had a fair chance of tasting it at perfection, it having been recently slıaken up."

A Silver Mecial was awarded for each of the bottles described below.

A bottle of wine furnished by Mr. T. L. Prevost, Greenville, Greene county, was tested, which was represented to be four years old. "A sort of Hock, of fine flavour, but in a state of fermentation, the sugar not being dissolved and the spirit formed."

A bottle from Mr. Charles Peabody, made by him from a native grape found on the banks of the Uchee creek, in Russell county, Alabama, was pronounced by the judges, "a pleasant wine, sweet, like Malmsey, and if no sugar has been added to the juice, as is represented, it is remarkable in its character."

It is recorded in the Southern Cultivator, "that some of the most celebrated wine connoisseurs of Columbus, describe the wine made from the Uchee Grape as having the body of Port, with a little of the Muscat flavour, and equal to the best imported."

\section{SELECT DESCRIPTIVE LIST OF PEACHES,}

Continued from page 110, Part III.

Baltimore Beauty. A native variety. Fruit rather small, roundish oval; skin deep orange, with a rich brilliant red cheek; flesh yellow, but red at the stone, sweet, and very good. Ripens early in August.

Bergen's Yellow. A native of Long Island. Fruit large, often measuring nine inches in circunference; skin deep orange, with dark red cheek; flesh deep yellow, melting, juicy, and delicious. Ripens early in September.

Colrs Early Red. A good early market fruit of medium size; skin palo red, mottled with darker red; Hesh melting, juicy, rich, and very sprightly.

Druid Hill. A seedling peach, raised by Lloyd N. Rogers, of Druid Hill, near Baltimore. Fruit very large, roundish ; skin greenislı white, clouded with red; flesh juicy, melting, and rich : towards the end of September.

Early York, Large Early York. Fruit of medium size, roundish; skin pale red, dotted and mottled with dark red; flesh greenish white, full of rich sprightly juice. Ripens towards the end of August.

Early Newington Freestone, Newington Peach. A large and exceedingly ligh-flavoured peach ; skin pale yellowish white, dotted and mottled with a rich red; flesh white, but red at the stone; juicy and melting : end of A ugust.

Haines' Early Red. A popular orchard fruit in New Jersey, of medium size; skin pale white, nearly covered with bright red; flesh greenish white, very juicy, sweet, and melting. Ripe about the middle of August.

La Grange. A late peach, raised by Mr. John Hulse, Burlington, N. J. Fruit large, oblong; skin greenish white, tinged with red ; flesh juicy, melting, and delicious. Ripe towards the end of September.

Oldmixon Freestone, Oldmixon Clearstone. A large American peach, slightly oval; skin pale yellowish white, marbled with deep red; flesh white, and tender, with a rich vinous flavour: early in September.

Pool's Large Yellow, Pool's Late Yellow Freestone. A large and handsome Pennsylvania peach of the Melocoton family ; skin deep yellow, with a dark red cheek ; flesh juicy, and of excellent flavour: late in September.

Rareripe, Late Red, Prince's Red Rareripe. One of the finest of all peaches. Fruit large and heavy, roundish oval; skin downy, palo yellow, thickly marbled with red and fawn coloured specks; flesh white, but deep red at the stone ; very juicy, melting, and of an unusually rich flavour. Ripe the second and third week in September. 


\title{
SELECT DESCRIPTIVE LIST OF PEARS,
}

\author{
Continued from page 123, Part III.
}

Beurre D'Anjov. A first-rate Autumn pear, imported from France by Col. Willer, of Boston : fruit rather above medium size; obovate; skin greenish yellow, a little clouded with russet ; flesh very fine grained, buttery, and melting, with a rich, sprightly vinous flavour.

Bezi de la Motte, Bein Armudi, Beurre Blanc de Jersey. Fruit of medium size, bergamot shaped, skin pale yellowish green, sprinkled with russet dots; flesh white, very fine grained, buttery and juicy, with a sweet perfumed flavour: an old Autumn variety, ripe in October.

Bishop's Thumв. An old English Autumn pear, usually considered firstrate : fruit ratlier large, obloug and narrow; skin yellowish green, dotted with russet, and tinged with red; flesh juicy, melting, and of rich vinous flavour.

Bon Chretien Fondante. A new Flemish pear, abounding with juice, and having a refreshing and agreeable flavour; skin pale green, mottled, and dotted with russet : ripe in October.

Buffum. A native orchard pear, from Rhode Island, of the Doyenne family : fruit of medium size, oblong, ovate ; skin deep yellow, finely suffused with bright red, and russet dots; flesh sweet, and excellent : ripe in September.

Compte de Lamy, Beurre Curté, Dingler, Marie Louise the Second. A rich Flemish Autumn pear, of medium size, roundish obovate; skin yellow, with a brownish red cheek, and russety ; flesh melting and high flavoured.

Duchesse de Mars, Duchess of Mars. A French autumn pear of medium size, obovate; skin dull yellow, partially covered with brown russet, with a dull red cheek; flesh very melting, and of a rich perfumed flavour.

Dunmore. A truly admirable and hardy pear from the garden of the London Horticultural Society. Fruit large, oblong obovate; skin greenish, speckled with russet; flesh buttery, melting, and rich : ripe in September.

EYEwOod. A hardy and prolific seedling of Mr. Knight's. Fruit of medium size, oblate or flattened; skin much covered with russet; flesh buttery, rich, and melting : in October and November.

Fondante Van Mons. An excellent melting pear, introduced by Mr. Manning. Fruit of medium size, roundish; skin pale yellow; flesh white, juicy, sweet, and palatable : towards the end of October.

Jalousie de Fontenay Vendee. A fine autumn French pear, of medium size; turbinate, or obtuse pyriform; skin dull yellow, and green, with red cheek, marked with russet; flesh melting, with a rich flavoured juice.

Lawrence. A seedling winter pear, from the nursery of Messrs. Wilcomb \& King, Flushing. Fruit rather large, obovate; skin yellowish green, with patches of brown; flesh melting, and rich : from November to January.

Paradise D'Autome. A newly imported early autumn pear, of large size; pyriform, tapering into the stalk; skin dull yellow, russeted ; flesh white, fine grained, melting, and luscious.

Petre. This fine autumn variety, originated in the old Bartram Botanic Garden, near Philadelphia, from a seed furnished by Lord Petre of London, in 1735. Fruit of medium size, obovate ; skin pale yellow, marked with greenish russet; flesh fine grained, and melting, with a perfumed high flavour.

Queen of The Low Countries, Reine des Pays Bas. Fruit large, broad pyriform; skin dull yellow, mottled with russet, aud overspread with fine dark red; flesh melting, with a rich sub-acid vinous flavour: early in October.

Rostiezer. A German pear of medium size; oblong pyriform; skin yellowish green, with reddish brown clieek, and light coloured dots; flesh juicy, melting, sweet, and palatable: in September and October.

St. Guusualv. An excellent Belgium autumn pear, introduced br S G. Per- 
rins, Esq., of Boston. Fruit of medium size, pyriform ; skin pale yellow, with a few gray specks; flesh white, buttery, juicy, and of a rich sprightly flavour. Thompson. This fine autumn pear was named in honour of Mr. Robert Thompson, Superintendent of the London Horticultural Society's garclen. Fruit of medium size, obovate; skin pale lemon-yellow, dotted and streaked with russet; flesh white, buttery, and melting, with an agreeable aromatic flavour: tree hardy and prolific, producing its fruit in October and November.

Van Mons Leon Le Clerc. A splendid autumn pear, imported by Col. Wilder of Boston. Fruit large, oblong-ovate; skin yellowish, mingled with brown; flesh yellowish white, rich, and melting : in October and November.

VAn Buren. A seedling raised by Gov. Edwards of New Haven. Fruit large, obovate; skin clear yellow, with a rich orange-red blush, and russet spots; flesh sweet, and perfumed; excellent for baking and preserving.

\section{SELECT DESCRIPTIVE LIST OF PLUMS,}

Continued from page 131. Part III.

Autumn Gage, Roe's Autumn Gage. A new late plum, raised by William Roe, Esq., of Newburgh. Fruit of medium size, oval; skin pale yellow, with whitisl, bloom; flesh juicy, and of delicate pleasant flavour : in September.

Buel's Favourite. An excellent clingstone plum, raised by Isauc Denniston, of Albany. Fruit pretty large, ovate; skin pale green, sprinkled with lighter dots, and a little red; flesh juicy, and high flavoured : end of August.

Cruger's Scarlet, Cruger's Seedling. A seedling raised by Henry Cruger, Esq., of New York. Fruit rather larger than the Green Gage, roundish oval; skin a lively red covered with thin blue bloom ; flesh of a sprightly flavour.

Damson, Common Damson, Purple Damson, Black Damson. A favourite fruit with old housekeepers for preserves, of which there are many varieties, which from being frequently raised from seed varies somewhat in character They ripen in succession from September to November.

Denniston's Superb. Fruit round, a little flattened; skin yellowish green, with purple blotches, overspread with a thin bloom; flesh very thick, juicy, with a rich vinous flavour: a freestone, ripening towards the end of August.

ICKWorti Imperatrice, Knight's No. 6. A choice seedling from Mr. Knight of Downton Castle. Fruit above medium size, obovate; skin purple, embroidered with streaks of golden fawn colour; flesh juicy and rich : it ripens early in October, and may be kept till Christmas if laid away in paper.

IsABELLA. An attractive looking English clingstone plum of medium size; skin dark red in the sun, paler in the shade, and dotted; flesh yellow, rich, juicy, and of delicious flavour: towards the end of August.

Jefrerson. A plum of high merit, raised by the late Judge Buel. Fruit large, oval; skin golden yellow, with a purplish red cheek, covered with a thin bloom : flesh rich, juicy, and high flavoured : towards the end of August.

Lombard, Bleecker's Scarlet, Beekman's Scarlet. This variety was brought into notice by Mr. Lombard, of Springfield, Massachusetts. Fruit of medium size, roundish oval; skin delicate violet, dotted with red; flesh yellow, juicy, and pleasant : in August.

Orange Plum, Orange Gage. A plum of extraordinary size from the garden of Mr. Teller, of Rhinebeck, New York. Strin bronze yellow, clouded with purple; flesh deep yellow, a little coarse grained, but of a pleasant acid flavour: ripens the last of August.

Purple Favourite. This variety was first introduced by A. J. Downing, Esq., of the Newburgh Nursery. Fruit above medium size, roundish ovate; skin light brown in the shade, purple in the sun, dotted with golden specks, and thin light bloom ; flesh pale green, very juicy, tender, luscious, and melting : ripens towards the last of August. 


\section{AMERICAN STANDARD HORTICULTURAL BOOKS.}

The Young Gardener's Assistant, containing Catalogues of Garden and Flower Seed, with Practical Directions under each head for the Cultivation of Culinary Vegetables and Flowers; also, directions for cultivating Fruit Trees, Shrubs, and Vines, including the Fig, the Cranberry, and the Grape Vine. To which is added a Calendar to each part, showing the work necessary to be aone in the various departments of Gardening each month of the year. The whole adapted to the climate of the United States. The 12th edition, improved, 520 pages octavo. By T. BRILGEMAN, Gardener, Seedsman, and Florist: New-York.

25 As each part of the above Work makes a complete volume, a large Edition has been published in three separate books, with a view to accommodate the different description of cultivators. They are entitled as follows :-

The Kitchen Gardener's Instructor; which contains ample directions for the cultivation of Culinary Vegetables and Herbs throughnut the urdinary season; and instructions for Forcing and Forwarding Vegetables in winter and early in the spring.

The Florist's Guide, contains all the necessary information for managing a Flower Garden, and fur cultivating Exotic Plants, either in a Greenhouse, or warm room.

The Fruit Cultivator's Manual, is designed to qualify the novice in Fruit Culture for the superintendence of his own Orchard and Fruit Garden.

Each of the abnve Volumes contains 176 pages, 12mo. Price Fifly Cents, half bound; Sixty-two Cents, full bound.

[Do Booksellers and Seedsmen supplied on liberal terms, by the Author, Broadway, corner of Eighteenth Street, New-York. 
42

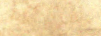

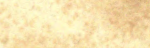

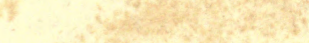

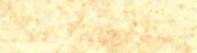

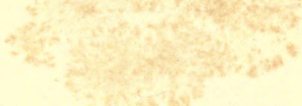

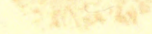

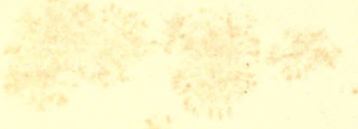

wat $x^{2} x^{2}$

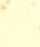

$$
\text { 政 }
$$





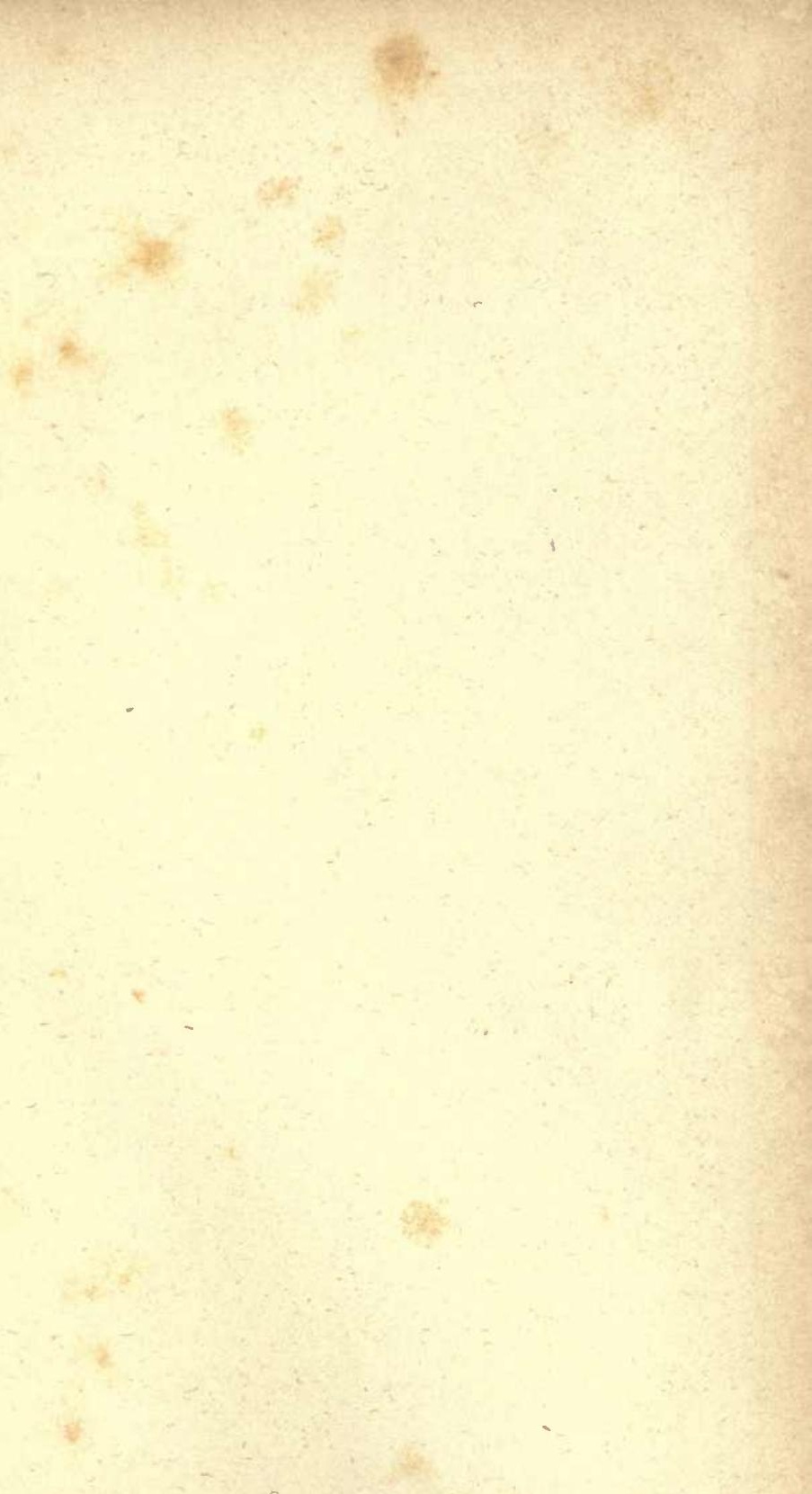




\section{UNIVERSITY OF CALIFORNIA LIBRARY}

BERKELEY

Return to desk from which borrowed.

This book is DUE on the last date stamped below.

\section{LIBRARY USE}

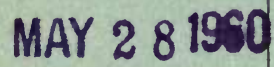

REC'D LD

MaY 28 1950ก 
Yo 28687

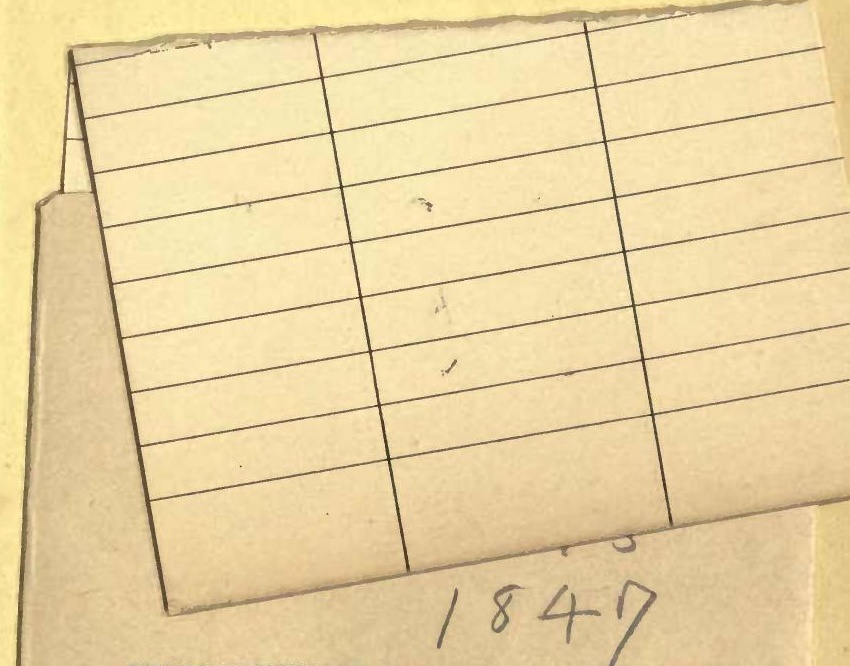

UNIVERSITY OF CALIFORNIA LIBRARY 


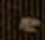
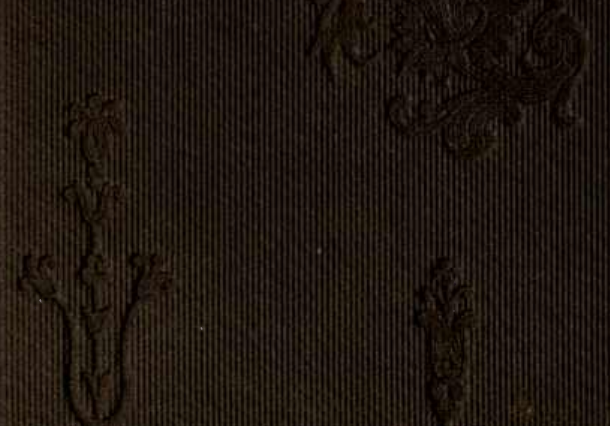

(3)
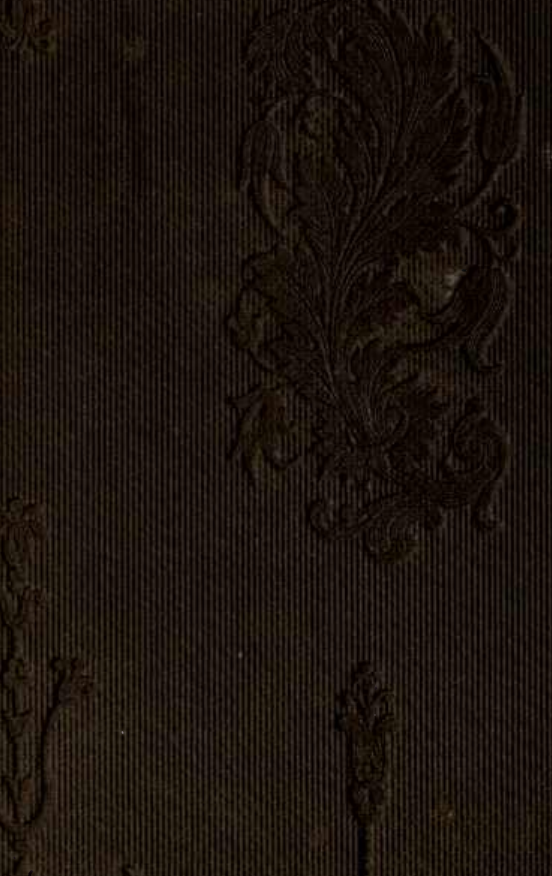